\title{
La Generación Inefable
}

Trayectorias, Percepciones y Posiciones de adultxs que trabajan con niñxs y jóvenes

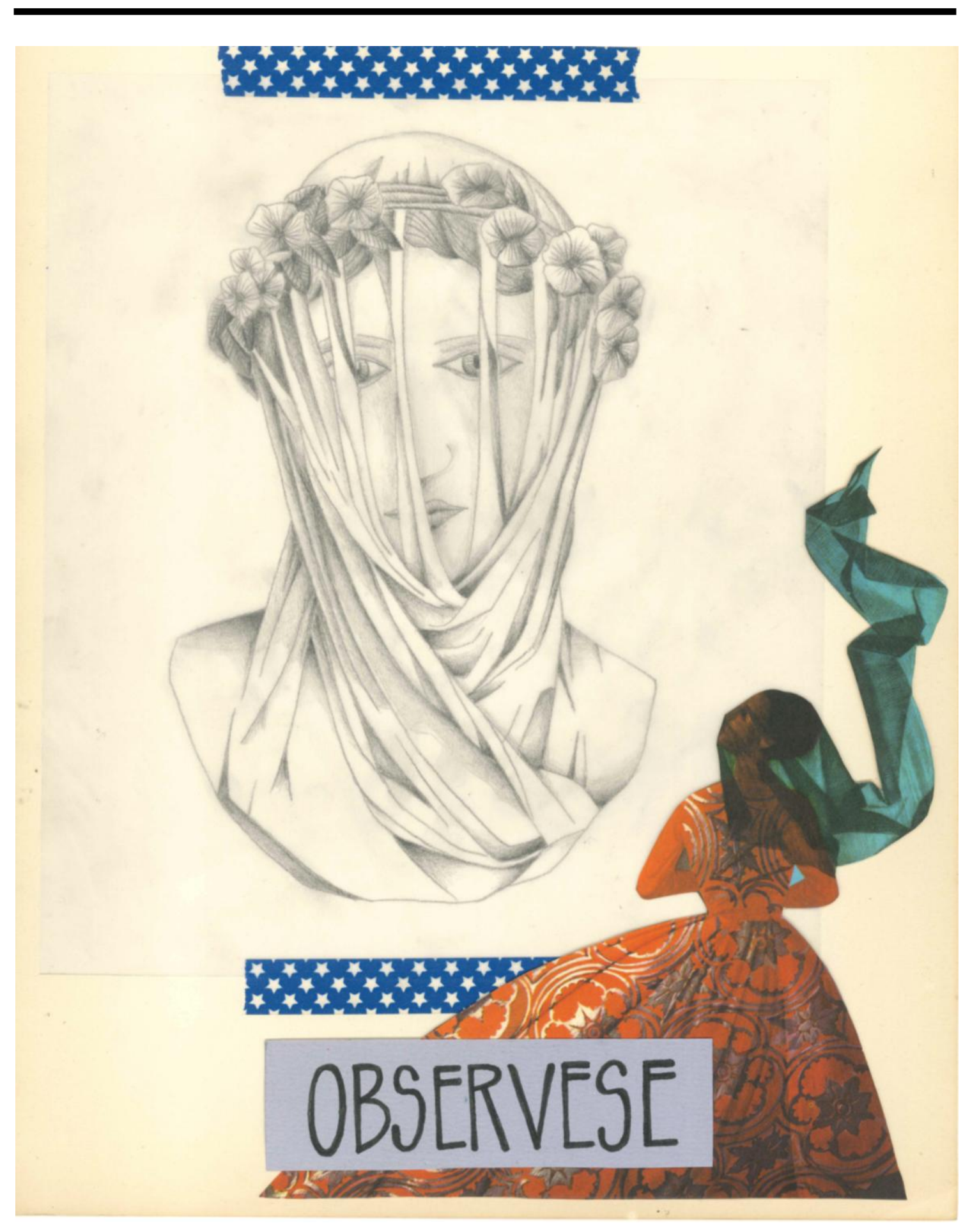

Tesis Final. Maestría en Comunicación y DDHH -Facultad de Pe riodismo y Comunicación Social-UNLP

Maes tranda: Lic. Martina Iribarne

Director: Dr. Esteban Julián Fernández - Co-Director: Mg. Nicolás Colombo 


\section{Índice:}

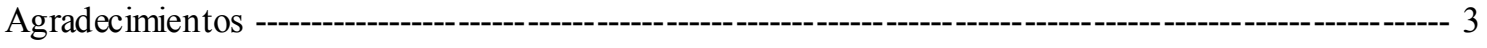

Dedicatoria -------------------------------------------------------------------------------------------------------------------- 6

Introducción: ¿Qué me trajo hasta acá? -

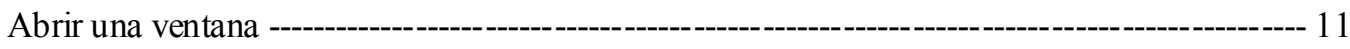

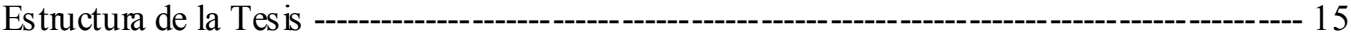

Capítulo I: Políticas del posicionamiento -----_-

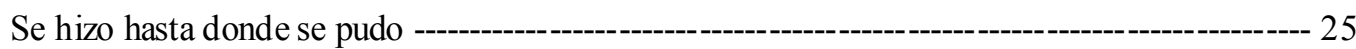

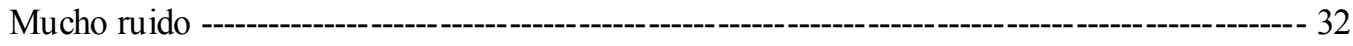

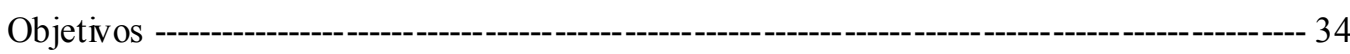

Algunas sospechas ----------------------------------------------------------------------------------------- 35

Sens ibilidades compartidas: trayectorias, percepciones y posiciones -------------------------- 37

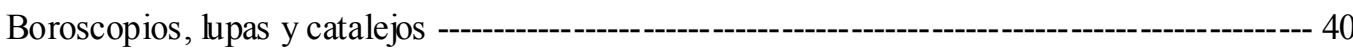

Sumario del capítulo: Es cribir con intereses ------------------------------------------------ 44

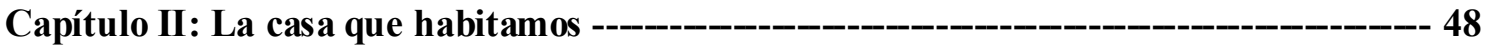

Centro gravitacional ------------------------------------------------------------------------------------------- 49

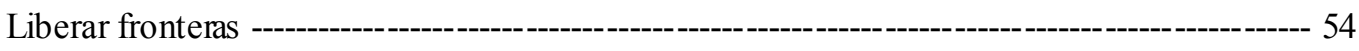

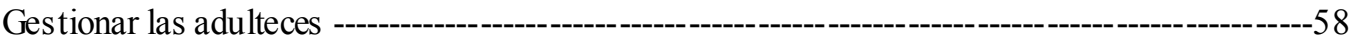

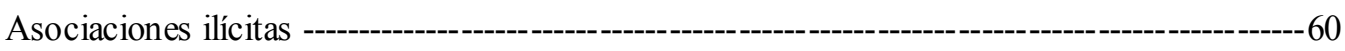

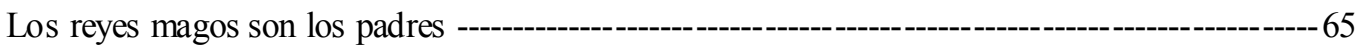

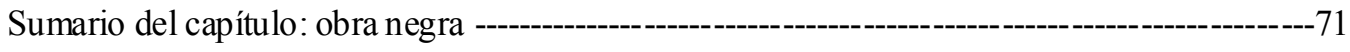

Capítulo III: Zona franca -----

Universo -----------------------------------------------------------------------------------------------------------76

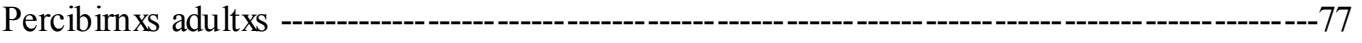

Hablar de privilegios --------------------------------------------------------------------------------------- 82

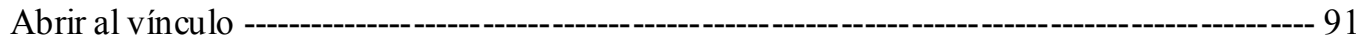

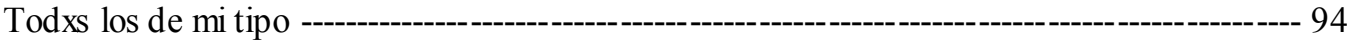

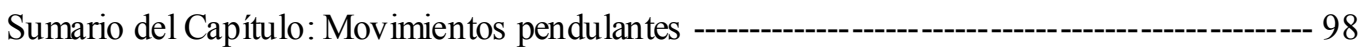

Capítulo IV: Profanxs - - - -

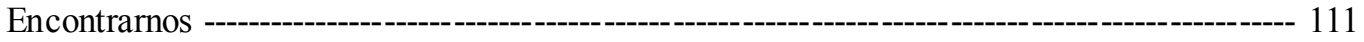

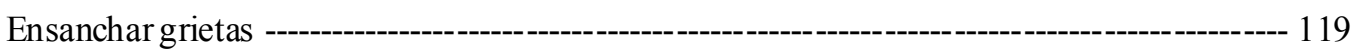

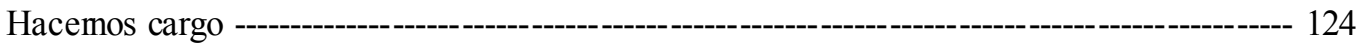

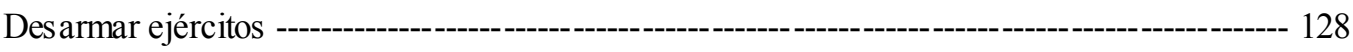

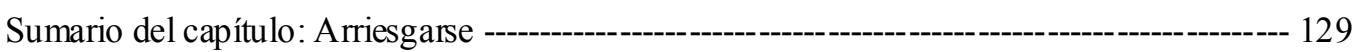

Conclusión: Afectaciones extrañas -- - -

Bibliografía - 140 


\section{Agradecimientos}

Porque ninguna idea nace en singular, y todo es un producto colectivo:

A lxs muchxs niñxs con quienes he habitado y compartido el Hospital Público, porque a ellxs les debo la pas ión por descubrir cosas y la alegría de conocer historias nuevas. Y porque en el fondo -y también en la superficie-, son el motivo por el que algunos lugares todavía me parecen habitables. Gracias por enseñarme a burlarme de mi adultez.

A Esteban, Julián o Sebastián Fernández, porque necesitaría que fuera al menos tres personas para que comprendiera lo importante que es para mi vida y para esta Tesis, y porque como él dijo una vez: no sabemos cuándo se originó esta complicidad, pero tenemos la certeza de que es infinita. Gracias por tu amorosidad compañera y por la humildad con la que me alentas a pensarque siempre es posible destruir y construir todo lo que existe.

A Nicolás Colombo, porque aunque no lo sepa, fueron sus palabras las que me incitaron a pensar que construir esta Tesis era una aventura posible. Gracias por la generosidad de acompañarme con tanta calidez y paciencia, incluso sin saber bien a qué.

A Carla Padovani, porque es mi hogar y mi refugio en este mundo, gracias por enseñarme tanto sobre el amor y sobre la vida. A Limay Padovani Torres, porque desde que nos acompañamos en la aventura de vivir yo me siento una persona increíblemente feliz.

A Silvina Fuentes, porque aunque reniegue de las familias, me encanta pensar que es mi hermana en esta vida. Y porque su valentía y convicciones me ayudan a ser mejor y a creer en otros mundos posibles.

A Belén Doumecq, porque su forma tan increíble de existir me devuelve la esperanza cuando me siento perdida. A Sofía Castro porque es el brote más hermoso que conozco.

A Natalia Rocchetti, Candelaria Medina, Geronimo Cárdenas, Victoria Barbieri y Eva Lutteri, porque ser parte de esta manada comprueba que la amistad es la forma más hermosa de construir el mundo. Y también, porque creen en mi incluso cuando yo no logro creer en nada.

A mi familia, porque sin ellos no sería la persona que soy, y porque nos hemos propuesto acompañamos siempre, aunque no sepamos bien a dónde. A mi papá porque secretamente creo que es un niño atrapado en un cueppo adulto, y porque si un día me dejaran tener un superpoder, elegiría la capacidad para mirar el universo con la increíble sensibilidad y profundidad con la que él lo hace.

A Alejandra Quintero, Soledad Lizarraga, Corina Chimelaro, Laura Zucherino, Marina Cabral, Luisina Corrales, Evelina Moriones, y Anabela Herrera porque de las muchas cosas que le debo al Hospital Público, una de las que más le agradezco es haberme cruzado con ustedes. Y porque me hacen reír 
cuando me siento triste, y me compran caramelos cuando estoy enojada. Gracias por enseñarme a pensar y sentir en plural. A Eve, también, porque en lugar de reclamarme porque dibujo mientras la gente hace cosas serias, convirtió esos borradores de pared en un hermoso fanzine. A Lucía Weber, porque cuando me dice 'tía sabías que...' yo siento que el mundo es infinito.

A Gabriela Gómez, Liliana Contreras, Nelly Lencina y Betty Lencina, porque llevan una vida demostrándome que ser diferentes no es impedimento para el encuentro. A Agustina Pérez Lencina, porque es especial en mi vida, y porque me enseño que las familias también se construyen con los amores que elegimos.

A Lucía Belaunzarán, Alejandra Quintero, Luis ina Corrales, Manuel Rodriguez, Julián Fernández, Silvina Fuentes, Gustavo Docters Fontana, Mariano Girini, Sofía Porta y Marina D’Alonzo, porque la lista de esas entrevistas se construyó sobre la premisa lxs adultxs a los que conocía y me hubiera gustado que hablaran con la niña que yo fui. Pero ahora que ya lxs conozco, no puedo más que desearles a todxs, independientemente de la generación que elijan, que un día se lxs crucen y puedan ser acompañadxs por ellxs. Gracias por ayudarme a sentir que existen otras formas de la adultez. Ustedes son, como decía Rodolfo Walsh, la esperanza insobornable.

A mis compañerxs de Derechos de Infancia, Familia y Cuestión Penal de la FTS, porque se la pasan organizando planes y empresas para luchar contra todo lo que está mal.

A mis compañeras de la Sala 13 y del Servicio de Nutrición, porque tengo el privilegio de trabajar con mujeres a las que quiero y admiro profundamente, y porque cuando la gente dice 'pasan cosas increíbles en los lugares menos pensados' yo siempre pienso en ellas. A Miriam Galarraga por haberme abierto las puertas de este mundo tan generosamente. Gracias por enseñarme que la afectividad y el respeto son condiciones imprescindibles para trabajar con niñxs y jóvenes.

A mis compañerxs del Servicio Social porque se siguen indignando con todo lo que produce desigualdad y porque me ens eñaron muchas cosas sobre el Trabajo Social. Gracias por enseñarme a escuchar.

A la Universidad Pública y Gratuita y a las Políticas Públicas, por permitir que personas como yo podamos formarnos y repensar el mundo. A la Facultad de Periodismo y Comunicación Social por alojarme en sus aulas. A Luis Carlos Chávez por el millón de teorías que nos inventamos sobre la Comunicación Social mientras cursábamos, y porque, después de tanto tiempo, pensar la vida sin sus teorías cósmicas me parecería algo muy aburrido. 


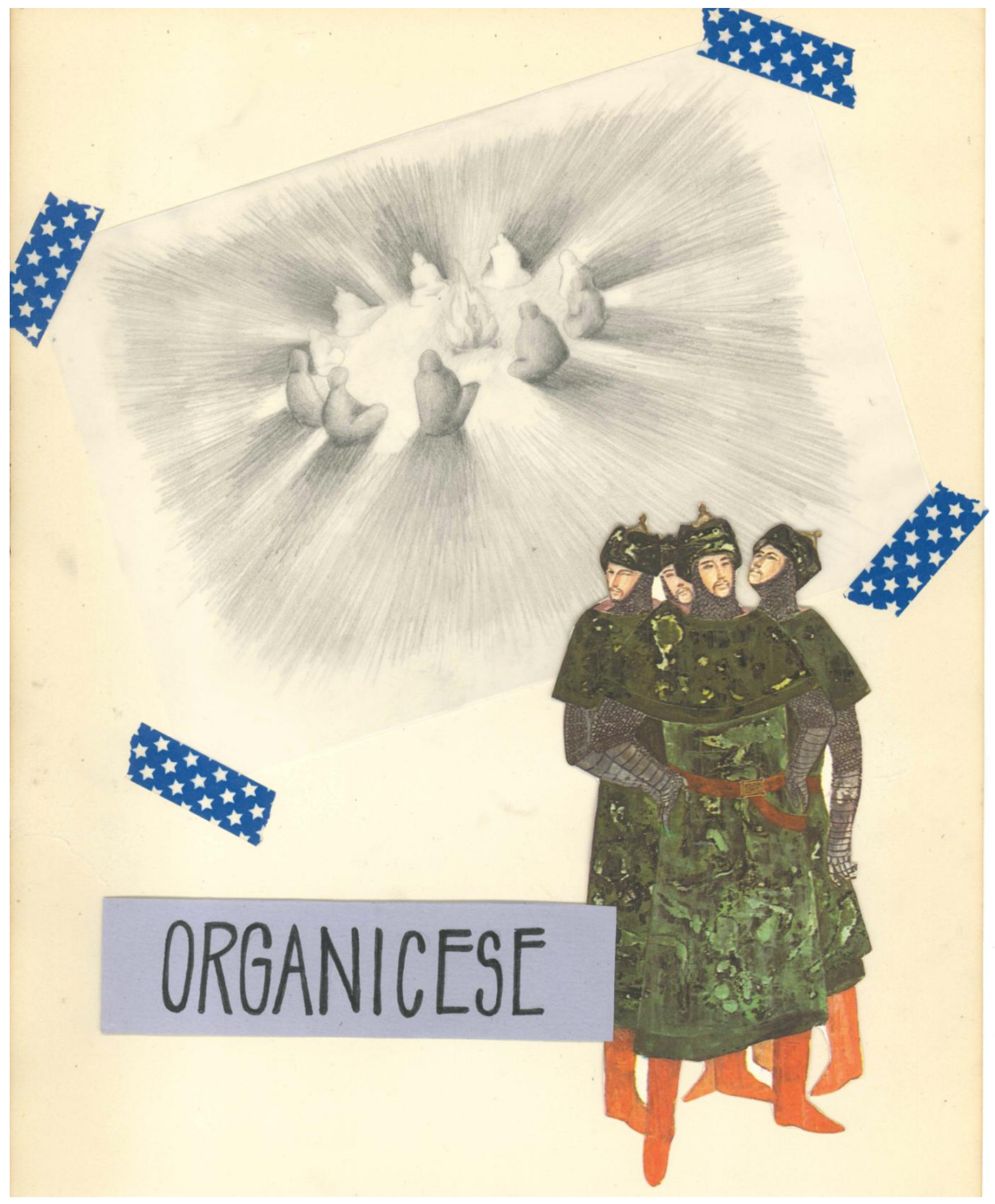


Esta tesis está dedicada:

A mi tío Juan, porque me enseñó que no hay nada de natural en la desigualdad, y porque construyó un refugio habitable para que la niña que un día fui sintiera que también hay lugar para lxs distintxs.

A mis sobrinos Lorenzo, Nicolás y Benjamín, porque son muy sabios y me enseñan a ensanchar los horizontes del mundo, y porque cuando estoy con ellos siento que puedo ser -o dejar de ser-todas las generaciones que quiera. 


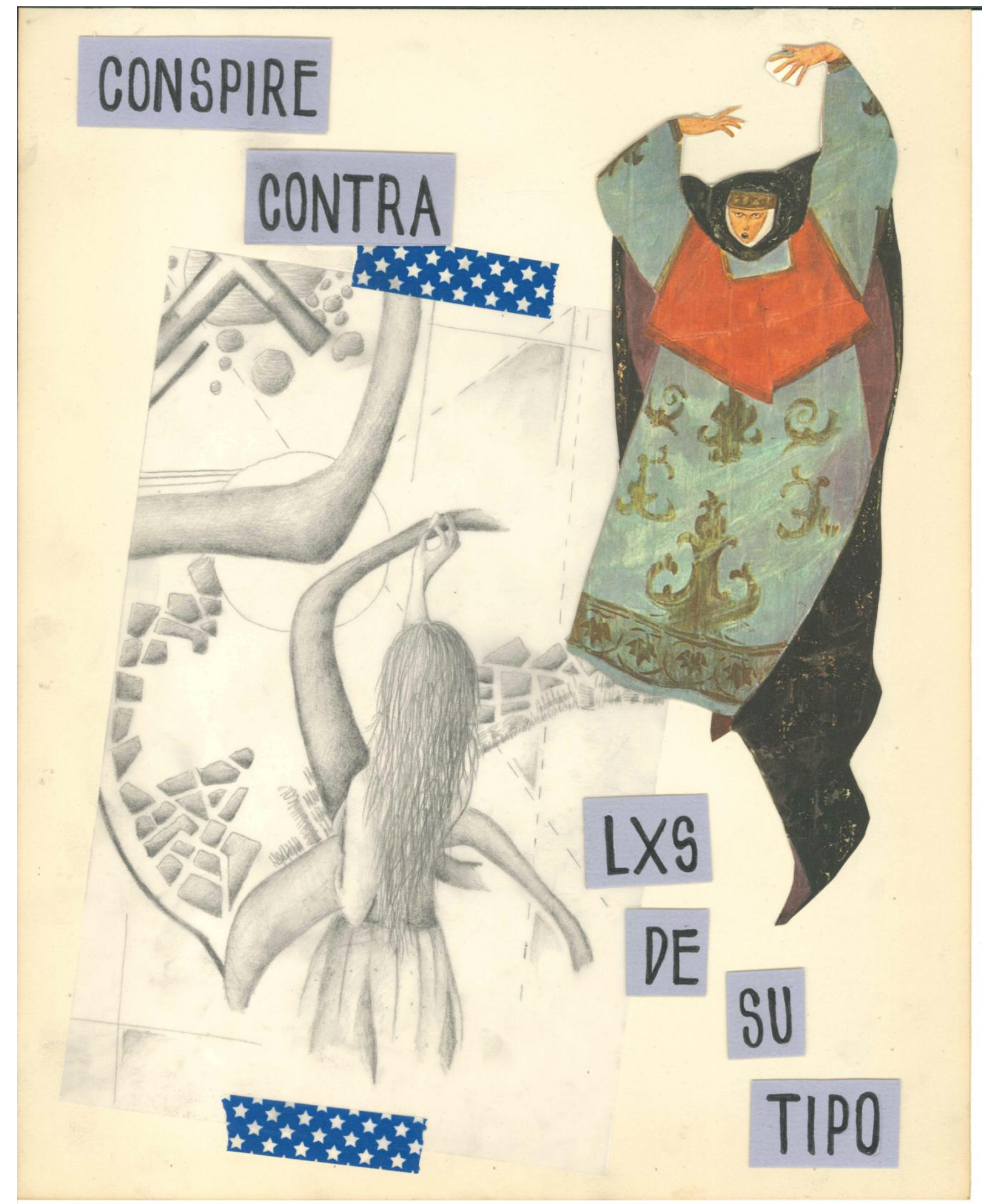




\title{
Introducción: ¿Qué me trajo hasta acá?
}

\author{
Estoy escribiendo porque me han dicho \\ que nunca empiece una frase con 'porque'. \\ Pero no intentaba formar frases: intentaba liberarme.
}

En la tierra somos fugazmente grandiosos

Ocean Vuong

¿Sabes por qué estas acá? suele ser una de las preguntas iniciales en las entrevistas que realizamos a lxs niñxs en el espacio socio-ocupacional del que formo parte. Ese interrogante abre a una serie de diálogos por demás interesantes que van desde el silenc io total o la realización de mapas procedimentales minuciosos, hasta el desarrollo de extensos relatos sobre historias fantásticas. Muchos de estos diálogos, sin embargo, participan de la idea de que niñxs y jóvenes han llegado hasta el espacio que compartimos porque hicieron algo mal, porque les pasó algo que se convirtió en un problema, porque no saben qué hacer frente a ciertas situaciones o condiciones que les causan sufrimiento, o, simplemente, porque alguien los ha obligado a permanecer en lugares en los que no se sienten a gusto. Respecto de todo lo que aquí está escrito, yo me percibo como esxs niñxs con quienes comparto mi cotidianidad.

No todxs sabemos por qué estamos donde estamos, aunque la mayoría podemos encontrar a lgunas pistas, seguir rastros, enunciar sospechas y/o construir hipótes is sobre lo que nos sitúa. Este trabajo habla sobre esa búsqueda, en un campo específico, que es el de los estudios generacionales; y sobre un propósito particular, que es la inda gación y anális is de los modos en que lxs adultxs que realizamos actividades vinculadas al Sistema de Promoción y Protección de Derechos ${ }^{1}$ ponemos a jugar nuestras posiciones adultas, en el vínculo con niñxs y jóvenes, en los procesos de trabajo que desarrollamos. La inexistencia de algo que pueda nominarse como estudios sobre la adultez me constriñe a iniciar a partir de una negativa: esta no es una Tesis sobre infancias, aunque haya sido el vínculo con niñxs y jóvenes lo que originó la incomodidad con la que adscribo a esta posición de mundo y el organizador desde el que se construyeron los interrogantes que aquí emergen. Soy consciente de que esta distinción solo puede producirse en un sentido abstracto, aventurándome en la disección de trayectorias

\footnotetext{
${ }^{1}$ Se utilizarán indistintamente las acepciones: SPPDNNA, Sistema de Promoción y Protección y/o Sistema, para hacer referencia al Sistema de Promoción y Protección de Derechos de Niñas Niños y Adolescentes.
} 
vitales que en el mundo social aparecen enlazadas, entremezc ladas, difusas y variables. Me esfuerzo por reponer que mi análisis se centra en quienes nos percibimos adultxs, porque en una época anterior yo también creía que para hablar sobre desigualdad y generación había que poner el ojo únicamente en quienes se encuentran en situación de subordinación.

Abandonar estas posiciones, o, suspender los anális is de corre latividad entre teoría y práctica o norma e institucionalidad, no resta importanc ia ni supone un cuestionamiento a los estudios sobre niñez y juventud: por el contrario, los recupera y se nutre de ellos, pues son quienes abrieron la puerta a los interrogantes sobre adultocentrismo y participación. A pesar de esto, considero que hay un límite en nuestro pensamiento generacional que aún debe ser conmovido y desarticulado. Ello es imposible sin cuestionar eso que consideramos natural, y, que en este caso, habla de las características y condiciones de nuestra propia participación en ese sistema de relaciones. Podría argumentar que este es un problema de reconocimiento, representación, simbolización y comunicación respecto de quienes se constituyen en nuestrxs otrxs; sin embargo, entiendo que este escollo acontece en un lugar toda vía más subterráneo y que habla de las formas en que, en estos marcos de sociabilidad, los sujetos producimos, somos producidos y establecemos mecánicas de reproducción que nos alcanzan corporal y pos ic ionalmente.

Recogiendo esas resonancias, elijo trabajar sobre lo viviente y dinámico que existe en nuestrxs marcos de interpretación-acción, y por tanto, este ensayo insiste en lo relacional y performativo de los enfoques. Es decir, la pregunta sobre el modo en que los DDHH inciden en nuestra vida cotidiana y en el vínculo que establecemos con otrxs, puede ser instalada a modo de conquista-concesión sobre un número definible de instrumentos y procedimientos, o bien, puede ser pensada, a partir de las disputas y luchas que lxs sujetos traccionan para ser reconocidos en los marcos socio-políticos que conocemos, de las tácticas, estrategias y alianzas que despliegan, del cuestionamiento a ciertas experiencias de desigualdad -o en su equivalente socio-jurídico, de vulneración de derechos-, y de las experiencias de resistencia y transformación. Ninguna de estas posibilidades es ingenua, pero la segunda implica, ineludiblemente, hacer cuerpo de los modos en que formamos parte de esos procesos. Por eso acuerdo con Joaquín Herrera Flores (s/f: 22) en que Los derechos humanos, más que derechos "propiamente dichos" son procesos; es decir, el resultado, siempre provisional, de las luchas que los seres humanos ponen en práctica para poder acceder a los bienes necesarios para la vida. 
Por qué mejor no te miras vos, que estás sentada en la misma guardia que yo en tu único día libre, me reclamó una vez una joven a la que intentaba convencer de ir a un espacio al que se había negado varias veces. Diría que este fue un evento extraordinario, pero eso sería una mentira. Nuestros encuentros con niñxs y jóvenes están plagados de estas invitaciones a repensarnos, pero, sin embargo, alojar esas preguntas supone un movimiento desestabilizante para el que no siempre nos sentimos dispuestxs. Asimismo, las condiciones de los espacios en los que trabajamos, frecuentemente se organizan en base a ese ocultamiento, haciendo que escuchar, con esa escucha que te desarma -como bien advirtió una entrevistada-, termine considerándose un agenciamiento de resistencia más que la condición impresc indible de todo diálogo.

Esto pone en evidencia que, aunque el observable esté a la vista, la posibilidad de visualización requiere, irremediablemente, de una serie de ópticas y tecnologías de deconstrucción y reconstrucción. Una aproximación desde la dimensión comunicacional permite, frente a este estado de situación, analizar la forma en que los regímenes de producción de lo visible y lo enunciable se relacionan con la institucionalización de lo legítimo tanto del orden y el equilibrio, como de las transformaciones tan abiertas como especificas de la lucha por los derechos (Delfino, 2016:2). Las formas que adquieren esos discursos y narrativas, tanto como los huecos provocados por su ausencia, y por los silencios y omisiones, forman parte de los hilos sobre los que estas experiencias se traman y significan. La producción de saberes y prácticas comunicacionales resulta así indisociablemente vinculada tanto a las acciones de defensa de los Derechos Humanos como a la organización política que propone nuevas estrategias para problemas históricos permanentemente renovados (Maestría en Comunicación y DDHH; 2011: 12).

La primera vez que oí a Fernand Deligny (1945:33) diciendo 'no les digas: ¿te parece que yo...? Quizás eres un modelo de adultx. De seguro ya no eres un modelo de niño' sentí el sonido de la reiteración de narrativas y encuentros cotidianos en las que eso que niñxs y jóvenes son -y/o deberían ser-, se pone en juego sistemáticamente. No obstante, cuando volví sobre esa afirmación, noté que lo que en verdad me perturbaba no era tanto la crítica a los modos en que ciertos sistemas de dominio nos constituyen molecularmente, sino la idea latente de que existe algo que construimos como modelo en los tipos de adulteces de las que somos representantes. Y, que es a partir de ellos, que establecemos parámetros de mundo y sistemas comunicativos. Advertí en esta premisa 
que la falta de controversia sobre esos estatutos es una condición necesaria para que los sistemas que se sostienen en base a la desigualdad permanezcan indemnes.

Hace poco alguien me dijo como al pasar que la adultez es como esas monedas que no se devalúan nunca y que se presentan como pilares de los sistemas financieros independientemente de cómo se produzcan o de la afectación que puedan tener sobre nosotrxs. Esta me pareció una definición precisa, puesto que ser adultxs, es, también, la potestad de regular el va lor de uso y el valor de cambio en la economía de los cuerpos. Por ese motivo, hablo de lo adulto: no solo como condición material de ciertos sujetos, sino, fundamentalmente, como una posición de mundo que puede ser habitada por diversos actores y actrices de acuerdo con los lugares ocupados en el sistema social.

Por la imposibilidad de deshacerme del hastío que me provocan nuestros agenciamientos es que abandoné la idea de que mi sujeto de análisis eran otrxs diferentes de mí. Si bien me he propuesto acompañar tránsitos de niñxs y jóvenes afectiva y respetuosamente, no puedo ignorar la complicidad que me aturde cada vez que observo que es mi posición -y la de otrxs que son como yo-, lo que produce trayectorias de dis gregación e invisibilización. Estas resonancias son las que me alientan a pensar que esta búsqueda se sostiene, fundamentalmente, en una obligación ética y política por repensar las formas deseables de habitar el espacio colectivo.

Admito que una Tesis sobre desigualdad escrita desde el lugar del privilegio supondrá, ineludiblemente, la enunciación de relatos sesgados, y por eso me propongo ensayar movimientos y pensamientos sobre los huecos donde hacen agua las propias narrativas. Escribo sabiendo que estas palabras nacen con una posibilidad de fracaso infinito; pero, también, con el deseo de que -si eso acontece-, no quede nada en pie. Prefiero, en todo caso, que sea una catástrofe de esas que arrasan aquello cuanto tocan; porque, a veces, arruinarlo todo, es la única garantía para no que dar intactxs.

\section{Abrir una ventana}

En la adultez, la pregunta acerca de cómo organizamos nuestros propios agenciamientos y cuáles son las lógicas de poder que nos atraviesan. es compleja: en tanto ostentamos posiciones amparadas en la invisibilidad representacional dominante, que hace que las narrativas sobre la utilización de privilegios no sean siempre explícitas o implícitas, colocándolas en zonas de opacidad y transparencia de acuerdo con sus intereses. Por este motivo, la forma en que nos percibimos generacionalmente, se encuentra modulada 
por experiencias, acciones, representaciones y creencias que inciden en los modos de situarnos en vinculación con nuestras trayectorias temporales-corporales. Estas, asimismo, no acontecen de manera única sino que se encuentran afectadas interseccionalmente por otras condiciones socio-políticas y materiales de existencia (Platero; 2012), que hacen de las trayectorias generacionales experiencias múltiples y diversas, produciendo relaciones de hegemonía y subalternidad.

Esta desigualdad estructural que ofrecen los Sistemas Adultocéntricos, y, que es modulada y organizada en torno a las condiciones generacionales de los sujetos, ha sido ampliamente analizada por distintxs teóricxs (Duarte, 2012; Pavez Soto, 2012; Bustelo, 2012; Gaitán y Liebel, 2017; Magistris y Morales, 2018). Aunque, un aspecto particularmente llamativo de los estudios del campo, es que la dimensión e implicancias de lo adulto en esos procesos, aparece aún como un elemento marginal de indagación. Ello de seguro se encuentra afectado por el hecho de que el sujeto colectivo que, con mayor frecuencia estudia y analiza los procesos que involucran a las generaciones, es el mismo que detenta una posición de privilegio en los sistemas intergeneracionales. Dicho de otro modo: debemos admitir que el manto de invisibilidad sobre el que se amparan las posiciones de mundo que ostentamos ha sesgado los anális is del campo, pues ha ocultado nuestra incidencia en esos modos de construcción delvínculo, a partir de relocalizar todo interés en las condiciones y particularidades de niñxs y jóvenes.

En este marco, recuperar la perspectiva de DDHH como enfoque, suspendiendo provisoriamente las cristalizaciones y materialidades a partir de las que nos aproximamos a su abordaje en nuestra cotidianidad, posibilita re-situar estos interrogantes, incorporando para su análisis los elementos que emergen como conflictivos y/o tensionantes en las formas de construcción de lazo social cuando, eso que nominamos como espacio común y compartido, no es habitable para todxs los sujetos desde una potencia equivalente. Al mis mo tiempo, esta perspectiva, también nos permite advertir y disputar alternativas de transformación para todo eso que en el orden de lo colectivo se expresa como productor de desigualdad, traccionando las formas de reconocimiento de lo diferente. Al preguntarse sobre lo que implica la vivencia y experiencia de la perspectiva de derechos en la cotidianidad de los sujetos, Martín Gras retoma de Eleanor Roosvelt esta observación:

En definitiva ¿dónde empezamos los Derechos Humanos universales? Pues en pequeños lugares, cerca de nosotros, en lugares tan próximos y tan pequeños que no aparecen en los mapas. Pero eso son los lugares 
que conforman el mundo del individuo: el barrio en que vive, la escuela o la universidad en que estudia, la fábrica, el campo o la oficina en que trabaja. Esos son los lugares en que cada hombre, mujer y niño busca ser igual ante la ley, en las oportunidades, en la dignidad sin discriminación. (Gras, s/f: 10)

En concordancia con esta consideración, durante una internación, una niña nos cuestionó acerca de Por qué ponen un cartel con mi nombre mirando para el lado de afuera, si yo estoy del lado de adentro, cuando, en uno de esos proyectos que pretendían humanizar la atención, habíamos colocado unas pizarras con los nombres de quienes estaban hospitalizadxs. Ese señalamiento fue muy interesante, puesto que -si bien las pizarras habían sido realizadas en el marco de un proceso de reconocimiento que apostaba a horizontalizar las relaciones-, la decisión resultaba, al final de cuentas, igualmente direccionada: ya que los carteles seguían estructurándose y ordenándose de acuerdo con una lógica adulta-institucional, en lugar de interactuar con quienes se suponía que eran sus destinatarixs.

La posibilidad de nombrar, entonces, no puede ser pensada por fuera del sentido con el que se establecen esas nominaciones y representaciones, de los sujetos a lxs que afecta, $\mathrm{y}$ de la forma en que, en ese entramado, se producen narrativas y diálogos respecto de los modos de ser, permanecer y transitar por los espacios sociales de los que formamos parte. Para que algo sea transmisible es imprescindible que, antes, haya sido posible diagramar y establecer códigos comunes y comunicables de construcción de sentido. Si bien ello ha de ser pensado en vinculación con sistemas de poder que afectan las lógicas de visualización y omisión, no debemos perder de vista que toda experiencia comunicativa es soportada por producciones narrativas interesadas.

Lo visible, lo enunciable y lo decible de cada época, está lejos de ser una resultante natural asociada a un tipo de destreza lingüística y/o capacidad de raciocinio de los sujetos. Por el contrario, las formas de producción de discursos y cuerpos, se encuentran profundamente entrecruzadas con las consideraciones éticas y políticas de mundo, y con las tácticas y estrategias de composición, materialización, y localización. Si pensamos este movimiento en vinculación a los modos de componer posiciones, la idea de que la adscripción a una forma identitaria se construye necesariamente bajo una lógica de exclusión y/u oposic ión de otros modos de as ir el mundo, opera en un sentido doble: por un lado, haciendo necesaria la existencia de lo individual e inmanente como presencia fija y delimitable, y por el otro, estableciendo sobre la premisa de lo diferente una serie de atributos y condiciones de distanciamiento y separación. 
En este sentido, a pesar de que asumimos, con mayor o menor acuerdo, que todas las posiciones identitarias son políticas, dinámicas, simultáneas, múltiples y provisorias, las adscripciones generacionales no suelen nominarse como marcaciones de relevancia en los debates sobre las relaciones de poder en la adultez. Por ello, uno de los elementos más interesantes que aporta el debate sobre las condiciones generacionales, es la importancia de comprender que nuestras posiciones de mundo utilizan anclajes o soportes que los conforman y configuran -como ocurre con nuestros propios cuerpos o con ciertas condiciones materiales de existencia-, pero que no se limitan a ellos, o, que incluso, pueden transformarse sin que eso suponga, necesariamente, un cambio de posición o elección (Mannheim; 1928).

Por su parte, a lgunas formas de vinculación entre posiciones generacionales, objetos y lugares, han sido interpretadas como cristalizaciones de identidad innatas más que como relaciones situadas socio-contextualmente, en las que confluyen intenciones y contingencias en una temporalidad simultánea. Este movimiento que se nos aparece, $a$ priori, como forma de interpretación o de vinculación de los sujetos con la sociedad incluye ndo las significaciones, identificaciones, y naturalizaciones necesarias para la integración social-, ta mbién enlaza tránsitos, trayectorias y vivencias que, cuando no se sitúan, se imponen a esos sujetos como modos de fijación identitaria (Llobet; 2010, Fernández, 2018).

Por ese motivo, en el orden de las construcciones generacionales y del sistema de relaciones intergeneracionales, la correspondencia entre experiencia corporal-temporal, posición de mundo y vivencia, requiere ser desanudada, interrogada, cuestionada y reconstruida. Es decir, que es necesario desandar aquello que nos aparece como devenir innato de la vivencia de las identidades en vinculación con las experiencias temporales del mundo y la portación de formas de corporalidad que se presuponen acordes a ello (Chaves y Segura; 2014). Poner en diálogo la relación entre marcadores generacionales y posiciones de mundo no tiene por objetivo cancelar nuestras propias vivencias o evaluarlas en términos de corrección o incorrección, sino que apunta a reconocerlas y situarlas, procurando disputar y romper con las formas jerarquizadas de construc ción de vínculos.

Debería agregar que, nombrar, también potencia la posibilidad de poner en juego: no solo en el sentido de dar visibilidad a aquellos actores que -por las condiciones y organización del poder ocupan lugares subalternos-, sino, también, porque remite a la posibilidad de hacer narrables las trayectorias que nos acontecen como singulares y 
diferenciables, y, que, en el vínculo intergeneracional, aparecen en zonas de opacidad que se enuncian vinculadas a experiencias concretas de la desigualdad. Es decir, nombrar permite hacer comunicable esa complejidad que enlaza la experiencia social colectiva que, en clave generacional, y, en su configuración actual, segmenta, separa y disgrega. También hace posible reconocer las posiciones y propuestas que resisten y transforman aquello que nos es presentado como las creencias y mandatos hegemónicos de las generaciones.

De esta manera, si volvemos sobre la dimensión comunicacional del análisis, poniendo a jugar las disputas entre lo instituido e instituyente respecto del sentido común compartido, y en vinculación a los modos que asume el vínculo intergeneracional, es fácil advertir la puja permanente entre los mecanismos de fijación y las estrategias de disolución. Dicho de otro modo: mientras que una serie de discursos insisten en la necesidad de establecer fronteras y criterios de separación a partir de la construcción y asignación de atributos pretendidamente innatos e inherentes a los sujetos de acuerdo a su posición corporal-temporal, otras narrativas y prácticas que, progresivamente, disputan fuerza y sentido, proponen la disolución de marcaciones, abonando a la idea de que la experiencia de lo diferente no necesariamente supone lógicas de exclusión.

Cabe destacar que, las posiciones temporales-corporales sobre las que se sustentan los marcadores generacionales, solo pueden leerse despojadas de otros marcadores o clivajes en un sentido analítico y abstracto, siendo imprescindible pensar su vinculación en una red de sistemas organizados en torno al pluridominio (Duarte, 2014). A pesar de que se trata de un entramado complejo y multiproducido, entiendo que, éste anális is, ha de pensarse especialmente enlazado a los estudios de género, no solo por la vinculación directa entre el establecimiento de un orden patriarcal y la construcción de sistemas adultocéntricos (Duarte, 2012), sino porque estas teorías y perspectivas echan luz respecto del análisis de las relaciones de poder y dominio, de las experiencias de desigualdad, resistencia y transformación, de los procesos de marcación y las estrategias de demarcación, del modo en que se configuran los sujetos interseccional y performativamente, y sobre producc ión social de los cuerpos, entre otras cuestiones.

\section{Estructura de la Tesis}

Reorganizar el desorden originado por esta indagación ha sido dificultoso, puesto que la producción en linealidad, en ciertas circunstancias, omite aquello que es simultáneo y/o 
que se enlaza contingencialmente a relaciones no producidas por quien escribe. Frente a esto, tres cosas he priorizado: 1) Construir una narrativa que atienda a lo procesual del enfoque, colectivizando las ópticas de visualización a partir de las cuales se estructuraron los saberes y pareceres que aquí son presentados; 2) Establecer siempre puntos de partida y opiniones como modo de proponer anális is anc lados en modelos de objetividad fuerte (Harding, 1996); y, 3) Enfatizar en los interrogantes y teorizaciones que ponen en jaque los modelos establecidos y que permiten fugas a nuestros pensamientos generacionales.

Asimismo, la escritura de la Tes is está modulada, sobre todas las cosas, por una serie de diálogos e interrogantes devenidos de mi propia experiencia de trabajo con niñxs y jóvenes, y por lo que he descubierto -sobre mí y sobre el territorio que construimos y habitamos-, en esos encuentros compartidos. Por cons iguiente, si tuviera que asumir una perspectiva o flujo de pensamiento que actúa como marco estructurante, debería decir que, la mayoría de los presupuestos teóricos que porto, provienen de las ideas, creencias y preocupaciones de lxs niñxs a los que conozco: y que resultan ser ellxs $-\mathrm{y}$ las trayectorias compartidas-, la matriz referencial a la que acudo con mayor frecuencia cuando necesito analizar, problematizar, desanudar y reconfigurar los modos de pensarme y de pensar algunas relaciones sociales.

Haciendo eco de estas premisas, la Tesis se compone de cuatro capítulos, que, enlazados, intentan dar cuenta de un pensamiento en interior (Artaud, 1925), que ahonda en los agujeros y detenciones que se producen en la relación entre espacios, tiempos, cuerpos y posiciones; y a partir de las cuales hemos construido nuestros pensamientos generacionales. La intención que acompaña la producción, asimismo, se centra en un movimiento doble y simultaneo de reterritor ia lización (como aquello que sitúa el espacio común de las adulteces) y de disolución (como aquello que permite deshacer las cristalizaciones que fijan modelos identitarios).

Por lo tanto, en el Capítulo I, he intentado desandar los motivos y sospechas por los que entiendo que las formas de la adultez que conocemos son problemáticas -e incluso peligrosas-, al momento de pensar en sociedades habitables para todxs. Esta creencia ha sido enlazada a una serie de preguntas respecto de las posiciones y trayectorias compartidas, así como a otros interrogantes acerca de los puntos de continuidad y ruptura establecidos por sujetos, movimientos y discursos socialmente legitimados en el campo de los estudios generacionales. En vinculación con ello construí algunos objetivos de estudio, procurando hacer localizables, a partir de la observación de ciertos 
vínculos socio-temporalmente situados, aquello que deviene como identitario o innato en las formas de construcción y socialización de lo adulto. La hipótesis general que ha acompañado esta escritura asevera que la mayoría de lxs adultxs no nos percibimos como sujetos privilegiados respecto de otras generaciones, y/o, que asumiendo la existencia de diferencias, entendemos que establecer pautas de jerarquización, exclusión y disciplinamiento, son aspectos inherentes e innatos a las experiencias generacionales subalternas.

Este Capítulo también repone en el modo en que fui construyendo un proceso de visualización, no ya como una secuencia mecánica de actividades asociadas a un método, sino, más bien, como una experiencia de localización, afectación, anális is y producción de observables. Me he amparado en las epistemologías feministas, puesto que considero que ellas me permitieron comprender que esa masa multiforme a la que llamamos conocimiento de la realidad, habla de un constructo performativo viviente por el que somos afectadxs de innumerables maneras; y, por lo tanto, la aspiración no es la comprensión total de lo real, sino la posibilidad de ser honestxs con nuestros puntos de vista, haciendo del poder de ver una herramienta colectiva de liberación. Dentro del mismo, he reservado un apartado en el que se explicitan aspectos operativoinstrumentales de la investigación, y que habla acerca de los sujetos individuales y colectivos que co-construyeron este trabajo, y de las dimensiones y procedimientos respecto de los cuales se estableció una visión en perspectiva.

En este sentido, he realizado una indagación de tipo exploratoria-cualitativa, enfocada en el análisis de las trayectorias, percepciones y posiciones adultas, entendiendo que esta constelación categorial condensa aquellos saberes que son construidos atendiendo a las experiencias, representaciones, sentido, sentires y afectaciones de lxs adultxs acerca de sus propias consideraciones generacionales, promoviendo así la construcción de conocimientos situados. Específicamente, me interesé por conocer las fuentes de legitimación sobre las que se sitúan las posiciones adultas, las percepciones acerca de la utilización de privilegios, las narrativas en torno a las cuales se recrea el vínculo intergeneracional, las disposiciones, valoraciones y sentidos que priman en las interacciones, y su incidencia en la comunicación con niñxs y jóvenes.

En el Capítulo II, por su parte, desarrollo aquellas categorías y concepciones que han sido estructurantes en el proceso de indagación, con intención de deconstruir y reconstruir los cimientos sobre los que se organiza nuestro pensamiento generacional. Para ello pongo en discusión nociones como las de adultocentrismo y poder de la 
mayoridad, hablo acerca de las creencias y mandatos que permean las trayectorias adultas, y me pregunto acerca de las asociaciones simbólico-discursivas que modelan las trayectorias de niñxs y adultxs en este momento sociohistórico. También participo de la idea de que, edad y generación, son categorías performativas, y, por lo tanto, propongo situar su anális is en directa vinculación con los estudios de género.

Atendiendo al hecho de que son escasos los desarrollos de este campo que observan las formas de participación adulta, me he valido de las discusiones y planteamientos que aportan las perspectivas de derechos, participación y co-protagonismo de la niñez, para repensar otras alternativas de construcción de vínculos no jerarquizados. He de destacar que, dentro de estas perspectivas, las narrativas que tensionan los modos hegemónicos de edificación de la adultez siguen permaneciendo en zonas de subalternidad: aunque su enunciación permite desandar los sistemas comunicativos que se han construido para reforzar -o por el contrario, cuestionar-, estas posiciones de mundo.

Recupero aquí una serie de desarrollos y perspectivas que, en distintos campos y a lo largo de la historia, han propuesto e implementado dispositivos de trabajo y/u ópticas de análisis que subvierten el modelo adultocéntrico, construyendo alternativas que prescinden de la jerarquización, reconfiguran las relaciones corporales-temporales y cuestionan la utilización de privilegios. Estas experiencias son el observable de las grietas por las que se cuelan aquellos pensamientos que se rebelan a los órdenes establecidos. Los desarrollos de estxs autorxs me han servido de brújula, encauzando los puntos de visión cuando mis estrategias de invisibilización y ocultamiento me nublaron la perspectiva. También han sido un punto de apoyo para nuevos conocimientos, un sistema de vigilancia cada vez que he tomado como natural algún conocimiento generacional, y una oportunidad de apertura para desafiar aquello que todavía no existe.

Como contraparte de esto, el Capítulo III recupera y desarrolla el análisis producido a partir de la implementación de un cuestionario digital implementado con el objetivo de conocer los modos en los que se organiza la experiencia adulta, indagando sobre percepciones, trayectorias y posiciones de adultxs que trabajan con niñxs. Estas observaciones me permitieron estudiar y comprender aquello que se presenta como el espacio común en las trayectorias adultas, y que aparece frecuentemente bajo la idea de sentido compartido. El conocimiento obtenido también fue relevante para profundizar en los movimientos de opacidad y transparencia de aquello que aparece como admisible 
e inadmisible en el vínculo intergeneracional, y que actúa edificando fronteras de separación y valoración de sujetos.

Este ejercic io de reterritorialización ha hecho posible poner en el orden de lo hablado y dialoga do aquello que aparece como supuesto e inmanente en las construcciones adultas a las que adscribimos, así como también permitió esclarecer algunos elementos y supuesto de las hipótesis planteadas como organizadores de la investigación. Las preguntas contenidas en el cuestionario procuraron indagar en lo obvio y cotidiano respecto de los modos en los que se organiza la experiencia y trayectoria adulta recuperando una pregunta fuerza: ¿Cómo se compone la noción de lo adulto y cuáles son las afectaciones que esto provoca en las formas de construcción de vínculos intergeneracionales?

En la misma línea, el Capítulo IV contiene los diálogos a partir de los cuales me fue posible visualizar puntos de fuga, reuniendo las experiencias de actores y actrices que, si bien se consideran adultxs, disputan sentidos, habitan contradicciones, se pre guntan y preguntan a otrxs sobre las formas de percibirnos generacionalmente. Todxs ellxs habilitaron nuevas preguntas y pensamientos, abriendo los huecos de aquello que entendía como posición y experiencia adulta. Entiendo que sus prácticas contienen un fuerte componente profano (Agamben, 2005), puesto que en todas ellas subyace explicita e implícitamente, una urgencia por devolver al uso libre lo que ha sido separado.

A pesar de situarse en el capítulo final, esos diálogos compartidos, hablan sobre una de las preguntas centrales de esta investigación, y que es la que se interroga respecto de si podemos deconstruir y/o diluir las posiciones adultas y hegemónicas de las que somos representantes, para proponer devenires y vínculos que suspendan valoraciones y jerarquizaciones. La narrativa contenida en él se presenta a modo de montaje literario (Benjamín, 2005), haciendo explícita la relevancia de tramar narrativas a partir de los discursos y diálogos producidos en primera persona. De la misma manera, he considerado imprescindible poner de manifiesto la potencia y relevancia que tienen las experiencias pequeñas y anónimas para la construcción de lo común y compartido.

Finalmente, he reservado un pequeño Capítulo que reúne las conclusiones, comprueba y refuta hipótes is, reconfigura preguntas, propone argumentaciones y desarrolla una serie de hallazgos, que hablan sobre los desplazamientos necesarios y los desafíos que supone habitar nuestras experiencias de mundo desde posiciones que promuevan tránsitos equivalentes. 


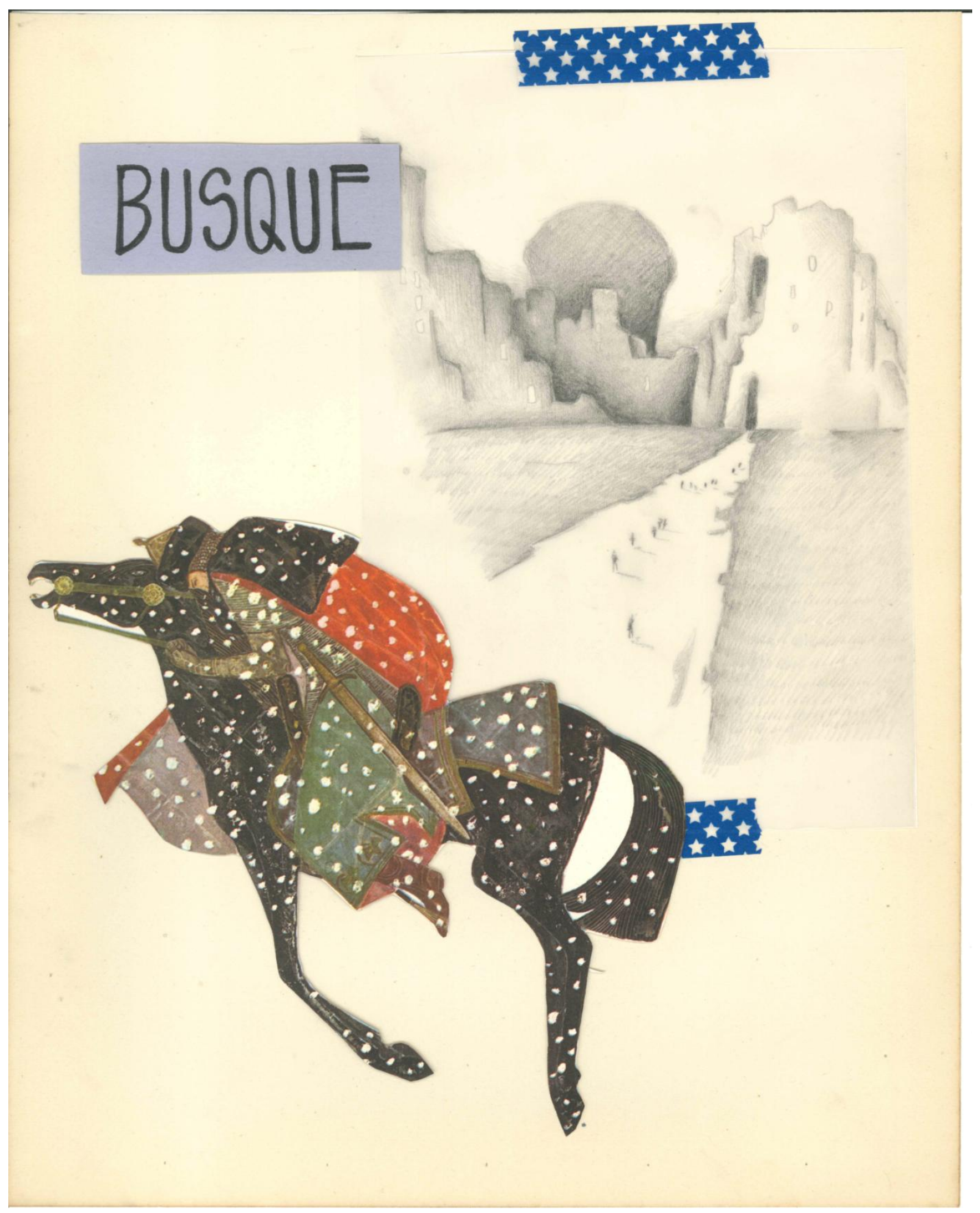




\title{
Capítulo I: Políticas del posicionamiento
}

\author{
Toda óptica es una política del posicionamiento \\ Mujeres, Ciencia y Cyborgs \\ Donna Haraway
}

Lo producido en esta tesis encuentra su origen en una carencia y en un exceso. Aunque estas afectaciones parezcan superficialmente excluyentes, por el contrario, ambas expresan límites claros a la posibilidad de dar respuesta a la desigualdad. Al hablar de carencia me refiero a la sensación constante de que nada alcanza para transformar el lazo social. No hablo aquí solo de mi propia experiencia, sino de la de otrxs con quienes comparto el trabajo con niñxs y jóvenes, y a quienes también les permea cotidianamente una afectación paliativa sobre el quehacer. Esta sensibilidad se expresa, en muchos casos, en la reconversión forzada de lo deseable/necesario a lo posible de acuerdo con las condiciones de estructuración del campo, mientras que en otros, aparece como fantasma utópico de un tipo de sociabilidad inexistente. Por el contrario, la obscenidad del exceso, habla de la arbitrariedad con la que aquellas situaciones conflictivas que involucran a niñxs y jóvenes son resueltas a partir de decisiones adultas completamente ajenas a sus intereses. La impotencia es la marca del exceso, y su narrativa por excelencia es la denuncia clara de que a esxs adultxs lxs pibxs no les importan nada.

Ustedes me enseñaron que las personas no tienen dueño, pero ahora me dicen que es Niñez el que va a resolver a dónde tengo que ir, y a mí eso no me parece que sea tan distinto a lo que hacía mi abuela, nos discutió una vez una niña, porque el equipo que la acompañaba, no había cuestionado lo suficiente las condiciones de su egreso a una institución Convivencial: y ella entendía que, aunque con interlocutores diferentes, persistía la discrecionalidad con la que se decidía su trayectoria. Su señalamiento me sirvió para comprender que, carencia y exceso, la mayoría de las veces, no solo no son excluyentes, sino que, además, se complementan en experiencias que alimentan la misma mecánica a la que cuestionan, en tramas de las que cotidianamente formamos parte.

En relación con esto, parto de considerar que toda propuesta comunicacional contiene, organiza y construye un conjunto de posiciones, omisiones, disputas, alianzas, condensaciones y fugas respecto del modo en que ocurren ciertas relaciones sociales, histórica y políticamente situadas. Quienes reponemos en estos modos de construcción 
de lo social no somos ajenos a las mediaciones que conocemos ni a las que hemos construido, y, por ello, transitamos en una trama de afectaciones de las que somos, al mismo tiempo, escribas, mensajeros y destinatarios. La afectación es una condición en la producción de visualizaciones más que un efecto de la organización de ciertos conocimientos, es decir, también somos eso que investigamos. En mi caso particular, esto es evidente, puesto que soy una persona que se percibe adulta y que trabaja con niñxs y jóvenes, que busca conocer trayectorias, percepciones y posiciones de otrxs, que son y hacen, lo mis mo que yo.

Entonces, cuando digo 'adultxs', digo también, sobre mi propia trayectoria, sobre las experiencias de haber sido sujetada a una generación que sue le serme extraña, y sobre las identificaciones a las que adscribo y que me devuelven cotidianamente a este colectivo. Además advierto que algunas de las preguntas que he realizado a otras personas en esta indagación, me serían muy difíciles de ser respondidas en lo personal y con total honestidad. Silvia García Dauder, al analizar la participación de lxs investigadores en los procesos de producción de conocimiento, aporta esta visión:

...la mayor objetividad se produce al dar cuenta de las posiciones de partida y las relaciones en que nos inscribimos, considerando nuestra parcialidad y contingencia. Esta concepción de una objetividad feminista encarnada -una "objetividad fuerte" en términos de Harding (1996)sitúa lo político en la misma base de la producción de conocimiento. Pero reconocer las implicaciones políticas de una posición o de un conocimiento, lejos de invalidarlo como ideología o de conducirnos a un relativismo del todo-vale, emplaza (...) a una producción de conocimiento socialmente comprometida y responsable. Este carácter responsable de los conocimientos situados, presupone la aplicación de una reflexividad fuerte (Harding 1996) donde los sujetos de conocimiento son examinados en los mismos términos que los objetos de conocimiento. Lejos de presuponer una distancia aséptica, la reflexividad fuerte supone una participación comprometida por la cual el sujeto de conocimiento no se desvincula del proceso de investigación y los efectos que provoca (Cruz, Reyes y Cornejo; 2013, 4)

Hasta aquí puedo decir, entonces, que me percibo mujer, heterosexual, blanca, rural, universitaria, trabajadora, hija de una familia de clase media-pobre, y adulta, y que estas localizaciones conforman, igualmente, mi matriz de visión. Asimismo, asumo que el cuestionamiento de muchos de mis privilegios no nació de un proceso introspectivo y reflexivo sobre la desigualdad humana, sino que fue producto de las discusiones, cuestionamientos e incomodidades surgidas del vínculo con niñxs y jóvenes: tanto en mi espacio laboral como en mi vida cotidiana, y, que, por tanto, no vivo esas 
experie ncias como conquistas incuestionables, sino como advertencias y vigilancias a la utilización de prerrogativas.

Hace casi una década, en un contexto de alta militancia sobre el reconocimiento y acceso a derechos de niñxs y jóvenes, y, sintiéndome muy interpelada por las perspectivas de participación y protagonismo infantil, se me propuso el acompañamiento a un niño que llevaba tres meses de internación, y que previamente a eso, había vivido durante los primeros años de su vida en el hospital. En su narrativa, la importancia de explorar el espacio que compartíamos -y de habitarlo de otros modos-, aparecía como una urgencia. Atendiendo a eso, resolvimos organizar una suerte de expediciones en las que, alternadamente, nos proponíamos redescubrir algún sector de la institución. Proponer una estrategia de intervención caracterizada por el movimiento, en un espacio que se organiza en base a las detenciones temporales-espaciales, la demora y el reposo, fue una acción altamente disruptiva, que implicó pujas y discusiones, $y$, por consiguiente, la autorización para su realización se nos representó como una forma de triunfo y reivindicación.

Sin embargo, en el primer encuentro, cuando cada quien presentó su mapa de lugares misteriosos, ocurrió algo impactante: mientras él había marcado una serie de lugares que se ubicaban centralmente en el subsuelo y en zonas deshabitadas, mi mapa situaba puntos en el tercer piso y en zonas centrales. En su explicación del lugar, él advertía que, en su trayectoria, la posibilidad de deambular estaba asociada a lo subterráneo e ilocalizable, que eran sitios donde nadie nos iba a mirar como fuera de lugar, porque en todo caso, esos eran espacios no habilitados para nadie. Por el contrario, yo había priorizado como criterio los espacios que nos conectaban con el afuera, ya que todo lo que ocurría hacia adentro me parecía del orden de lo indeseable, tanto para su experiencia como para la mía, y, porque, en las estructuraciones hospitalarias todas las edificaciones insisten en dirigir la mirada hacia el interior.

Cuando llegamos al tercer piso, que era una de las zonas delimitadas en mi mapa ya que ese sector poseía grandes ventanales por los que entraba sol y se podía ver el parque, noté por primera vez que todas las ventanas de ese ala estaban construidas por sobre la altura de la mayoría de lxs niñxs a lxs que conocía -y que incluía en particular al niño que me acompañaba-, y que entonces, ese era un lugar fantástico solo para quienes medíamos más de 1,2 metros. Entiendo que así presentada la escena, esto parecería del orden de lo obvio, aunque no estoy segura de cuantxs de nosotrxs nos hemos detenido a pensar si lxs espacios por los que transitamos son materialmente habitables para todxs, 
en una potenc ia similar. En cualquier caso, un solo rondín me alcanzó para aprender que no existen revoluciones totales que derrumben por completo nuestra matriz de pensamiento, y que también podemos producir prácticas de ocultamiento, invisibilización y/o diferenciación, incluso cuando creemos que ocupamos el lugar del bien.

En este sentido, se vuelve relevante volver sobre los huecos y detenciones que portan nuestras propias experiencias, advirtiendo que instalarnos allí donde el choque entre trayectorias nos confronta con otros modos de construcción de lo diferente, puede producir movimientos disímiles: ya sea para la edificación de cristalizaciones de separación, tanto como, por el contrario, para permitirnos pensar en formas colectivas de transitar el mundo social sin necesidad de delimitar sistemas de valoración y exclusión. Sobre estas alternativas éticas y políticas se asientan los debates fuerza en torno a los que se edifican los enfoques de DDHH. Hemos de reconocer también, que esta es una invitación a repensarnos -y re-situarnos- en esos procesos, no ya a partir de enunciaciones políticamente correctas acerca de las condiciones y características que ciertos vínculos deberían asumir, sino, por el contrario, considerando las tensiones y resistencias que emergen de las vigilancias y transformaciones que debemos realizar para que lo común y compartido sea posible.

En otro plano de análisis, pero también reponiendo en estas encrucijadas y contradicciones que estructuran nuestras matrices de visualización, Donna Haraway recupera que:

... "ser" es mucho más problemático y contingente. Asimismo, una no se puede situar de nuevo en ningún puesto ventajoso sin ser responsable de ese desplazamiento. La visión es siempre una cuestión del "poder de ver" y, quizás, de la violencia implícita en nuestras prácticas visualizadoras. ¿con la sangre de quien se crearon mis ojos? Estos temas se aplican también al testimonio desde la posición del yo. No estamos presentes de inmediato para nosotras mismas. El conocimiento de una misma requiere de una tecnología semiótica que enlace los significados con los cuerpos. (Haraway; 1995:333)

De este modo, en lo que ocupa a la indagac ión y anális is que pretendo desarrollar, parto de una sospecha acerca de lo que acontece en el vínculo entre adultxs y niñxs, que como tal, contiene observables, localizaciones, relaciones y afectaciones de condicióncontingencia situadas, aunque también guarda dentro de sí lugares inconclusos, asociaciones no producidas, espacios que poseen una correspondencia en disputa $\mathrm{y} / \mathrm{o}$ 
que no forman parte de las narrativas legitimadas del campo. Es por ello que este capítulo habla sobre problemas, preguntas, objetivos e hipótesis de un modo encadenado, entendiendo que lo desconocido y lo conocido ocupan lugares oscilantes y variables.

Asimismo, y, atendiendo a la necesidad de situar aquello que se produce, me enfocaré también en los procesos de visualización, recuperando algunos aspectos operativoinstrumentales que me sirvieron de soporte $\mathrm{y}$ dieron estructura $\mathrm{y}$ forma a esta investigación, porque toda óptica necesita también de boroscopios, lupas y catalejos para guardar una perspectiva. He aprendido de las epistemologías feministas que ninguna posición está exenta de examen crítico, de deconstrucción, de localización y de interpretación, y esta no es una excepción a esa propuesta. Desmantelar y re-ensamblar los andamiajes de la narrativa que aquí se propone, es un modo de someter a vigilancia los insumos sobre los que se producen los relatos de la adultez.

\section{Se hizo hasta dónde se pudo}

Suele suceder, en el espacio en el que trabajo, que se piensan alternativas de acompañamiento a niñxs y jóvenes que fracasan, no solo por un error en nuestras visualizaciones y propuestas, sino porque casi nunca están da das las condiciones para que ciertas trayectorias de la niñez transiten por experiencias de éxito. En esos momentos de frustración y enojo, usualmente pasa que algún/a compañerx se acerca, y a modo de consuelo enuncia: no te sientas mal, se hizo hasta donde se pudo. La idea de que se hace hasta donde se puede permea a la mayoría de los espacios que acompañan y asisten a niñxs y jóvenes, y opera como explicación, justificativo y condición para pensar los vínculos intergeneracionales.

Muchxs de nosotrxs hemos cuestionado las condiciones de estructuración y configuración de las instituciones dirigidas a niñxs y jóvenes, hemos analizado las relaciones de correspondencia entre cuerpos legales y procedimentales y propuestas de intervención, y/o hemos puesto a discusión los lugares que ocupa esta población en nuestro trabajo. Las grietas son infinitas. Enunciarlas y discutirlas me ha permitido saber, también, que son posibles mejores gestiones, pero ellas no resolverán el problema de la desigualdad generacional.

En este marco, desde hace tiempo me interrogo respecto de aquellas condiciones objetivables presentes en nuestros procesos de trabajo que producen experiencias de la 
desigualdad para niñxs y jóvenes. Entendiendo, que eso que observamos como falencias, son -en realidad-, producciones necesarias y eficaces de estructuración de modelos que se sustentan en formas de jerarquización y distribución diferencial del poder. Así, a pesar de que los estudios sobre participación y protagonismo infantil me han permitido repensar las relaciones de poder y dominio sobre las que se construyen los vínculos generacionales, y que afectan de manera significativa a las relaciones entre adultxs y niñxs en nuestros procesos de trabajo, considero que existe una pregunta sobre el 'yo' adultx (Butler; 2015), que aún permanece inexplorada, y, por lo tanto, obstaculiza el análisis de estas relaciones.

El cuestionamiento de estatutos y ritos de pasaje o de fenómenos transicionales a partir de los cuales se establecen trayectorias adultas, así como de las formas hegemónicas de transitar con éxito esa experienc ia corporal-vital, no necesariamente ponen en discusión la utilización de privilegios y prerrogativas respecto de otrxs generacionalmente diferentes. Esta ficción de lo generacional se sustenta, entre otras cosas, en un movimiento doble que consiste, por un lado, en crear atributos que funcionan como estatutos propios o innatos de la condición etaria, y, por otro, a la vinculación por correspondenc ia exacta entre la noción de edad y la de generación, sujetando esta última a una relación única, lineal y predefinida entre posición identitaria, cronología y corporalidad.

Es pertinente aquí hacer una distinción: mientras que la edad da cuenta de una delimitación lineal, numérica, acumulativa y temporal de la existencia de un objeto, sujeto o proceso, la generación es una localización sociopolítica de pertenencia a un colectivo que utiliza como marcador la trayectoria, conformando así formas de experiencia vital situadas fundamentalmente en las relaciones temporo-espaciales y socio-culturales de los sujetos con el mundo. En nuestra cotidianidad, edad y generación, se nos aparecen como condiciones indisociables, naturalizando la asignación de características específicas -sociales, culturales, políticas, económicas, etc.-, a ciertas experiencias corporales-temporales. Esto es aplicable a todas las experiencias generacionales, no solo las de la niñez y juventud. En este sentido, la edad se ha utilizado de modo arbitrario para delimitar las competencias y capacidades de los sujetos, como si ello fuera parte de un devenir innato y progresivo de la condición humana (Duarte; 2019).

Asimismo, es necesario tener en cuenta que este proceso de sujeción que establece una relación directa entre la condición etaria y la adquisición o pérdida de capacidades opera 
en las múltiples formas de construcción simbólico-material del discurso, y tiene un impacto significativo en los dispositivos de disciplinamiento asociados sobre todo a la dimensión corporal-sexual de los sujetos. Aunque se desplieguen mayoritariamente por zonas de opacidad, estas delimitaciones también hacen a las formas de configuración de las trayectorias adultas (Korczak; 1924).

Aquellas experiencias que no logran establecer parámetros de integración y/o funcionalidad de acuerdo con estos mandatos, frecuentemente ocupan lugares conflictivos, o se convierten en trayectorias problemáticas, que requieren acompañamiento y asistencia específica para guardar formas de sociabilidad y de construcción de vínculo admisibles. En cualquier caso, queda en claro que no es posible desprenderse de la condición generacional as ignada o renunciar a ella sin tener costos significativos.

Los mecanismos de disciplinamiento, que modelan las propias experiencias generacionales de acuerdo con un orden adultocéntrico dominante, no solo acontecen a partir de ficciones de legitimidad asociadas a trayectorias exitosas, sino que también se soportan de una serie de reglas y premisas, sutiles e invisibles, que permean nuestro universal simbólic o y material. Es decir, todo eso que es asumido como innato en el orden de las cronologías y corporalidades. En este escenario, se vuelve difícil dar cuenta de qué es lo que constituye, conforma, organiza y evidencia nuestras posiciones adultas de mundo, sin reproducir estereotipos y narrativas hegemónicas y acríticas. Por el contrario, la ausencia de este interrogante, contribuye en la reproducción y sostenimiento de formas desiguales de vincularnos generacionalmente.

En una asociación libre pero intencionada, es posible articular estos postulados con lo mencionado por Boaventura de Sousa Santos respecto de que:

La pérdida de los sustantivos críticos, combinada con la relación fantasmal entre la teoría crítica eurocéntrica y las luchas transformadoras en la región, no sólo recomiendan tomar alguna distancia en relación al pensamiento crítico pensado anteriormente dentro y fuera del Continente; mucho más que eso, exigen pensar lo impensado, o sea, asumir la sorpresa como acto constitutivo de la labor teórica. Y como las teorías de vanguardia son las que, por definición, no se dejan sorprender, pienso que, en el actual contexto de transformación social y política, no necesitamos de teorías de vanguardia sino de teorías de retaguardia (De Sousa Santos, 2011: 28). 
Si bien esa observación hace referencia a un análisis de otro tipo, es imprescindible recuperar aquello que ocupa el lugar de lo impensado en nuestras visualizaciones de mundo -en todas sus dimensiones-, analizando los modos de organización sociopolítica desde nuevas ópticas. En este caso, proponer modelos no jerarquizados del vínculo en base a la generación, constituye todavía un impensado como forma de relación social, al mismo tiempo en que pone en duda una condición estructurante de este sistema: la idea de que la desigualdad es un evento natural de toda experiencia generacional.

Hace algunos años recibí una llamada de una compañera pidiendo la asistenc ia de urgencia para interceder en la situación de unos niños autistas a quienes acompañaba desde hacía mucho, y que estaban solos destruyendo la sala de espera mientras su mamá buscaba en el Hospital a una hermana que se había extraviado. En la comunicación mi interlocutora afirmaba que: es terrible, si los ves no te podes dar cuenta cuál es el que dirige la batuta, porque se van relevando sin sentido en las acciones. Se tiran, corren y gritan, no responden a la palabra de ninguna de nosotras y si queremos agarrarlos se asustan y se golpean. Fue la inclusión en ese mundo lo que me permitió incidir en su dinámica -en un proceso de vinculación que nos había llevado muchís imo trabajo y tiempo compartido-, y no el uso de la autoridad o la presunc ión de obediencia. A pesar de intentar compartir esa observación con mi compañera, noté que el comportamiento de esos hermanos le aparecía, en ese momento, como doblemente conflictivo, ya que, por un lado, no había logrado determinar cuál de ellos mandaba ni el sentido de sus acciones, al mismo tiempo, en que ninguno se sometía al mandato de otrxs ni seguía criterios de obediencia. No pudimos encontrar, en ese momento, un código común de diálogo para hablar acerca de esa experiencia que se le representaba en el orden de lo incomprensible; puesto que, a pesar de compartir el mismo observable, no fue posible establecer significaciones compartidas.

En este caso, la perspectiva comunicacional para el análisis de los debates sobre visibilidad y opacidad ocupa un espacio central, puesto que se inmiscuye en lo visible, lo decible y lo compartido de los discursos y narrativas sobre las que se construyen las posiciones adultas que conocemos, así como también, en aquellas omisiones y clausuras que imposibilitan todo dialogo. Reponiendo en aquello que plantea Washington Uranga al mencionar que:

Cuando nos referimos aquí a la comunicación, lo hacemos entendiéndola como interacción social. Mediante la comunicación se construye una 
trama de sentidos que involucra a todos los actores, suj etos individuales y colectivos, en un proceso de construcción también colectivo que va generando claves de lectura comunes, sentidos que configuran modos de entender y de entenderse, modos interpretativos en el marco de una sociedad y de una cultura. (Uranga, 2012:7)

En la misma línea, si lo devolvemos a la forma de emergente concreto, más allá de lo que implica en el orden de la configuración de discursos y prácticas, este es uno de los tantos ejemplos para dar cuenta que la dependencia suele ser considerada como un elemento del orden natural de la existencia humana, más que como una consecuencia de cierto tipo de relaciones, ubicando en la esfera de lo natural una forma de producción social que construye una vinculación inalienable entre estrategias de protección y regulación de las libertades (Colangelo; 2012). Para que la protección sea efectiva deben ocurrir, al menos, dos movimientos: 1) que esos cuerpos otrxs intercambien obediencia por cuidado -es decir, que actúen en vinculación con las capacidades y condiciones que les fueron asignadas-; y, 2) que no se ponga en duda la necesariedad de la presenc ia y autoridad adulta -respecto de lxs niñxs que transitan sin presencia adulta, no importa cuántos sean ni su forma organizativa, nos preguntamos: ¿Dónde están sus padres? Y, ¿Por qué están solxs?

En este punto, se vuelve ineludible realizar esta aclaración: el reconocimiento de una condición o necesidad particular no implica, per se, una forma de dominio en el espacio de lo colectivo. Esta distinción es re levante, puesto que usualmente el requerimiento de asistenc ia y/o acompañamiento para algunas activida des vita les es visualizado como un elemento legitimador de desigualdad. Es decir que, pareciera que la realización de tareas de cuidado y crianza, en sus distintas formas, resultan habilitantes para la toma de decisiones $\mathrm{y} / \mathrm{o}$ el ejercicio discrecional de poder sobre otrxs.

Por este motivo, es importante volver a analizar la forma en que lxs adultxs establecemos o no sistemas de reciprocidad e intercambios con otrxs, qué es lo que les exigimos a cambio de ciertas acciones vitales $\mathrm{y}$, de qué modo, utilizamos nuestros privilegios para delimitar una posición de mundo en la que somos imprescindibles (Cussianovich; 2012). Debemos mantener siempre presente, que este es uno de los pocos sistemas de dominio en el que persiste abiertamente la idea fundante $\mathrm{y}$ discrecional de que para la resolución de una necesidad -y/o para su asistencia en tal resolución-, es imprescindible la imposición de un tipo de desigua ldad en el lazo.

La importancia de que la experiencia colectiva sea habitable para todos en una potencia equivalente está dada, entre otras cosas, por la posibilidad de establecer formas de 
reconoc imiento y reciprocidad no jerarquizadas. Cuando lo propio y lo ajeno se vuelven terreno de disputa es difícil situar la ocurrencia de lo diferente sin que ello suponga algún tipo de expulsión o delimitación. Participamos a otrxs en la toma de decisiones solo para algunas cuestiones, generalmente vinculadas a tareas secundarias, o en las que no se pone en juego ninguna condición estructurante. A veces, por el contrario, utilizamos a niñxs y jóvenes de testimoniantes, justificando en la encarnación de su voluntad absoluta, toda decisión que tomamos (González; 2016).

Es impresc indible mencionar que, en las organizaciones e instituciones que trabajan con niñxs y jóvenes, la posición adulta se construye en simultaneidad, en tanto somos material, corporal y posicionalmente adultxs, y en cuanto, usualmente, se nos demanda encarnar una posición asociada a las adulteces hegemónicas que repone -y sitúa en nosotrxs-, las condiciones de saber, experticia y poder de decisión en relación a ese vínculo intergeneracional (Fernández, 2015; Fernández, 2018). Sin embargo, es la noción de experticia o quehacer profesional/calificado la que usualmente prima, invisibilizando su interjuego con nuestras propias consideraciones adultas $\mathrm{y} / \mathrm{u}$ homologándolas a otras formas interseccionales por las que somos afectadxs.

En gran parte de ellas, los procesos de despolitización, tecnificación y procedimentalización del vínculo y agencia adulta son utilizados como paliativo para negar, invisibilizar, neutralizar o normalizar todas aquellas conflictividades que devienen del ejercicio de la desigualdad (Chaves; 2014, Llobet; 2010). Es decir, no poder hacer lugar al deseo y temporalidad de esos otrxs en nuestros procesos de trabajo suele encontrar un justificativo en las condiciones mismas de la tarea, en la falta de herramientas, en lo que puede ser contenido en el marco de la institucionalidad, y, cuando no, en el cuestionamiento de esa posición otra como elemento del orden de lo ideal o irracional.

Sobre esta discusión, Julián Fernández advierte:

El despliegue y rutinización de prácticas profesionales en base a una mirada instituida y cristalizada respecto de NNyA, además de condicionar la exploración de otros posibles respecto a los que-haceres y como-haceres en la intervención con esta población, coarta modos de interacción originales y/o novedosos en el marco de las agencias estatales. Por ello, se hace necesario concebir el espíritu de la legislación en materia de promoción y protección de los derechos como una brújula que orienta formas de encuentro profesional con NNyA, problematizando la intención adulta de domesticar a las infancias y 
adolescencias y fundando figuras de autoridad más empáticas y respetuosas con las nuevas generaciones. (Fernández, 2020:408)

Cotidianamente debatimos con otrxs operadorxs del SPPDNNA -institucionales e interinstitucionales-, respecto de las formas correctas de intervenir en situaciones que emergen como conflictivas para niñxs y jóvenes, sobre pautas de cuidado y crianza, sobre ejercicio de derechos y/o sobre habilitaciones o restricciones de tránsitos. Sin embargo, en escasas oportunidades nos interrogamos sobre por qué, cuándo y en qué casos es necesario o pertinente que despleguemos nuestra opinión adulta -no necesariamente calificada-, respecto a situaciones que atañen a niñxs y jóvenes. ¿Es nuestro acompañamiento siempre necesario? ¿Negociaremos para ello condiciones del vínculo intergeneracional? ¿Permitiremos que niñxs y jóvenes nos señalen, tal como lo hacemos con ellxs, aspectos referidos con nuestras formas de comprender y habitar el mundo?

Entonces, en esa relación compleja que mantenemos con nuestras temporalidades, podríamos afirmar que existen en el orden de lo generacional dos elementos identitarios que conceden posición: Saber ser-es decir, saber situarse en una posición de mundo de acuerdo con la relación edad-generación-, y saber transicionar -es decir, saber devenir una posición otra de acuerdo con la relación tiempo-corpora lidad-. Ampliamente hemos analizado el modo en que mandato y moratoria se interjuegan en la singularidad de los tránsitos de niñxs y jóvenes, dejándonos exentos respecto de la pregunta acerca de cómo nuestras trayectorias adultas también se conforman sobre posiciones generacionales, y, de qué manera, esto incide en nuestras formas de relación social: sobre todo cuando ellas involucran el trabajo con niñxs y jóvenes, en procesos de reconocimiento y ejercicio de derechos.

Estas trayectorias producen, son producidas y reproducen, narrativas y discursos de opacidad respecto de los modos en que nos situamos sociopolíticamente. Por tanto, a pesar de establecerse en posiciones hegemónicas, lo adulto no pareciera ser demasiado localizable en su dimensión colectiva si no es a partir de otras formas interseccionales entre las que podemos destacar las marcaciones de género, clase, etnia y territorio-, y/o de ciertas posiciones, funciones, roles y/o nominaciones de habilitación o censura. Al parecer, ser adultxs en el vínculo con otrxs, implica asumir ciertas condiciones y mandatos que permean nuestras trayectorias, percepciones y posiciones, y, que, 
explícita e implícitamente, inciden en los modos de construcción del lazo intergeneracional.

Diría que sos grande, pero a veces lo dudo, porque no te veo mandando tanto, pero a la vez me parece que debes ser más importante de lo que yo creo porque cuando llegas todxs te saludan y ya vi que otros nenes te conocen, me dijo un niño que había llegado por primera vez a la Sala en la que trabajo, y que en nuestro intercambio inicial intentaba dilucidar si yo era una adulta-adulta, una persona grande pero no adulta, o solamente una persona grande y común. Permeaba en su representación la sospecha de que la adultez correspondía, antes bien, a un tipo de actitud, que a una condición material, y amparaba su argumento en que nuestras corporalidades no eran marcadores obvios en esa Sala, puesto que todos los cuerpos enfermos se escapan, de una o varias formas, de las estructuras corporales que se supone les corresponden como condición de normalidad. Su capacidad para reconfigurar la corporalidad que, cotidianamente creemos que nos delimita y evidencia en un sentido único, me permitió pensar en las múltiples materialidades y simultane idades sobre las que se organiza lo adulto.

En este marco, si bien la indagación hace foco en una experiencia específica: la de aquellxs adultxs que desarrollamos procesos de trabajo en vinculación con niñxs y/o jóvenes, considero que este es solo uno de los tantos observables a partir de los cuales pueden ser repensadas las propias posiciones y los vínculos intergeneracionales de los que participamos.

\section{Mucho ruido}

Los interrogantes que modelaron el proceso de investigación fueron múltiples y diversos. Algunos de ellos, han sido excluidos en el tie mpo por su falta de pertinencia o su generalidad; otros, fueron reagrupa dos o reconvertidos mientras que, un conjunto de ellos, emergieron en el devenir del análisis. La persistencia de estas preguntas ha constituido el ruido que acompaña esta escritura, y que es un equivalente a ese sonido que nos invade en la reiteración de aquello que no sabemos explicar, pero que tampoco podemos ignorar. Algunas de esas preguntas operaron como puntapié, ya que por su generalidad, hacían referencia a cuestionamientos sobre lo adulto en términos amplios, entre las que se encontraron: 
- ¿Nos preguntamos sobre nuestras adulteces? ¿En qué contextos y sobre que prácticas lo hacemos? ¿Cómo inciden nuestras trayectorias y posiciones identitarias en estos interrogantes?

- ¿Qué percepciones tenemos respecto de nuestra propia experiencia adulta? ¿De qué maneras ellas se ponen en juego en nuestra cotidianidad? ¿Qué elementos configuran el espacio común de las adulteces?

- ¿Nos percibimos en posición de privilegio/desigualdad respecto de otrxs que son generacionalmente diferentes a nosotrxs? Y, en ese caso, ¿De qué manera hacemos uso de nuestros privilegios adultos en los espacios por los que transita mos?

- ¿Qué habilitaciones y/o clausuras de la experiencia adulta se establecen utilizando como argumento la apelac ión a las perspectivas de derechos?

- ¿Cuáles son los observables a partir de los cuales se evidencia la desigualdad generacional en nuestros espacios labora les?

- ¿Cómo producimos -y son producidxs- nuestros cuerpos en la experiencia adulta?

Otras, por el contrario, se centraron en los cuestionamientos y propuestas que han realizado una serie de perspectivas, movimientos, organizaciones y experiencias, en pos de visibilizar la pregnancia de lo generacional como marcador interseccional sobre el que también se estructuran nuestras trayectorias. Entre esas preguntas estuvieron:

- ¿Qué discusiones plantean quienes, en los estudios sobre otras generaciones, se preguntan acerca de la propia trayectoria? ¿Qué lugar ocupa el debate sobre los lugares de poder en estos estudios?

- Quienes promueven el reconocimiento de derechos, formas más horizontales del vínculo y/o espacios de participación/protagonismo infantil, ¿se preguntan acerca de los movimientos de desmantelamiento de privilegios que debemos hacer lxs adultxs en ese proceso? ¿Qué es lo que han propuesto en vinculación con ello?

- ¿Cómo se construyen las narrativas sobre lo adulto en los espacios que trabajan con niñxs y jóvenes desde perspectivas que apuestan al reconocimiento y respeto? 
Finalmente, existieron una serie de interrogantes surgidos de la urgencia por repensar las formas del vínculo intergeneracional que conocemos, y que fueron movilizados por estas preguntas:

- ¿Cómo podemos deconstruir las posiciones adultas dominantes y generar vínculos no jerarquizados?, ¿Qué dis putas deberemos darnos para ello?

- ¿Qué estrategias poseemos, en nuestros espacios de trabajo, para disputar narrativas y prácticas que visibilicen la desigualdad generacional e instalen interrogantes sobre nuestras formas de vincularnos?

- ¿Cuáles son las prácticas que cuestionan estos mandatos y/o los estatutos de las adulteces hegemónicas? ¿Cómo se han organizado y quiénes son lxs que las agencian?

Con estos interrogantes pasó lo mismo que con todo lo no resuelto, es decir, hubo momentos donde su presencia fue intensa, y, por ello, algunos apartados de esta producción reponen fuertemente en su importancia, mientras que hubo otros espacios donde fueron puestos en duda seriamente hasta casi desaparecer. Advirtiendo este movimiento, estas preguntas fueron enlazadas a algunos objetivos, para poder situar el anális is y a varias hipótesis para hacer explicitas las posiciones de partida.

\section{Objetivos}

En este estudio me he propuesto como objetivo ge neral: Indagar y analizar, en clave generacional, los modos en que lxs adultxs que realizan actividades contempladas en el Sistema de Promoción y Protección de Derechos ponen a jugar sus posiciones adultas en el vínculo con niñxs y jóvenes en sus procesos de trabajo, estableciendo como unidad temporal el período Enero-Junio 2021.

En este marco, los objetivos específicos que organizaron el proceso de exploración estuvieron orientados a:

○ Conocer las percepciones de lxs adultxs que forman parte del SPPDNNA respecto de su propias trayectorias de la adultez en vinculación al uso de privilegios y/o la vivencia de experiencias de la desigualdad; 
- Indagar las fuentes de legitimación sobre las que estxs adultxs sitúan su posición generacional en los espacios sociales por los que transitan;

- Identificar las disposiciones, valoraciones y sentidos que motivan a lxs adultxs a interactuar con niñxs y jóvenes en el espacio laboral;

- Reconstruir las narrativas en torno a la adultez que se recrean en el vínculo intergeneracional;

- Identificar los modos en que las posiciones adultas inciden en la comunicación con niñxs y jóvenes, y en socialización de discursos que refuerzan y/o transforman posiciones de desigualdad;

- Advertir prácticas de subversión de los mandatos generacionales que despliegan algunxs agentes que forman parte del SPPDNNA.

Parto de considerar que la indagación sobre cómo lo adulto es percibido por lxs adultxs que trabajan con niñxs y jóvenes posibilita conocer qué elementos permanecen en zonas de opacidad, cuáles son visibles y cómo es la forma en la que emergen, en qué textos y contextos ello es viable, qué apreciaciones aparecen como enunciables, cuáles de estas se construyen como comunicables, qué aspectos operan en simultaneidad y multiplicidad, cuáles de ellos han sido cancelados y por qué -y cuáles simplemente no han sido explorados-, qué intencionalidades se entrelazan, cómo se conjugan interseccionalmente, entre otras cuestiones.

Asumo, asimismo, que para que la pregunta sobre la generación sea posible -y no se convierta en una interrogación binomizante o de cancelación-, es necesario encontrar las codificaciones que la alojan y le permiten existencia y expansión en las trayectorias de los sujetos que las crean y recrean.

\section{Algunas sospechas}

Está claro que no es lo mismo tener una idea que desarrollar una explicación, aunque las ideas puedan crear narrativas y argumentaciones legitimables. En todo caso, ambas se apoyan en recursos, registros y conocimientos, que contienen mayor o menor rigurosidad, y se sustentan en observables y anális is que pueden o no situarse. Hago esta distinción, porque las hipótesis que dieron origen a este trabajo, eran antes bien ideas y percepciones, que explicaciones, $\mathrm{y}$, por tanto, en el mismo movimiento por el que 
algunas sobrevivieron al análisis riguroso y a la construcción de conocimientos situados, otras debieron ser desechadas por imprec isas o infundadas.

Una hipótesis gene ral que operó como directriz en el proceso de conocimiento fue construida sobre la idea de que la mayoría de lxs adultxs no se perciben a sí mismos en condición de privilegio respecto de otras generaciones $\mathrm{y} / \mathrm{o}$ entienden que establecer pautas de jerarquización, exclusión y disciplinamiento son aspectos inherentes e innatos de toda experiencia generacional, y que, por tanto, si bien piensan formas de vinculación más respetuosas, no necesariamente ponen en cuestión los sistemas de desigualdad sobre los que se sostienen.

En la misma línea, otra hipótes is que se hizo presente estuvo asocia da a la creencia de que un elemento legitimador de los sistemas adultocéntricos se vincula a la correspondencia exacta entre cronología, corporalidad y posición generacional. Esta relación, que se nos presenta como única e incuestionable, asigna competencias y capacidades que no solo delimitan modelos de integración social y crean mandatos sino que, fundamentalmente, invisibilizan la pregunta respecto de cómo se construyen las experie ncias generaciona les.

Como todas las posiciones de privilegio, las adulteces gozan de la invisibilidad analítica de quienes construyen relatos y discursos; y, por tanto, lo generacional no suele aparecer como una marcación interseccional, quedando implícitamente incluida en otras posiciones de relevancia como las de género, clase, etnia, o territorio. De este modo, otra hipótes is, que también ha sido una intenc ión de esta producción, es la que sostiene que hacer visibles las circunstancias sobre las que se producen sistemas de dominio incluyendo de manera directa a lxs actores que ocupan posiciones diferenciales-, posibilita romper con la hegemonía representacional que naturaliza la ocurrencia de experiencias de la desigualdad asociadas a lo generacional, como condición necesaria para la vida social.

Finalmente, también he sostenido como hipótesis que existen una serie de perspectivas y prácticas profanas (Agamben, 2005), que se organizan proponiendo rupturas a los modelos generacionales que conocemos, y que se embarcan en procesos de deconstrucción y disolución para pensar en lo común-compartido, pero que ellas aún no han obtenido valor en el espacio colectivo. 


\section{Sensibilidad compartida: trayectorias, percepciones y posiciones}

Reconoc iendo la importanc ia de establecer, desde esta óptica de visualización, una serie de observables y esquemas de aproximación al análisis, me ha interesado, antes bien, conocer las trayectorias, percepciones y posiciones que sitúan a los sujetos en el espacio, suspendiendo brevemente las valoraciones de correspondencia entre norma y realidad, o entre teoría y práctica, ya que, para que las posiciones de privilegio dejen de ser intocables, deben dejar antes, de ser invisibles e irreconocibles. Asumo que este estado de situación, supone una dificultad para prec isar los elementos que componen el problema de investigación en un sentido estricto o clásico, pero también arriesgo, entendiendo que esta alternativa posibilita una búsque da que contempla una diversidad de agencias y representaciones respecto de aquello que sitúa a lxs adultxs en sus posiciones generacionales, otorgando dinamismo y flexibilidad al proceso de conocimiento.

Exploro sobre la sensibilidad común en un territorio que es tan dominante como invisible, y renuevo la pregunta: ¿Qué partículas de nuestra adultez nos hacen sentirnos identificados con otrxs que experimentan una relación similar entre posicióncorporalidad y tiempo? Ana Lanfranconi se hace una pregunta equivalente en la observación de la relación espacio-tiempo que propone Walter Benjamin, y por eso escribe:

Nuestra apuesta por los modos de sentir (se), de percibir (se) apunta a las maneras de establecer relaciones con el entorno externo e interno que configura unos mundos determinados. Los sistemas de recepción y respuesta - corporal y no corporal - ante lo que nos rodea y constituye exceden los límites del sujeto individual, no se corresponden con los límites del cuerpo que detentamos. La sensibilidad común es ya un espacio de exceso y composición: no sólo lo que ya está ahí, sino sobre lo que se puede intervenir. Lo dado y lo por construir, lugar de encuentro y lo que resulta de encontrarnos, composición variable de lo heredado y lo nuevo. Otros sistemas componen con elementos similares, no obstante este lugar de lo común de la sensibilidad creemos que pone en contacto más puntos privilegiados para abordar estas cuitas sobre la compacidad del orden del aparecer. Cómo se (nos) presenta, cómo aparece: lo naturalizado, luego natural, lo siempre ahí así; lo normalizado, luego lo normal. Para parecer perenne, anuncia un orden eterno. Orden frágil que se sustenta sobre nuestros hábitos (perceptivos), y un entramado de sistemas de respuesta: automatismos, reacciones motrices, reflejos, clichés, estereotipos, refuerzos y repeticiones. Formas fijas de reproducción social, de la vida social: lo que hay como premisa del y que así sea, porque así debe ser. (Lanfranconi; 2017:29) 
De este modo, las formas de representación vital, tanto en lo individual como e n lo colectivo, están moduladas por una multiplicidad de saberes y afectaciones que funcionan como organizadores perceptivos, otorgando sentidos particulares a nuestros agenciamientos. Considerando que los discursos sobre la adultez son difícilmente localizables de manera directa, gozando del privilegio de la invisibilidad dominante, usualmente, sus formas de emergencia se encuentran relacionadas, tanto al vínculo intergeneracional, como a su asociación con otras condiciones y/o posiciones sociopolíticas.

Atendiendo a esto, considero que trabajar sobre la constelación conformada por la relación entre trayectorias, percepciones y posiciones, permite poner en juego un conjunto de observables que dan cuenta del modo dinámico y múltiple desde el cual construimos nuestros modos de ser en el mundo. Estas experiencias, saberes, sentidos, sentires, afectaciones y localizaciones, no necesariamente remiten a procesos tradicionales de construcción de discursos: y, por ello, resulta impresc indible recuperar aquellas formas de construcción de narrativas que acontecen en los márgenes de la comunicación y de los cuerpos mismos. Asimismo, la necesidad de comprender y complejizar los alcances e implicancias de este constructo, nos conduce a recuperar la advertencia que Fernand Deligny señala al enunciar:

Es que la constelación de cosas no tiene nada que ver con lo que nosotros condensamos en el momento, siendo ese momento un cierto momento en nuestro tiempo de ser consciente de ser, y que no hace más que pasar, siendo pasar un verbo que evoca una travesía aunque se trate de elaborar en lo pasado, aunque más no fuera para sentirnos presentes. (Deligny, 1967:58)

Por este motivo, he de esclarecer que, al hablar de trayectorias me refiero a los múltiples recorridos que se conforman en la vinculación entre temporalidad-movimiento y experiencia, y que remiten a una diversidad de saberes construidos a partir de los desplazamientos agenciados por los sujetos en contextos delimitables. Es decir, ellas ponen en juego disposiciones y prácticas para la construcción de saberes sostenidos en la experiencia, afectados por condiciones de contexto, vivencias situacionales y eventos contingenc iales.

Es imprescindible considerar que las trayectorias se despliegan en vinculación a marcos referenciales que significan esos desplazamientos en asociación a ciertas condiciones de producción, reproducción y/o transformación. Así, el anális is de una trayectoria, se 
encuentra necesariamente vinculado al punto de vista de quien se desplaza, tanto como de quien observa ese desplazamiento. Del mismo modo, las trayectorias de los sujetos no acontecen aisladamente, sino que dibujan trazos e interactúan con otros, conformando redes o tramas de experiencias y saberes que organizan sensibilidades colectivas.

Las formas de interpretación, organización y modulación de esos sentidos, sentires y afectaciones dan cuenta de los marcos de percepción de los sujetos agenciantes, conformando sistemas de codificación y decodificación de aquello que acontece en la experiencia vital de los sujetos. Asimismo, estos sistemas se encuentran influenciados por nuestras condiciones materiales y simbólicas de existencia, situadas en territorios socio-político definibles, asentados en experiencias corporales-temporales específicas. Cabe mencionar que aquello que aparece como incomprensible, irracional, o imprevisible, también irrumpe de manera significativa en nuestros marcos interpretativos (Foucault, 1966; Deleuze, 1985; García Canal, 1997). Esto, no necesariamente implica que el choque con lo emergente y contingencial suponga una irrupción de la representación previa, aunque sí es una condición de posibilidad para la producción de desvíos en las trayectorias. Al mismo tiempo, estos desvíos no se producen en un sentido prefijado, originando traumas, clausuras, habilitaciones, posibilidades y/o potencias de lo impensado.

Estos modos de situarnos en el espacio, en una relación singular entre interior-exterior o individual-colectivo, en disposiciones y desplazamientos corporales-temporales específicos, construidos en vinculación a sistemas perceptivos particulares, construyen posiciones: las cuales, a su vez, se estructuran en base a sistemas de coordenadas que articulan intersecciones, provocando que la ubicación espacio-temporal sea igualmente individual y colectiva. Es importante agregar que las posiciones se sostienen en relaciones de detención y movimiento, y, que, incluso, aquellas que se plantean mantener su ubicación en el sistema deben someterse a desplazamientos, puesto que no existe relación de determinación entre sistema y sujeto. Por ese motivo, en esta indagación se enfatiza en los procesos de afectación sociopolíticamente situados.

De esta manera, las posiciones dan cuenta de las localizaciones posibles de los cuerpos, en relaciones temporales-espaciales singulares, construidas en asociación a un sistema de coordenadas. No es posible pensar en formas posicionales considerando vectores únicos, tal como ficticiamente acontece en la relación edad-generación. Es necesario admitir que aquellos procesos sobre los que se construyen nuestras posiciones adultas, 
no son la resultante exclusiva de un fenómeno cronológico, sino que dan cuenta de disposiciones y desplazamientos asociados a sistemas de codificación y decodificación, construidos en torno a experiencias corporales-vitales situa das socio-contextualmente.

\section{Boroscopios, Lupas y Catalejos}

Procurando dar operatividad a este proceso de conocimiento y evidenciando la necesidad de proponer abordajes anc lados en objetividades fuertes (Harding, 1996), esta investigación se ha valido de métodos y técnicas cualitativas. Asimismo, he priorizado la utilización de fuentes primarias puesto que ello me ha permitido explorar, exhaustivamente y con detenimiento, los modos de organización de la sensibilidades comunes, las construcciones singulares y sociales que permean el pensamiento generacional, la forma en que se expresan los mandatos y creencias de la adultez, y las tramas que componen las experiencias particulares de quienes resisten y cuestionan estos modos tradicionales de habitar el mundo. La utilización de fuentes secundarias documentales, estadísticas, periodísticas y de investigación- se encuentra contenida en la producción de la dimensión teórica de esta Tesis.

Fueron incluidas para el estudio aquellas personas que son $\mathrm{y} / \mathrm{o}$ se perciben como adultas, y cuyas prácticas -asistenciales, docentes, investigativas, o de activismo- se dirigen al trabajo con otrxs que son y/o se perciben niñxs o jóvenes -tanto para la promoción y protección de derechos como para la participación-, en cualquiera de sus dimensiones y ámbitos de gestión. Respecto de ello, un organizador interesante por su carácter general y su composición múltiple, diversa y flexible, fue el Sistema de Promoción y Protección de Derechos de Niños, Niñas y Adolescentes, entendiendo que el mismo nuclea a sujetos, organismos, entidades, colectivos sociales y servicios que trabajan sobre la formulación, orientación, ejecución, supervisión, y/o contralor de institucionalidades, Planes, Programas y acciones, que. en cualquiera de los ámbitos de gestión, en el espacio públic o o privado, se orientan a promover, proteger, resguardar y/o restituir derechos, asistir a niñxs y jóvenes, y/o promover y garantizar formas de participación, en vinculación con la Política Estatal y las normativas vigentes en la materia (Ley $\mathrm{N}^{\circ}: 13.298$ ).

Esta delimitación no suspende interrogantes y contradicciones, ya que, por un lado se trata de una nominación de composición socio-jurídica que no siempre es percibida como un espacio de pertenencia para lxs agentes del campo; es decir, para muchxs 
adultxs, trabajar para el 'Sistema' o para 'Niñez', se reduce específicamente a las dependencias y/o programas contenidos por Senaf, el Organismo Provincial de Niñez o las Direcciones de Niñez municipales, mientras que otras actividades -también dirigidas a niñxs y jóvenes-, son englobadas dentro de sub-campos como salud, responsabilidad penal juvenil o educación. Como contracara de esto, otrxs actores y actrices entienden al Sistema como un territorio de disputa de las Políticas Públicas dirigidas a la niñez, y/o como una red que solo puede ser comprendida en el entramado de relaciones institucionales e interinstitucionales por los que niñxs y jóvenes transitan. En lo personal adscribo, a esta segunda acepción.

A pesar de la conflictividad que permea y modela estas trayectorias, el Sistema de Promoción y Protección ofrece una potencia exploratoria difícil de hallar en otra forma colectiva que vincule a niñxs y adultxs, ya que reúne experiencias diferenciables, diversas, desiguales y disidentes. Es decir, se trata de un escenario que congrega a sujetos individuales y colectivos con trayectorias y perspectivas diversas, lo que permite conocer una multiplicidad de percepciones, consideraciones e inquietudes, asociadas a experiencias y territorialidades variables, en el interjuego con otros marcadores interseccionales, y en vinculación a alguna de las dimensiones de la Política Pública.

Considerando todos estos aspectos, el ejercicio que me he propuesto requiere de un movimiento doble: por un lado, resulta necesario reterritoria lizar aquello que conforma y organiza las experiencias adultas, hac iendo visible lo que aparece como identitario e inmanente en los modos de construir posición, $\mathrm{y}$, por el otro, es imprescindible pensar en las tácticas y estrategias de disolución y/o resistencia que despliegan ciertos agentes, cuando esos modos de localización y fijación reproducen estándares de valoración y jerarquización, a la vez que perpetúan experienc ias de la desigualdad.

He divisado una singular necesidad en reterritorializar, puesto que si los análisis generacionales fueran distribuidos a modo de mapas: con territorios, poblaciones, recursos, conexiones, vínculos, pasajes, alianzas y restricciones, es posible que el vasto y diverso universo de lo adulto formara parte de eso que los cartógrafos trazaban como terra incógnita, y que servía, no solo para describir las zonas inexploradas del globo, sino también para crear ficciones y narrativas respecto de seres fantásticos, malditos y divinos, y dar explicaciones de movimientos de afectación de lo desconocido sobre lo conocido. Así, a pesar que somos adultxs, y de que nuestra existencia es innegable, los estudios sobre la adultez son escasos, y, frecuentemente, se dirigen a esos procesos de afectación y poder respecto de otrxs generacionalmente diferentes. 
De esta manera, aunque mi interés inicial se orientaba hacia el conocimiento de perspectivas y prácticas singulares de adultxs que ponen en cuestión sus privilegios en los vínculos intergeneracionales, noté que esta investigación corría el riesgo de convertirse en una búsqueda de seres míticos y fantásticos, si no era capaz de geolocalizar, antes, a esa porción de terra incógnita -aunque solo fuera provisoria y parcialmente- en alguno de estos mapas de territorialización, pertenencia poblacional, sistemas de vinculación, recursos, alianzas, restricciones, y relaciones de poder y dominación. Esto, lejos de resolver el problema, agregó un interrogante imprescindible para que esta indagación guardara rigurosidad: ¿Qué constituye, entonces, el territorio común de las adulteces?

Para aproximarme a esa incógnita, diseñé una herramienta de recolección de datos que permitiera incorporar a una diversidad de actores y actrices, pero también me posibilitara recuperar las experiencias de la adultez de un modo situado. La confección de una guía que tomara como base cuestionarios digitales de divulgación rápida se impuso como una condición de contexto -en plena pandemia-, pero rápidamente se convirtió en la alternativa más adecuada para el tipo de conocimiento al que esperaba acceder. De este modo, los cuestionarios digitales -en este caso utilicé Google Formsno solo posibilitaban una divulgación rápida y masiva, sino que además permitían mantener el anonimato en las respuestas. Este es un aspecto relevante, ya que favoreció la obtención de respuestas honestas, sin que lxs encuestadxs se percibieran observadxs o valoradxs de acuerdo con el tipo de participación ${ }^{2}$.

Si bien el muestreo se hizo utilizando la técnica bola de nieve, su difusión se restringió a espacios y actores delimitados de acuerdo con la unidad de referencia empírica. Como no se trataba de un muestreo de tipo probabilístico sino de construcción de opinión, se valoró específicamente que el instrumento pudiera llegar a interlocutores variados, con perspectivas diversas $\mathrm{y}$, con ese objetivo, se incluyeron algunos descriptores que permitieran dar cuenta de la población alcanzada por la encuesta. La resolución total del cuestionario fue estimada en 15' aproximadamente, y los encuestadxs tenían la alternativa de contestarlo total o parcialmente de acuerdo con sus intereses. Era posible acceder al mismo desde dispositivos portátiles con escaso uso de datos y/o requerimiento de conectividad.

\footnotetext{
${ }^{2}$ En el territorio de los estudios generacionales, en nuestro país, la corrección respecto de los discursos y nominaciones ha ocupado un lugar significativo en las discusiones sobre cambio paradigmático, y por tanto, la corrección narrativa suele permear las formas comunicativas de lxs trabajadores del campo.
} 
Una vez realizado el proceso de geo-localización perceptivo-posicional de las adulteces, me propuse adentrarme en la segunda parte del movimiento analítico enunciado, indagando en profundidad acerca de las posiciones profanas (Agamben, 2005), puesto que considero que son esas experiencias las que hablan sobre las fugas (Deleuze y Guattari, 2004) posibles al pensamiento generacional que conocemos. En este caso, la atención estuvo puesta en los discursos y prácticas emergentes y/o de resistencia, que se han edificado en los intersticios de quienes se sienten interpeladxs al asumir formas hegemónicas en sus posiciones de privilegio, que posibilitan deconstruir las fijaciones generacionales de las que participamos y que proponen devenires que no supongan exclusión y desigualdad. Es de destacar que, estxs entrevistadxs, no se perciben a sí mismos como referentes y/o personas destacadas del campo, y ninguno de ellxs ocupa lugares de conducción o liderazgo formal en sus espacios de pertenencia, a pesar de ser reconocidos por colegas y compañerxs por el tipo de trabajo que desarrollan. La mayoría de ellxs, incluso, definen a sus propias intervenciones como incompletas, llenas de preguntas y/o minimizan una serie de interrogantes dirigidos a transformar algunas experiencias de la desigualdad.

Reponiendo en ese propósito, realicé entrevistas en profundidad semi-estructuradas. La selección de interlocutores fue dirigida, aunque la conformación de la muestra resultó ser variada, y estuvo compuesta por actores y actrices de instituciones diversas, que realizan tareas diferenciales y no siempre conectadas entre sí, y que poseen ocupaciones disímiles, aunque todxs ellxs desarrollan tareas actividades vinculadas al SPPDNNA. Estas entrevistas fueron entendidas como experiencias singulares de diálogo situado e interesado, lo que supuso un modo particular de establecer vínculo, delimitado por condiciones específicas de ocurrencia y producción del discurso. Cabe destacar que la elaboración de líneas de interés y de preguntas flexibles favoreció el trabajo sobre los elementos contingentes y emergentes surgidos de los encuentros. Considerando que, la posibilidad de mantener una rigurosidad investigativa en este proceso, guardaba relación con la necesidad de reconocer el propio marco interpretativo (Guber, 1994).

Si bien las entrevistas fueron mayoritariamente individuales, el dialogo producido a partir de ellas, ha sido pensado y construido como una polifonía, entendiendo que es posible producir un encuentro imaginario entre estxs entrevistadxs que comparten interrogantes, sentires y pareceres, pero que se aproximan a ellos de formas muy diversas. Ese montaje literario (Benjamin, 2005) habla sobre el carácter interactivo, dinámico y múltiple que otorgan los procesos de investigación cualitativa, y que 
permiten articular diálogos y experiencias a -modo de collage- para pensar y analizar ciertos procesos sociales. Asimismo, este ejercicio repone en la importancia de tramar una red no solo a partir de lo que evidentemente se enlaza, sino también, incorporando aquello que aparece como hueco y/o potencia de todo encuentro (Deligny, 1967).

Si bien esta forma de composición aparece como una delimitación del orden de lo metodológico, no es posible escindir la intención política en su configuración (Willis, 1994), explicitando el interés por mostrar como estrategia para el decir, reponiendo en aquellas narrativas pequeñas y situadas, en las que el saber compartido se muestra en su mayor potencia. Construir un relato a partir de la composición de fragmentos, es también una apuesta por reconfigurar las narrativas colectivas partiendo del ejercicio de enlazar y poner en diálogo el sentido colectivo que subyace al discurso.

En ambas dimensiones de este ensayo analítico, los instrumentos fueron construidos y revisados con la colaboración de otrxs agentes del campo como estrategia de vigilancia a las valoraciones propias. En el mismo sentido, la indagación se organizó procesualmente, en tanto la primera de las dimensiones de trabajo fue la que delineó algunos tópicos de indagación incluidos en la segunda. En el caso de las entrevistas, la mayoría de lxs entrevistadxs propusieron formas de intercambio que excedieron el encuentro presencial, convirtiéndose en diálogos sostenidos. Este proceso de trabajo, además, incluyó operaciones instrumentales tales como la indagación de técnicas y modelos de muestreo y sistematización de datos, la realización de pruebas de testeo, la triangulación de información, la desgrabación y transcripción de entrevistas, entre otras acciones.

\section{Sum ario del Capítulo: escribir con intereses}

Si bien han sido presentados como elementos separados a lo largo del capítulo, esta relación entre problema, preguntas, objetivos, hipótes is y proceso metodológico, ha de ser pensada, más bien, en forma de madeja. Entendiendo que lo que se propone es un tipo de cuerda que compone una trama, construida sobre una forma específica de enlazar hilos, que no compone un todo acabado, sino la materia prima para crear ovillos y tejidos. El hilo central a partir del que se han entramado otras fibras, y que acompaña la estructura total del análisis, es el cuestionamiento a la idea de que la desigualdad es una condición necesaria e ineludible para ciertas experiencias generacionales. 
De este modo, en el desarrollo del problema, he intentado poner en evidencia que, aunque nos hemos aproximado a esa discusión a partir de los debates sobre perspectiva e institucionalidad, acceso y garantía de derechos para niñxs y jóvenes, y/o asignaciones presupuestarias y mejores gestiones, todas estas son expresiones y configuraciones necesarias para un siste ma que se organiza en torno a la jerarquización, diferenciación y exclusión de algunos sujetos.

Es por este motivo que la pregunta respecto de la posición dominante se vuelve impresc indible, ya que su invisibilidad analítica obstruye la posibilidad de cuestionar los sistemas adultocéntricos en su complejidad. Esta premisa ha sido unida a una hipótesis general, en cuanto considero que, la mayoría de lxs adultxs no se percibe a sí mismx en condición de privilegio, y/o entiende que el establecimiento de modos diferenciales y excluyentes de transitar la vida social es condición innata de ciertas experie ncias generaciona les.

Así, he enunciado, a modo de objetivo, mi interés por conocer y analizar las trayectorias, percepciones y posiciones de adultxs que trabajan con niñxs y jóvenes, investigando acerca de las fuentes de legitimación sobre las que se sitúan estas experiencias, las percepciones sobre la utilización de privilegios y las narrativas a partir de las cuales se recrea el vínculo intergeneracional. Como corre lato de ello, también me he preocupado por conocer las experiencias que proponen puntos de fuga a las posiciones y corporalidades adultas hegemónicas, indagando en prácticas y saberes de sujetos concretos que se preguntan respecto de su propia posición generacional, al mismo tiempo que proponen a lternativas no jerarquizadas de vínculo.

De esta manera, el anális is recupera los aportes desarrollados por las epistemologías feministas, que hacen especial hincapié en los modos de incorporación de los sujetos en los procesos de investigación, configurando la noción de objetividad fuerte. Esta propuesta no suspende las formas de afectación de quienes investigan sobre sus objetos de investigación, sino que promueve la estructuración de ópticas de visualización rigurosas y reflexivas, que explic iten tanto los puntos de partida como los de llegada.

Enuncié, asimismo, la dificultad de aproximación de un campo que es, al mismo tiempo, evidente e invisible. Esto implicó la emergencia de un espacio dirigido al anális is de la relación entre construcción de sensibilidades comunes y conocimientos situados. El problema de territorialización respecto de qué construye el espacio común de las adulteces, hizo necesaria una aproximación desde los márgenes de estas posiciones, y en la vinculación con otras experiencias generacionales. 
Contemplando este estado de situación, utilicé la constelación cognitiva comprendida por la relación entre trayectorias, percepciones y posiciones, procurando una aproximación que diera cuenta de las formas de percibirse de lxs adultxs en el mundo, no solo a partir de sus narrativas, sino también de sus experiencias, sentires y afectaciones. Se trató de una investigación de tipo cualitativa, que incluyó como sujetos de análisis a personas que eran y/o se percibían adultas y que desarrollaban procesos de trabajo con niñxs y jóvenes.

Por su parte, para el análisis de las trayectorias y experiencias singulares, la realización de entrevistas semi-estructuradas en profundidad, me permitió conocer aquello que aparece como imposible e indecible en el discurso generacional hegemónico, y que da cuenta de una serie de narrativas y prácticas que ponen en cuestión y/o desestructuran las relaciones de poder conocidas. Tramar estos relatos en red, fue una apuesta por colectivizar una serie de diálogos y experiencias que permanecen aún en la órbita de lo desconocido y no valorado.

He de mencionar que, la insistencia por visibilizar y hacer localizable aquello que constituye lo adulto se enlaza a la convicción de que ninguna posición de privile gio es natural e intransformable. Como correlato de ello, crear narrativas y prácticas que apuesten a la destrucción de los órdenes que se sostienen en base a la desigualdad supone una urgencia ética impostergable. 


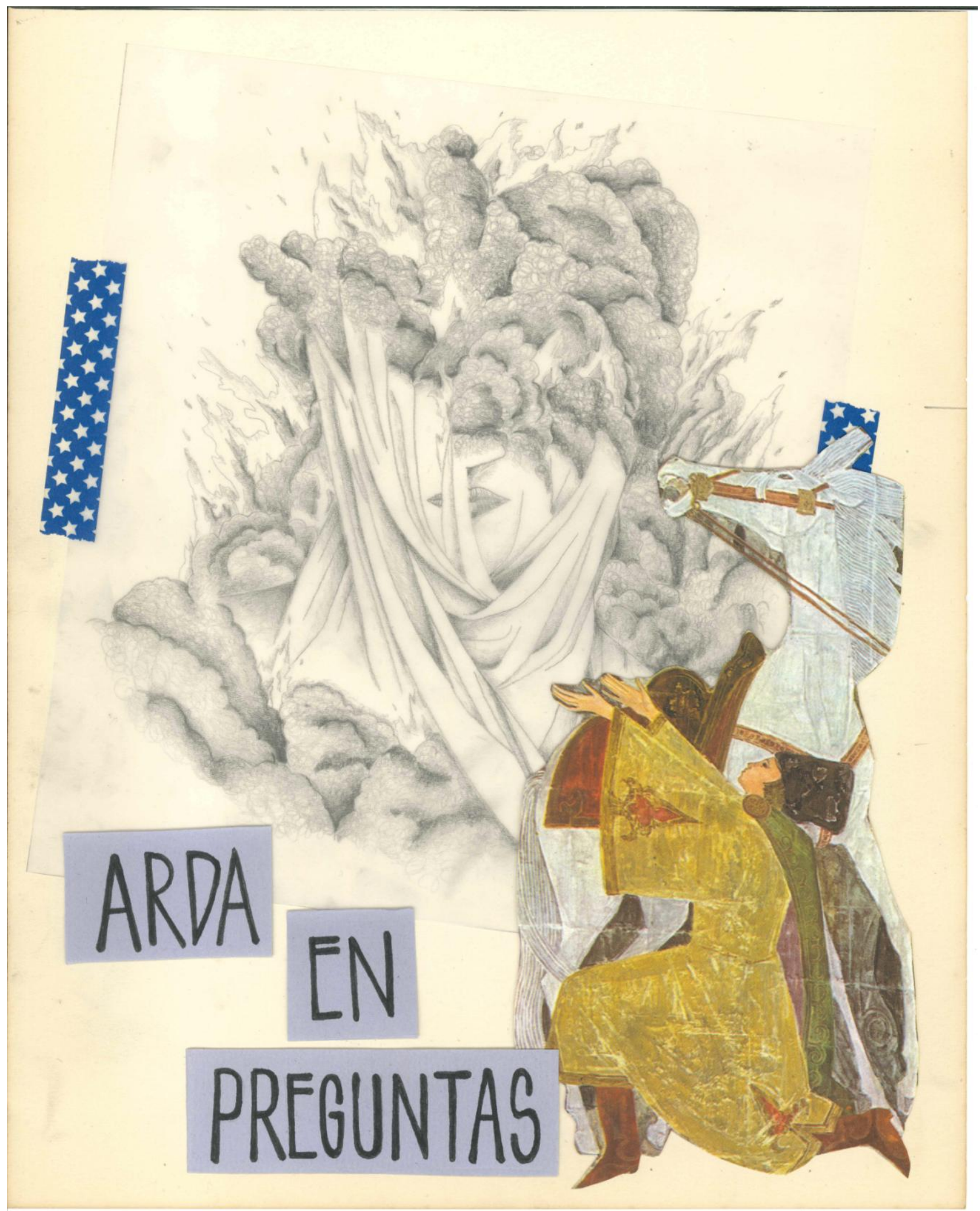




\title{
Capitulo II: La casa que habitamos
}

\author{
Hay quienes reciben de nacimiento \\ una identidad que les resulta suficiente, \\ o que al menos no cuestionan, \\ y hay quienes emprenden el camino de la reinvencion, \\ por supervivencia o por placer, y viajan muy lejos. \\ Algunas personas heredan valores y costumbres \\ que son como una casa en la que habitan; \\ algunos tenemos que prender fuego esa casa, \\ encontrar nuestro suelo, \\ empezar a construir desde cero.
}

Una guia sobre el arte de perderse Rebecca Solnit

En los estudios astrológicos, las casas hablan acerca de diversas áreas de experiencia a partir de las cuales interactuamos con el exterior y miramos el universo tomando en consideración una serie de variables, constelaciones, territorializaciones y posiciones de mundo. De esta manera, somos influídxs por constelaciones que, utilizando coordenadas de localización y desplazamiento, permean ciertas condiciones de existencia modelando nuestras ópticas de percepción, visión y acción. Así, no existe un espacio de determinación total, ni de explicación absoluta, sino una condición de permeabilidad e incidencia, y por tanto, un mismo sujeto es afectado -al mismo tie mpo y en condiciones diferenciales-, por múltiples constelaciones que, en las distintas casas, actúan siguiendo coordenadas similares, creando sistemas de interpretación.

En un sentido análogo, el estudio de las generaciones podría ser comprendido como el análisis de una de estas casas que, articuladamente, entrama áreas experienciales, elementos de localización, y ópticas de percepción. Formando parte, a su vez, de un sistema que se sostiene en una relación de permanencia, reorganización y desplazamiento, vincula do a otras casas o regímenes de posición-acción. En este marco, nuestra percepción respecto de las condiciones y/o posiciones generacionales, y su forma de organización individual y colectiva, se encuentra afectada por constelaciones de poder que se nuclean en torno a la idea de lo adulto como principio regente. La posibilidad de poner a jugar estas visualizaciones se encuentra influida por múltiples intereses, sentidos y artificios, y por ello resulta relevante desandar, explicitar y volver a organizar los modos en que esta casa es estructurada en nuestros procesos de conocimiento. 
En este capítulo me he propuesto, por tanto, deconstruir y reconstruir los soportes y materialidades sobre lxs que han sido cimentadas estas edificaciones generacionales, analizando los diseños, modelos, ensambles, y formas de construcción en torno de las cuales se organizan. Esto supone, asimismo, desandar las relaciones de poder y las narrativas que la hacen necesaria para la mayoría, imprescindible para algunxs, habitable para otrxs y problemáticas para lxs restantes.

Para aproximarme a este objetivo, he partido de algunos interrogantes que considero que han operado en esta indagación como marcos de decodificación, anális is e interpretación de la experiencia adulta. Entre las preguntas más significativas que me he realizado se encuentran: ¿Qué es el adultocentrismo y por qué lo considero un Sistema Complejo de Dominio?, ¿Cuál es su relación con otros sistemas de dominio?, ¿Qué implica vivir en sociedades adultistas y cómo se construye el poder de la mayoridad?, ¿Qué relaciones y presupuestos se establecen en la relación entre edad y generación, y cuáles de ellas inciden en la vinculación entre posición, cronología y corporalidad?, ¿Cómo se construyen y cuáles son los mandatos de adultez?, ¿a qué sujetos aplican?, ¿De qué manera se organiza la relación dependencia, protección y regulación de la libertad en estos Sistemas?, ¿Qué rol juegan los procesos comunicacionales en estos modos de construcción de la adultez?, ¿cómo se recrean y significan estos postulados desde un enfoque de DDHH?

Seguramente existan otros interrogantes de relevancia y otros modos de aproximación al campo. También existen, sin lugar a dudas, otras perspectivas sobre cómo se configura lo generacional. Pero, como ya advertí, todo proceso de visualización implica una óptica del posicionamiento, y la mía se sitúa en la intersección de estas coordenadas.

\section{Centro gravitacional}

Al recuperar nuestras trayectorias y/o las de aquellxs a quienes conocemos, usualmente pensamos en la articulación de distintos marcadores asociados a localizaciones sociocontextuales. Como parte de esa observación nos es posible visualizar virajes que hacen que algunas condiciones o posiciones sean preeminentes en comparación con otras, en procesos que son dinámicos y multi-causales, y, sobre la mayoría de ellas, asumimos condiciones de producción social que definiríamos como de afectación más que como de determinación. Es decir, al hablar sobre nosotrxs -y sobre otrxs-, las narrativas que 
construimos recuperan, implícita y explícitamente, experiencias que son diversas, enlazadas a tiempos y espacios singulares.

Sin embargo, no todos esos marcadores o clivajes son comprendidos como performativos, es decir, como parte de producciones sociopolíticas. Esto ocurre, por ejemplo, con los clivajes o marcadores generacionales, haciendo imposible excluir la asociación etaria-generacional de la dimensión de lo inamovible y dado. Al mismo tiempo, esta condición se convierte, para las generaciones subordinadas, en un tipo de marcación que actúa como organizador diferencial de otros marcadores o clivajes.

De esta manera, la experiencia que habla sobre la vivencia temporal de los seres humanos continúa siendo medida, predominantemente, de manera cronológica, capacitista y longitudinal. Para ello utilizamos nociones como las de ciclo, curva o etapa, que, indefectiblemente, sitúan a lo adulto como medida gravitacional en torno de la que se organizan las demás fases o momentos de la vida, provocando que quienes detentamos privilegio nos ubiquemos en el punto de mayor desarrollo, capacidad o plenitud. Es decir, si separáramos aquello que subyace a las narrativas sobre lo generacional de sus enunciados, nos sería posible observar que el lugar de valor es ocupado frecuentemente por los mismos sujetos, desarrollando asimetrías de legitimación respecto de ello.

El adultocentrismo puede ser definido entonces, como la preeminencia de lo adulto en las formas de estructuración generacional, convirtiendo esta posición en un principiofuerza, y estableciendo en torno a ella el punto de medición desde el que se diagrama todo parámetro cronológico-posicional de mundo. La creación de habilitaciones y restricciones de acuerdo con la condición etaria -en una vinculación inamovible a tipos de capacidad-, es una expresión de esta forma de organización y distribución de las relaciones de poder. En un sentido análogo, Claudio Duarte define al adultocentris mo como:

Un sistema de dominación que delimita accesos y clausuras a ciertos bienes, a partir de una concepción de tareas de desarrollo que a cada clase de edad le corresponderían, según la definición de sus posiciones en la estructura social, lo que incide en la calidad de sus despliegues como sujetos y sujetas. Es de dominación ya que se asientan las capacidades y posibilidades de decisión y control social, económico y político de quienes desempeñan roles que son definidos como inherentes a la adultez y, en el mismo movimiento, los de quienes desempeñan roles definidos como subordinados: niños, niñas, jóvenes, ancianos y ancianas. (Duarte; 2012: 9-10) 
En este punto es necesario repasar dos cuestiones: por un lado que se trata de un sistema, y por el otro, que esta forma de organización se estructura en base a la dominación. Al conceptualizarlo como un Sistema, me refiero a que esta forma de vinculación desigual se ordena sobre construcciones generacionales complejas que enlazan relaciones, procedimientos y materialidades, que se expanden reterritorializadamente, combinándose e hibridándose para mantener fuerza y potencia, lo que les permite permanecer perceptivamente en la órbita de lo ya dado. Es decir, el valor otorgado a lo adulto como principio regente forma parte de nuestras percepciones como elemento obvio e inamovible de organización social, y si bien podemos rastrear las huellas que reafirman esta condición impregnada en nuestras prácticas cotidianas, cuando nos aproximamos a ellas, nos damos cuenta que nuestro observable es solo uno de los elementos que compone una trama difícil de deshilar.

Estas formas de obtención de consenso, sustentadas en la asignación de características inherentes e inamovibles a los sujetos de acuerdo con su condición etaria, así como la relación entre poder y coerción que define estrategias de re-encausamiento para quienes no obedecen a estas reglas de percepción-acción, hablan acerca de su carácter de dominación. Dicho de otro modo, el dominio da cuenta del ejercicio de formas de poder determinadas y sistemáticas, que suponen una afectación asimétrica de los principios y acciones de unxs sobre otrxs que -según los parámetros de esa relación- se sitúan en condición de subordinación. Claudio Duarte lo explica de esta manera:

Esta dominación se constituye en la imbricación entre poder y coerción, y cuando ella es aplicada institucionalmente, se supone que se le otorga una legitimidad que permite y asegura su reproducción. De esta forma, la obediencia a los mandatos aparece como un eje de relaciones desiguales entre agentes, a las que Weber denomina asociación; en el marco de esa asociación es que se inscribe esta dominación legítima. (Duarte, 2014:72)

De esta manera, Weber (1987) enuncia tipos de ejercicio del dominio que son presentados como formas legítimas de asimetría entre los sujetos, destacando aquellas que se producen a partir del establecimiento de obediencia a cuerpos legales/normativos, del respeto por las formas de autoridad personal -o, en su defecto, por los principios de autoridad-, de la sacralización de costumbres y tradiciones, de la exaltación y/o creencia en cualidades extraordinarias de ciertos sujetos, y en última 
instancia, del ejercicio de la violencia en sus diversas manifestaciones. Según este autor, en la cotidianidad, estos tipos se mezc lan, interjuegan, matizan y funden, produciendo fuerzas estructurantes, intencionadas y diferenciales de distribución del poder. Una consideración fuerza que sustenta este desarrollo es que, para la reproducción del dominio, resulta necesario que estas relaciones no sean percibidas por los sujetos -total o parcialmente- como coercitivas y/o producidas a partir de la imposición del poder.

Asimismo, la construcción de asimetrías no se produce de forma univariable y/o a partir de un único marcador social, sino que debemos pensar en la interrelación de sistemas de dominio que operan de forma compleja, articulando el uso de privilegios y la vivencia de experiencias de la desigualdad. En este movimiento se generan zonas de opacidad y transparencia que colocan a algunos de estos marcadores en lugares totalitarios mientras que otros son relegados o invisibilizados. Es decir, este sistema de dominio oc urre $-\mathrm{y}$ transcurre- en vinculación con otros sistemas análogos, creando y recreando constelaciones de poder que se conjugan, temporal y espacialmente, en el desarrollo de procesos de hegemonía y subalternidad habitados situacionalmente por ciertos sujetos, en contextos sociopolític os caracterizados por la estructuración de pluridominios.

En esta coyuntura, los estudios sobre interseccionalidad nos han permitido hacer observables los modos en que nuestras posiciones y cuerpos son afectadxs por estos sistemas de manera conjunta y aleatoria. En palabras de Raquel (Lucas) Platero Méndez:

... la interseccionalidad se puede entender como un estudio sobre las relaciones de poder, que incluyen también vivencias que pueden ser señaladas como "abyectas" o "pertenecientes a los márgenes", o "disidentes". Sin embargo, también sirven para teorizar el privilegio y cómo los grupos dominantes organizan estrategias de poder (conscientes o no) para preservar su posición de supremacía (Platero Méndez; 2014:56)

Esta concepción sobre el poder vuelve obsoletas a las teorizaciones que lo perciben como una fuerza de afectación uniforme desplegada de forma integral por algunos sujetos. Así, analizar los modos en que ciertas coyunturas y constelaciones de fuerza interactúan, en condiciones socio-temporalmente situadas, hace posible comprender cómo el ejercicio del privilegio y la experiencia de la desigualdad no son vivencias necesariamente excluyentes. Esto es particularmente llamativo en los estudios generacionales, puesto que el ejercicio de esos privilegios suele aparecer como 
componente inmanente a otros marcadores sociales, ya sea a modo de justificación o como condición de exaltación.

Estas redes de producción y distribución del poder no solo modelan las percepciones y posiciones respecto de nuestras experiencias vitales -en un plano que podríamos nominar como de superficie o forma-, sino que inciden en la producción mis ma de nuestras corporalidades en tanto potencias deseantes -en su dimensión estructural o de fondo-. Paul B. Preciado habla sobre ese movimiento de este modo:

Evidentemente ya Foucault, pero también las tradiciones del feminismo, las tradiciones del antirracismo, nos enseñaron a pensar el poder de otra manera, es decir el poder no solamente en relación con las instituciones jurídicas o el aparato del Estado, sino que el poder atravesando y capturando el cuerpo, eso que Foucault va a llamar biopolítica y yo llamo macro política. Yo creo que siempre tendemos a pensar el cuerpo como un objeto, como en el fondo una anatomía, como algo natural, y en realidad lo que más me interesa del cuerpo es la potencia deseante, el cuerpo como una artefacto imaginario, no una naturaleza. Me interesaba apuntar a ese lugar, las maneras a través de las cuales el poder captura la imaginación y captura por tanto la potencia deseante, la reserva última de una posibilidad revolucionaria. (Preciado, 2021: s/n)

Así, si bien estas vinculaciones y afectaciones son variables y múltiples, entiendo que en esa red de relaciones de dominación y poder algunas articulaciones requieren de un anális is particular. En lo singular, cons idero que el adultocentrismo necesita ser pensado en directa vinculación con el patriarcado, en tanto, ambos sistemas hablan de modelos de dominio que parten de subordinaciones amparadas en la condición biológica de ciertos sujetos, a quienes se han asignado atributos incuestionables incorporados en sistemas de jerarquías. Aunque forme parte del régimen de clausuras perceptivas dominantes, la generación es a la edad lo que el género al sexo.

No caben dudas que aquellas acciones y procesos que permanecen en sitios de clausura para niñxs y jóvenes, antes fueron sitios restrictivos para los cuerpos feminizados. Esto mismo ocurre con la delimitación de capacidades de acuerdo con experiencias corporales singulares, y con la utilización de argumentos biologicistas para el establecimiento de modelos de separación, valoración y jerarquización de los sujetos en base a su condición fenotípica. Cabe destacar que, aunque esta segmentación nos sea parcialmente localizable a partir de la visualización de procesos y tecnologías de producción y delimitación de las existencias generacionales, su análisis halla un límite 
cuando no es posible hacer observables los modos en los que, la temporalidad de nuestros cuerpos, también forma parte de esos mismos procesos de producción social.

La conjunción de ambos sistemas, además, asume una potencia inigualable, puesto que a lo largo del tiempo ha enfrentado a los sujetos subordinados presentándolos como opuestos entre sí. Es decir, durante décadas, se han legitimado discursos que erróneamente oponen las perspectivas de género a las de generación, colocando a lxs niñxs como responsables de la feminización de las tareas de cuidado, en la misma medida en que las mujeres-madres son garantes de la familiarización de las prácticas de crianza y de su correcto disciplinamiento. En todos los casos, la subyugación de estos cuerpos a ciertos mandatos ha sido el elemento más significativo, puesto que, ha utilizado datos de la biología -como la capacidad gestante por ejemplo- para crear mandatos y ficciones legitimantes respecto de que la propia posición es lo que determina per se otras posiciones de subordinación - tal como ocurre con la ilusión de que interrumpir una gestación es una decisión que de algún modo se encontraría vinculada a la existencia de un/a niñx-. Es de destacar que estos espejismos son por demás efectivos, ya que opacan y ocultan las condiciones de producción de dominación y a los agentes que la despliegan.

\section{Liberar fronteras}

El trazo que diferencia la línea que construye de la que delimita es a menudo difuso, y por tanto, las narrativas que ensayan nociones o visualizaciones suelen establecerse como dogmas o principios unívocos de comprensión. Para ello no son necesarias explicaciones totales, alcanza con construir valor legitimante respecto de ciertas agrupaciones fuerza. En nuestro caso, la percepción de que la generación es una consecuencia directa del devenir etario ocupa el estatuto de frontera, es decir, no es posible salir, entrar, o elegir una posición generacional libremente sin una acreditación identitaria elaborada sobre caracteres numéricos. Algunos cercos, señala Fernand Deligny (1967), no solo construyen adentros y afueras, sino que necesitan ser delimita dos circularmente, pues ello es lo que posibilita crear la ilus ión de que basta con un único marcador para establecer una línea divisoria de contorno total.

En el apartado anterior sostenía que existe un sistema de dominio construido en torno a lo adulto, pero esta afirmación no está completa sin asumir que la adultez no es una condición temporal e irrenunciable de ciertos sujetos, sino más bien, una forma de 
producción performativa tanto de nuestras trayectorias, percepciones y posiciones, como de nuestros cuerpos mismos. Es importante recordar que, antes de que la categoría infancia delimitara a sujetos particulares, existía una indistinción sobre esas trayectorias que hoy nominamos como generacionales. Esto no equivale a decir que no existía poder o desigualdad en esas formas vinculares, o que no existieran experiencias de la niñez o vivencias interseccionales moduladas por ese clivaje, sino que, ese proceso de visibilización y separación da cuenta del modo en que aquello que construimos como experiencia diferencial obvia, no es más que una producción social organizada, también, a partir del establecimiento de fronteras entre los sujetos en base a su edad.

Al hablar de estos procesos de separación generacional, Zygmunt Bauman explica:

Pues que las fronteras que separan a las generaciones no están ni pueden estar claramente definidas, que no pueden dejar de ser ambiguas y que no pueden pasarse por alto y, aún menos, ignorarse. Es necesario dibujarlas y respetarlas, argumentarlas y probar su legitimidad. Es necesario convencer a los individuos situados dentro de estas fronteras, tal vez hasta presionarlos, para que se queden, mientras que a los que están fuera se les debe cerrar la entrada y es necesario que los funcionarios de inmigración los mantengan alejados con la ayuda de los guardias de frontera, a veces armados, pero siempre equipados con un libro de normas y con detectores, ya sean electrónicos o de otro tipo. Tal como descubrió y evidenció Frederic Barth, uno de los antropólogos más perspicaces del siglo pasado, las fronteras no suelen dibujarse a causa de las diferencias. Más bien al contrario: las diferencias se notan y hasta se convierten en «un ente social y cultural» por el hecho de dibujar las fronteras. Primero se pone una frontera y después empieza una búsqueda enfermiza de rasgos distintivos, incluso incompatibles, de los individuos situados en el lado contrario, de manera que la legitimidad y el carácter indispensable de la frontera pueda justificarse más allá de la duda razonable y, en el caso de su fortificación, volverse convincente. (Bauman, 2007:113)

Frente a esta situación, la pregunta sobre la posición, en lugar de orientar el sentido desde el que se organiza la visión de mundo, se vuelve una afirmación de fijación -a modo de restricción identitaria- que genera una vinculación unilineal entre cronología y corporalidad. Analizamos los procesos generacionales del mismo modo en que nuestro pensamiento temporo-espacial se organiza, y por tanto, suponemos que hemos avanzado naturalmente desde posiciones conservadoras hacia otras garantistas, y que esto invierte per se toda forma opresiva. Es necesario advertir entonces que situar nuestras formas de conocimiento en el orden de lo generacional no apunta a la construcción de marcaciones o estatutos identitarios, sino que pretende, por el contrario, deshacer las delimitaciones 
restrictivas de la experiencia temporal en vinculación a las trayectorias corpora lesvitales.

Debemos tener en cuenta que la edad es un número absoluto que, en nuestras sociedades, se mide desde el nacimiento hasta un punto de observación, convirtiéndose en una variable obsoleta si se la separa de su producción de sentido y de la asignación de estatutos en la relación trayectoria-capacidad. La percepción de que podemos habitar socio-temporalmente una única generación -innata e irrenunciable-para dar cuenta de nuestras experiencias temporales es, ni más ni menos, que un artificio. Por ello resulta impresc indible, volver al origen de nuestras propias conceptualizaciones para asumir que las generaciones poseen un carácter móvil, no ya en sentido de pasaje o sucesión, sino en su condición performativa, múltiple y simultánea.

En este marco, las concepciones generacionales sobre las que hemos sido socializadxs sitúan, en su estructuración tradicional, un problema de doble orden: por un lado respecto de los mandatos que constriñen a ciertos cuerpos a asumir un carácter dado en asociación a posiciones identitarias basadas en la relación tiempo-capacidad, y por el otro, a la sujeción entre posiciones de mundo y experiencias corporales-temporales predefinidas. Judith Butler habla sobre la complejidad de estas composiciones, en un anális is que si bien se sitúa en las discusiones sobre sexo y género, resulta análogo de los vínculos existentes entre edad y generación:

Las cuestiones que entrarán en juego en tal reformulación de la materialidad de los cuerpos serán las siguientes: 1 - la reconsideración de la materia de los cuerpos como el efecto de una dinámica de poder, de modo tal que la materia de los cuerpos sea indisociable de las normas reguladoras que gobiernan su materialización y la significación de aquellos efectos materiales: 2 - la comprensión de la performatividad, no como el acto mediante el cual un sujeto da vida a lo que nombra, sino, antes bien, como ese poder reiterativo del discurso para producir los fenómenos que regula e impone; 3-la construcción del 'sexo', no ya como un dato corporal dado sobre el cual se impone artificialmente la construcción del género, sino como una norma cultural que gobierna la materialización de los cuerpos; 4- una reconcepción del proceso mediante el cual un sujeto asume, se apropia, adopta una norma corporal, no como algo a lo que, estrictamente hablando, se somete, sino más bien, como una evolución en la que el sujeto, el 'yo' hablante, se forma en virtud de pasar por ese proceso de asumir un sexo; y 5- una vinculación de este proceso de 'asumir' un sexo con la cuestión de la identificación y con los medios discursivos que emplea el imperativo heterosexual para permitir ciertas identificaciones sexuadas y excluir y repudiar otras. (Butler, 2015:17) 
Si lo pensamos en articulación con este análisis, la posibilidad de producir fijaciones se encuentra en directa relación con la permeabilidad para regular las trayectorias móviles, es decir, ya no de una acción sino de un sistema que organice la articulación entre la permanencia en una generación, la proyección de pasaje en ascenso hacia otras, y la negación de la experiencia negociada y pretendidamente abandonada. Hemos de recordar que, en el orden de lo generacional, dos condiciones nos son presentadas como constitutivas e irrenunciables: saber ser y saber devenir, y que por tanto, la relación entre fijación y movimiento adquiere características específicas. Probablemente este sea uno de los motivos por los que nuestras percepciones sobre tiempos y movimientos, frecuentemente se construyan utilizando soportes secuenciales y etapistas.

El poder reiterativo de los discursos en la producción de fenómenos ocupa un lugar preeminente en este proceso, logrando una sincronía entre cronología, corporalidad y experie ncia vital. La noción de devenir común en una vitalidad finita invisibiliza aquello que en el orden de la experiencia temporal aparece como simultaneo, yuxtapuesto, entreverado y diverso, presentando a las trayectorias etarias y generacionales como si poseyeran un único sentido, composición y destino. A propósito de esta idea de destino común dice Zygmunt Bauman:

Al menos la asunción, a veces explícitamente declarada pero muy a
menudo implícita, de la cual depende el significado del término, es que
compartir el rasgo reconocido como el rasgo distintivo y constitutivo de
la pertenencia a una generación -es decir, la característica de haber
nacido en un período de tiempo concreto- determina la identidad de la
situación, los retos, las oportunidades, las amenazas y las tareas y que,
por esta razón, quien comparte esta característica tiene la necesidad y la
obligación de tener como referencia a los compañeros de su misma edad
al escoger los modelos de conducta adecuados, o los criterios para
separar el bien del mal, lo que es correcto de lo que es incorrecto y, de
manera más general, aquello que es loable de aquello que es condenable. (Bauman, 2007:113)

Por el contrario, abandonar nuestros supuestos sobre los cuerpos que portamos y las posiciones que detentamos, implica ensayar nuevamente una serie de preguntas que hablan acerca de eso que comprendemos como originario y que hemos construido bajo la forma de fronteras. En este contexto, aseverar que las generaciones poseen un carácter performativo, múltiple y simultáneo supone además, indagar en los fenómenos, significantes y narrativas que dan cuenta de elecciones y afectaciones respecto de aquello a lo que situamos en el terreno de lo identitario. 


\section{Gestionar las adulteces}

Si bien en la órbita de las relaciones de fuerza la adultez es una categoría de mayorías, muy pocxs adultxs cumplimos con esa forma estereotipada de participación identitaria, incluso cuando cotidianamente reafirmemos el presupuesto de que se trata de una trayectoria vital única. En este sentido, así como se ha construido una idea de infancia hegemónica (Magistris y Morales; 2018), también se ha conformado una forma hegemónica de la adultez, que es soportada por la cristalización de roles y agencias que suponen, sobre todas las cosas, el uso de la autoridad, el ejercicio de la responsabilidad, el goce de la libertad y la ficción de la completud.

A menudo, asociamos la diversidad de trayectorias de la adultez a otros marcadores o clivajes -tales como el género, la etnia o el territorio- o incluso, a los roles y posiciones que ocupamos en el espacio -como responsables, cuidadores, referentes o expertxs-, invisibilizando que nuestros parámetros respecto de esta posición identitaria también son variables, conflictivos, dinámicos, contradictorios y diversos. Aparece entonces la idea de que lxs adultxs somos todos iguales, que es el modo de sistematizar y encauzar todas las afectaciones producidas por un mismo marcador, ocultando no solo nuestras trayectorias, percepciones y posiciones, sino además, la forma en que nuestros cuerpos se producen al mismo tiempo en que producen sentido.

Así, comportarse como adultx también implica en este universo de relaciones, hacer cuerpo de una serie de posiciones que individualizan y reducen la incidencia de nuestras operaciones respecto de acciones o fenómenos en las que se pone en juego al yo, a un número definido de rutinas $\mathrm{y}$ comportamientos dirigidos al establecimiento de diagnósticos, normas y procedimientos. Antes dec ía que para que la diagramación de las generaciones tal y como las conocemos sea efectiva es necesario del establecimiento de fronteras, pues entonces, es imprescindible agregar, que para que la permanencia dentro de sus lindes no sea conflictiva, es preciso acatar ciertos pactos de ciudadanía y convivencia.

Ese saber ser en una posición generacional prefijada tie ne un sentido simbólico y significante importante en las formas de construcción de lazo social que conocemos, puesto que genera una presunción de poder de gobierno -propio y ajeno-, que es maleable, mutante y frecuentemente opaco, pero que emerge siempre con un sentido directivo y determinante. Fallan lxs adultxs que han perdido autoridad frente a otrxs, 
puesto que relativizan la fuerza que les fue asignada y/o desconocen los modos correctos para su efectivización. Esto es innegable en el anális is de las relaciones familiaristas tradicionales, pero, lo más honesto sería preguntarnos respecto de cuantos poderes de gobierno y principios de autoridad hemos construido bajo la premisa del poder del padre. Debemos recordar entonces, que si bien lo adulto enuncia un tipo de experiencia corporal, también habla acerca de las posiciones que ocupamos en los espacios.

Estos constructos se nos aparecen en forma de creencias y mandatos, en tanto, a menudo nos encontramos con reglas implícitas y explicitas acerca de las formas legítimas de ser adultxs, no solo corporalmente sino, fundamentalmente, a partir de las posiciones que nos vemos constreñidxs a asumir -y/o padecer- en la trama sociopolítica. Ahora bien, debemos considerar que si los mandatos sitúan, son los microadultismos los que corrigen. Es decir, actúan modificando trayectorias, reencausando estos tránsitos a partir de la generación de narrativas y prácticas que señalan y cuestionan a aquellxs adultxs que se han separado de los estatutos establecidos. Hablo de microadultismos en referencia a las marcaciones que estructuran nuestro sentido común y permean nuestra cotidianidad, y que además de cristalizar posiciones hegemónicas, operan como organizadores de permanencia ${ }^{3}$.

Ningún mandato, creencia o microadultis mo se construye y sostiene individualmente y/o en singularidad, aunque sean sujetos concretos quienes los produzcan, encarnen y reproduzcan. Tampoco pueden ser comprendidos como meros efectos de la voluntad y/o como resultantes innatos de la decisión, ya que estas asociaciones cristalizan y ocultan los flujos de circulación del poder, reduciendo los procesos de construcción de sentido a su forma fenoménica, es decir, al comportamiento individual. Esto no solo abarca los procesos de producción, sino que también habla sobre las condiciones necesarias para su sostenimiento y reproducción, y sobre las alianzas, estrategias, intereses, direccionalidades y acciones que lxs adultxs desplegamos entre nosotrxs para mantener ese sistema de relaciones. A este último entramado me refiero cuando hablo de la existencia de un pacto adulto.

\footnotetext{
${ }^{3}$ Si observamos nuestras narrativas cotidianas, los discursos sobre los que se estructuran están cargados de nominaciones tales como: 'No seas infantil', 'es muy maduro para su edad', 'está quemando etapas', 'dejate de hacer chiquilinadas', 'está hecho un pendejo ', es cosa de grandes', 'son como chicos', 'gente grande haciendo esas cosas', 'no crecen más', 'es un nene de mamá', 'un bebé de pecho', 'ya está en edad de merecer', entre otras. La mayoría de estas expresiones tienen un sentido clausurante y/o disciplinante.
} 
De todas las percepciones sobre el mundo adulto, la noción de responsabilidad como elemento inherente a estas trayectorias ocupa un lugar preemine nte, siendo muy curioso su pasaje de valor general a condición individual e irrenunciable. Es decir, somos responsables, no ya porque producimos sistemas de desigualdad y privilegios -y porque su sostenimiento implica estructurar modelos de organización y afrontamiento de ciertas relaciones sociales-, sino porque, poseemos naturalmente mejores condiciones y más capacidad para visualizar la realidad social en su complejidad, y establecer y administrar pautas de acción y comportamiento acordes a ello. Así, existe una selectividad motivada por el qué y el cómo en esos procesos de afectación, en los cuales, la premisa de lo colectivo como parámetro de construcción aparece solo cuando han sido delimitadas y situadas las posiciones y tareas individuales.

No podemos obviar que la construcción y legitimación de creencias y mandatos acerca de las formas correctas de experimentar la adultez también contribuyen en la fijación de posiciones de privilegio, en tanto se establecen tipos de saber ser sustentados en lógicas de separación, valoración y jerarquización que colocan a quienes se ubican por fuera de sus fronteras en un limbo de permanente incompletud. Tampoco podemos afirmar que, sea este un sistema de desigualdad que nos afecte a todxs con la misma fuerza y potencia, es decir, los mandatos de la adultez nos constriñen, pero no lo hacen con la misma violencia y opresión con las que afectan a quienes ocupan lugares de subordinación. Ser sin querer no implica que el ser sea inerte advierte Fernand Deligny (1967), y es justamente por ese motivo, que la posibilidad de deconstrucción no puede pensarse por fuera de la ruptura de los pactos de solidaridad adulta que nos impiden poner en cuestionamiento, con quienes son pretendidamente nuestros pares, aquellas narrativas y localizaciones que nos sitúan per se en el centro de todas las escenas.

\section{Asociaciones ilícitas}

En su base jurisprudencial la noción de asociación ilíc ita ha servido para dar cuenta de aquellos agrupamientos de personas organizadas con el objetivo de causar algún tipo de daño y/o trasgredir una norma. Sin embargo, podríamos acordar que en nuestras sociedades ley y justicia -que son las dos acepciones posibles para pensar lo lícito/ilícito- no necesariamente son concepciones sobre las que se deba suponer un vínculo directo, sino que por el contrario, el cumplimiento de a lgunas leyes también nos ha colocado en situaciones de extrema injusticia. Si trasladamos la forma en la que se 
construye este pensamiento al universo de los vínculos intergeneracionales resulta posible advertir cómo el ama lga ma incuestionado de dos o más presupuestos atribuidos a un conjunto de sujetos, sobre principios morales de valoración -tales como lícito e ilícito o bien y mal -, también trastoca los márgenes mismos de las relaciones que se consideran legitimas e ilegitimas.

Así, qué cualidades o características posee un sujeto en vinculación con su experiencia corporal y su posición de mundo, es una condición de singularidad que se convierte en desigual cuando se establecen estándares y sistemas de sectorización y valoración. Es decir, si la diferencia no fuera retraducida en formas de sujeción y delimitación para el ejercicio desigual de nuestro poder, las cualidades y condiciones que asumen los sujetos -individual y colectivamente- deberían sernos irrelevantes como formas de marcación específica. En este contexto, si nos aventuramos a reorganizar nuestros supuestos perceptivos y nos permitimos desmenuzar las asociaciones que, como ocurre con este ejemplo, se han convertido en significantes instituyentes, es posible evidenciar un conjunto de nociones que han operado como andamiajes y soportes para la conservación de ciertas estructuras.

Alejandro Cussianovich aporta en este debate cuando reflexiona respecto de que:

... las categorías por sí mismas constituyen una manera de pensar, una pista para analizar y una direccionalidad para el actuar. Cuando desde las categorías se hilvanan discursos, se establece un campo conceptual más amplio, un campo lingüístico que da cuenta de las implicancias sociales del mismo, estamos en la construcción de discursos que son argumentativos, que juegan un papel de fundamentación que da mejor cuenta del sentido y de la significación de lo que todo discurso es portador. Con mucha razón, Zemelman recuerda que "no se trata sólo de organizar conocimiento sino de que desempeñe un papel de representación de espacios de vida para los sujetos, tanto concretamente como en el ámbito de lo simbólico". Y es que finalmente, lo que interesa es ver qué lugar en el discurso se le asigna al sujeto, en nuestro caso, al niño. Los discursos, de forma narrativa o analítica, son portadores de una fuerza emancipatoria o de un poder de dominación y lo son con tanta mayor fuerza que su coherencia y articulación juegan un impacto en las subjetividades, instauran identidades y moldean actitudes y comportamientos. (Cussianovich, 2012:26)

De esta manera, la forma en que los sujetos son producidos en nuestros discursos y narrativas tiene un efecto que excede lo simbólico y que se instala también allí donde acontece la producción material de nuestras propias corporalidades. Esto ocurre, por ejemplo, cuando enlazamos la noción de finitud de la experiencia vital c on el inevitable 
establecimiento de un curso o circuito vivencial devenido de la separación entre nacimiento y muerte, y caracterizado por la adscripción y superación de etapas. Es decir, utiliza mos con frecuencia la noción de 'ciclo vital' o 'cic lo de la vida' para referir a un proceso secuencial y unidireccional en el que un sujeto pasa por estamentos que se corresponden a su condición etaria y/o cronológica. Sin embargo, esa es una ficción confusa, ya que no porta reiteraciones o circularidades - cosa que podría ser incluso cuestionable-, sino que más bien representa una linealidad que asciende y desciende ubicando un único lugar de plenitud o privilegio. Podemos preguntarnos en este caso, si la verdadera asociación ilícita no está dada entonces por la utilización de datos de la biología humana para explicar unívocamente aquello que en realidad es la resultante del procesamiento social de las edades (Chaves, 2006).

En este orden de construcciones de sentido, otras asociaciones que aparecen como preeminentes en el universo de las relaciones intergeneracionales, y que requieren de una atención singular, son las de convivencia y obediencia, protección y regulación de la libertad, y autonomía y mediación. Subyace a todas ellas un principio de soberanía adulta que actúa como regente, ya que no debemos perder de vista que es la certeza de la autoridad más que el uso de la violencia material el elemento nodal de la hegemonía adulta $^{4}$, y que esta se estructura en torno al poder de la mayoridad. Este dominio de la mayoridad habla de la forma cotidiana en que se organiza y articula el ejercic io del poder de acuerdo a una escala jerarquizada de edad que nos otorga una posición de legitimidad según el número de años que nos separen de nuestro natalicio. Zygmunt Bauman aporta a esta visión cuando enuncia que:

Se crea la impresión de que las fechas de nacimiento tienen el poder de definir por adelantado límites claros y sólidos en lo referente a las decisiones humanas, mientras que asignarles una gran importancia o, al contrario, ignorarlos, o considerarlos menos importantes que otras cualidades para decidir qué alianza firmar y en qué conflicto embarcarse, no se deja como una elección humana. (Bauman, 2007:115)

De esta manera, el poder de la mayoridad (Duarte, 2014) no solo sitúa tránsitos y permanencias -que puede, debe y/o es deseable hacer o no de acuerdo a la edad-, sino que también fija relaciones -que hay que hacer en qué tiempos, con qué experiencias

\footnotetext{
${ }^{4}$ Es importante aquí de stacar que el ejercicio en acto de la violencia contra los cuerpos niñes sigue sien do totalmente legitima, en tanto se censuran solo aquellas expresiones asociadas a formas de la tortura -como el abuso sexual o el maltrato excesivo-, pero se consideran imprescindibles las formas de violencia física que se dirigen al establecimiento de límites, al disciplinamiento y/o a la corrección en el ámbito de la domesticidad.
} 
corporales-temporales y con quienes-, y establece modos de vinculación intergeneracional específicos $\mathrm{y}$ jerarquizados. Cuando ello disputa con otras constelaciones de poder o es materialmente impracticable, se retrotrae toda forma de experiencia desigual a su figura originaria: la niñez. Así, lxs locxs son como niñxs, lxs discapacitadxs tienen la capacidad mental de un niñx, o lxs viejxs se comportan como niñxs.

Santiago Morales y Gabriela Magistris aportan en el anális is de esta forma de poder cuando argumentan que:

... lejos de proponernos aquí negar las diferencias biológicas entre lxs niñxs y lxs adultxs, cuestionamos la idea de que esas diferencias justifiquen la negación del niñx como sujeto de pensamiento y coconstructor de su propia historia, permitan la imposición de la violencia como fundamento del vínculo intergeneracional, habiliten la disposición del cuerpo y la voluntad del otrx. La negación del otrx como sujeto no es algo determinado por la biología, sino un hecho cultural de carácter opresivo que merece ser sometido a una seria crítica para su transformación. (Magistris G. y Morales S., 2018:47)

Hay que destacar que esta idea de negación del otrx como sujeto no acontece bajo principios necesariamente explícitos, sino que suele permear aquello que construimos como inherente a los vínculos intergeneracionales. Por ejemplo, es admisible cuestionar que a cada adultx le corresponda un niñx - la obligatoriedad de gestar, de tener hijxs, o de asumir el cuidado de otrxs-, aún así, en nuestras representaciones de mundo permanece intacta la idea de que a cada niñx necesariamente le corresponde un adultx respecto de quien se encuentra a cargo. Subsiste la idea fundante de que hay algunxs de nosotros menos habilitados para el tráns ito social. Estos enunciados también hablan de una incomodidad latente que se entrama en la relación entre participación, regulación de la libertad, y mediación de mundo. De estas dimensiones, tal vez la más evidente sea la que encarna el presupuesto de que la palabra de lxs niñxs debe ser decodificada e interpretada, mientras que la palabra adulta aparece clara y transparente.

En aquellas instituciones que se encargan de complementar los sistemas de cuidado y crianza -tales como las escuelas, hospitales, asilos, clubes o iglesias-, la administración de este poder de gobierno ha de pensarse en articulación ya que poseemos corporalidades y posiciones materialmente adultas, al mismo tiempo, que en las posiciones que ocupamos se nos otorgan poderes como la superioridad, experticia y capacidad de decisión respecto de esas trayectorias otras. Es posible observar a partir de 
esta diagramación una multiplicidad de aristas y dimensiones donde esta premisa se pone en juego, pero una de las que reviste un interés particular por su frecuencia y naturalización, es la que habla sobre la incuestionable mediación de mundo a partir de la que se crean condiciones de exigencia y colocación de la demanda. Así, solemos pedirle a niñxs y jóvenes que nos expliquen a nosotrxs -aunque no nos conozcan ni formemos parte de su cotidianeidad- qué es eso que les acontece como problemático, y que lo hagan de un modo comprensible, racional y organizado, en un tiempo y espacio que hemos delimitado previamente. También demandamos ser incorporadxs en esa trama personal como agentes necesarixs, asignándonos la responsabilidad y el poder de tomar decisiones que inciden en sus vidas.

Recientemente asistí a un niño que, como alternativa a una situación conflictiva y permanente que experimentaba en su lugar de residencia, consideraba que separarse de su familia era la mejor opción para tener otras posibilidades. Respecto de su propia trayectoria había hecho un diagnóstico de situación por demás interesante, ya que no solo hablaba sobre eso que, en sentido estricto, emergía como problemático, sino que además, había evaluado alternativas y agenciado tácticas que le posibilitaron acceder a espacios de escucha. La mayor parte de la entrevista sentí que mi participación era innecesaria, por lo que, después de algún tiempo opté por preguntarle en qué crees que yo o este espacio podemos acompañarte? Rápidamente él me advirtió que se encontraba en desventaja para plantear esa demanda, y que necesitaba una táctica que reconfigurara una operatoria de poder, por lo que la mediación de alguien que pudiera retraducir esa demanda en términos adultxs le era una opción. Mi única función era, entonces, ser su soporte adulto de legitimación, puesto que para la consecución de su objetivo se requería hacer una presentación en otro organismo.

De más está decir que, a pesar de las muchas discusiones y pujas, esa estrategia fracasó, ya que la idea de que un niñx decida discontinuar la convivencia con su grupo originario, no está previsto como una condición de excepcionalidad, al mismo tiempo en que el deseo o la necesidad no son considerados argumentos suficientes. No fue necesario, tampoco, explicar tal negativa, puesto que es perfectamente legítimo faltar a lxs acuerdos que realizamos con niñxs. También lxs adultxs que acompañamos esa decisión fuimos acusadxs de tomar demasiado en serio esa escucha, de no adecuar el relato detallando experiencias de desigualdad y violencia, y de no haber sabido reencausar la demanda en un sentido opuesto a su propuesta. Paradójicamente, la 
posibilidad de alojar esa demanda, solo encontraba condición de posibilidad, si podíamos perpetuar el pacto de decisión adulta.

De esta manera, en la mayoría de los casos, existe una devolución de responsabilidades y condiciones, que aparece en las narrativas cotidianas bajo la forma de desobediencia, rebeldía o incomprensión. Podríamos mejor admitir que el agenciamiento de niñxs y jóvenes nos perturba justamente porque desorganiza, reorganiza y resiste a las formas de articulación del poder que conocemos, porque nos resulta ilocalizable en sus delimitaciones, y porque nos incomoda el modo en que organizan sus tácticas y estrategias. Sin embargo, si nos pensamos en las condiciones producidas y ofrecidas por las formas de ciudadanía que conocemos y por la organización del poder, y aún así permanecemos sin cuestionarnos nuestra participación en esas redes vinculares, es posible que la mayoría de los agenciamientos de niñxs nos acontezcan como impertinentes o desobedientes, independientemente de su condición o razón de ser.

\section{Los Reyes Magos son lxs xadres}

Si nos adentramos en aquello que hace a la producción de sentidos y sentires en las prácticas sociales de las que formamos parte, más allá de que nuestros observables por lo general se vinculen a los sentidos ya producidos, es imprescindible visualizar también los diálogos y narrativas que construyen percepciones y posiciones de mundo, y que operan como marcos de interpretación y simbolización de la realidad. En este escenario, entiendo que reducir los procesos comunicativos a una serie de fenómenos de transmisión de información entre extremos y/o a la resultante de un conjunto de procedimientos lingüístic os y semióticos, oculta su inmanente condición dialógica y colectiva.

Atendiendo a esto, he de alertar que no hay comunicación sin encuentro, del mismo modo en que no necesariamente alcanza con encontrarse para que exista alguna forma de dialogo o intercambio. Por este motivo, me inclino a considerar a los procesos comunicativos en tanto procesos interactivos que incluyen formas de codificación, decodificación, e interpretación, tanto como intereses e intenciones. Asimismo, pensar a la comunicación como dialogo, supone también situar las condic iones y características en las que se producen esos encuentros y desencuentros. Washington Uranga habla sobre esa relación de este modo: 
Existen muchas maneras de mirar la historia y nuestra vida cotidiana. Pero podemos asegurar que la historia es esencialmente una trama de relaciones, de vínculos entre personas que ponen en juego sus concepciones, sus intereses y, todo ello, en relación directa a la cuota de poder que cada uno posee. Podemos decir entonces que la historia puede entenderse como un entramado de "gramáticas discursivas", como bien lo señala Jesús Martín-Barbero, (Martin-Barbero, 2002: 234) que se expresa como estrategias comunicativas de los actores y que no se limitan a los formatos mediáticos masivos y comerciales. La comunicación es diálogo, la comunicación es relación. Diálogo y relación están en la base de cualquier definición que se intente sobre la comunicación. Esta perspectiva dialogal y relacional nos proyecta de manera inmediata a la sociedad, a los espacios donde se construyen los vínculos sociales y a sus modos de organización. (Uranga, 2012:4-5)

En este sentido, si nos pensamos en los discursos construidos sobre las experiencias generacionales subalternas, la idea de que la obturación de la interacción dialógica se produce por falta de comprensión, resulta ser la forma argumental utilizada con mayor asiduidad para justificar estrategias de imposición de relatos dominantes. Lenguaje, experiencia y capacidad de raciocinio, son las tres dimensiones predominantes para su expansión, mientras que su forma de resolución por predilección es la apelación, a modo de profecía, a la transformación de los lugares ocupados como garantía de legitimidad respecto del poder de ver (Haraway, 1995). La explicación es explíc ita: cuando seas adultx, vas a entender lo que te digo.

Sin embargo, para el análisis de estas relaciones, no hay que perder de vista que estos diálogos interge neracionales, sin duda, se encuentran afectados por aquello que plantea Jesús Martín Barbero acerca de que no podemos intentar reproducir las formas comunicativas conocidas sin más, puesto que se trata de una experiencia cultural nueva, o como W. Benjamin lo llamó, un sensorium nuevo, unos nuevos modos de percibir y de sentir, de oír y de ver, que en muchos aspectos choca y rompe con el sensorium de los adultos (Barbero, 2002:4). Justamente es Walter Benjamin quien advierte que aproximarse a lo que la palabra encierra es casi imposible, sobre todo en aquellos espacios del lenguaje y de la experiencia que se instalan en un sentido doble el de lxs niñxs y el de lxs adultxs-, y que participan de una forma de conflictividad que se debate entre la profanación y la dilución (Benjamin 1982).

La necesidad de trasgresión se impone como modo de agenciamiento imprescindible para irrumpir en los procesos de totalización simbólica y material, desorganizando nuestros marcos de percepción y acción. Estos movimientos pueden ser leídos en consonancia con lo que plantea Giorgio Agamben acerca de que: 
Si pensamos en el proceso de sacralización de algunos elementos de nuestra sociedad, llegaremos a la conclusión de que este consiste en su sustracción del uso común, no importa lo que sea, personas, lugares, cosas, prácticas; lo que importa es que algo del mundo 'humano' queda por fuera del uso común, y pasa a formar parte de la esfera de lo sagrado. El objetivo de la profanación, entonces, debe verse como una recuperación, una restauración de cosas al uso libre, no regulado ni convertido en un elemento de castigo o redención. Pero atañe también a esta separación entre los dos mundos, una negligencia necesaria con unas fronteras que, como suele suceder, dicen separar a los humanos de los dioses, pero en realidad solo separan a unos humanos de otros (Agamben, 2005,104).

En el universo de las experiencias adultas, debemos reconocer además que, lo que configura lo sagrado, aunque potente, presente y directivo, permanece aún en la dimensión de lo que sobrevuela pero no se nombra, y que se asemeja mucho al poder que le reservamos a la fe. Lo sacrílego y lo profano emergen, en este marco, como alternativas para devolver al plano de lo mortal y perenne, lo que aparece como superior, incuestionable y dado. Mientras que lo sacríle go habla de todo lo que infringe o se contradice a lo sagrado, lo profano se ocupa de devolver al orden de lo común, libre y compartido, a aquello que había permanecido separado y jerarquizado. Las profanac iones resultan necesarias, entonces, para habitar lo común.

Así, la posibilidad de transicionar generacionalmente otrxs implica una serie de sacrilegios y profanaciones que, de todas maneras, disputan territorios oscilantes de legitimidad y valor. Es importante pensar este movimiento atendiendo a la dimensión temporal de lo generacional, puesto que ello nos condiciona, en estos órdenes, a una imprescindible transformación material y posicional, es decir que, lo sagrado y lo profano no necesariamente acontecen como opuestos, sino que tienen la potencia de conformar una misma experienc ia de mundo. Por este motivo, es necesario repensar los modos en que algunas profanaciones son reconvertidas en consagraciones, siendo reencausadas nuevamente en discursos y experienc ias esperables del devenir.

Para dar cuenta de estos movimientos de reconversión, Giorgio Agamben (2005) introduce la noción de secularización, explicando que secularización y profanación son dos operaciones políticas en puja, puesto que, al mismo tiempo en que la primera encausa las relaciones de poder, adecuando los modelos interpretativos a partir de incorporaciones que permiten mantener lo sagrado como referencial, la segunda desactiva los dispositivos de poder que segmentan y diferencian, proponiendo una ruptura de los sistemas de religiosidad mismos. La edad como constructo resulta ser un 
elemento central en los procesos de secularización, puesto que ello ensancha las barreras de la incorporación discursiva sobre la premisa de proximidad cronológica.

Algunas perspectivas como las de participación y/o protagonismo infantil tocan las lindes de lo sacrílego y profano, dejando entrever lo que es permeable, lo que persiste vedado, y lo que resiste. De allí la oportunidad para visualizar, en esas disputas, los procesos de secularización, que usualmente advertimos bajo la lógica de la habilitación para la realización de ciertas prácticas y/o la participación en espacios, pero que se han instala do, sobre todo, en los modos en que sujetos y experiencias son nombrados. Si nos detenemos sobre esta afirmación, las lógicas de adecuación, regulación y progresividad, recorren casi todas nuestras percepciones respecto de los modos legítimos de experienciar el mundo cuando habitamos generaciones subalternas.

He aquí un laberinto en el que es muy fácil quedar entrampadxs, ya que hemos de comprender que, al mismo tiempo en que las disputas de lenguaje, participación y reconoc imiento de niñxs y jóvenes, tuvieron $-\mathrm{y}$ tienen- un origen profa no, no todas ellas han logrado desestructurar las relaciones de poder conocidas, e incluso muchas, han operado reforzando formas de valoración y jerarquización. Es decir, todavía se sostienen prácticas aberrantes utilizando como justificativo principios de protección, reconocimiento y derecho. Por eso se vuelve necesario distinguir el enfoque de DDHH de las cristalizaciones y nominaciones de sentido producidas a partir de él, puesto que fijación y disputa tienen la capacidad de asentarse en dos órdenes diferenciales -y no necesariamente complementarios- de anális is, respondiendo a intereses múltiples.

Diviso en esta experiencia opaca que los sistemas de vigilancia han de redoblarse, y observo en el cuestionamiento del privilegio adulto uno de los muchos modos posibles para avistar tácticas de desacralización. Me valgo para ello de una serie de teorizaciones y propuestas que persisten en la necesidad de desorganizar las estructuras generacionales que conocemos, no con una expectativa de equiparación o inversión, sino como apuesta a deconstruir y disolver lo conocido, fugando nuestro pensamiento para darle oportunidad a lo que aún no ha sido producido pero que existe como potencia. Sobre esa aspiración habla Walter Benjamin cuando propone esta reflexión:

... se ha descrito muchas veces lo 'deja vu'. No sé si el término está bien escogido. No habría que hablar mejor de sucesos que nos afectan como el eco, cuya resonancia, que lo provoca, parece haber surgido, en algún momento de la sombra de la vida pasada? [...] Es curioso que no se haya tratado todavía de descubrir la contrafigura de esa abstracción, es decir, el choque con el que una palabra nos deja confusos, como una prenda 
olvidada en nuestra habitación. De la misma manera en que ésta nos impulsa a sacar conclusiones respecto a la desconocida, hay personas o pausas que nos hacen sacar conclusiones respecto a la persona invisible: me refiero al futuro que se dejó olvidado en nuestra casa (Benjamin, 1982:129)

Al trastocar la relación pretendidamente inmóvil entre espacio, tiempo y experiencia corporal, ese autor propone un pensamiento anclado en la simultaneidad y la copresencia (Benjamin, 2006), argumentando que así cómo es posible pensar en la existencia de espacios múltiples, también deberíamos poder comprender la ocurrencia de tiempos múltiples, no solo en sucesión o secuencialidad, sino, fundamentalmente, en coexistencia. De esta misma posibilidad habla Janusz Korczak (2008) cuando hipotetiza sobre la posibilidad, en el orden de la experiencia, de habitar más de una generación, sin que ello acontezca como problemático o imposible. En este caso, la alternancia y el movimiento aparecen como fundamento de la experiencia múltiple. Ambos pensamientos comparten la necesidad de concebir al cuerpo como una potencia que no se agota en su materialidad, y en la importancia de cuestionar las formas conocidas de conformación de lo inmanente o identitario de los sujetos, poniendo en entrevero la relación entre delimitac ión y disolución.

Estos desarrollos también se encuentran en la necesidad de cuestionar aquello que se impone como movimiento único de la experiencia corporal-temporal, y en el mismo sentido en que Benjamin propone atacar esa compacidad desde objetos, sujetos, relaciones, nociones o conceptos que se convierten en posiciones privilegiadas desde donde objetarle a la realidad su incongruencia, su caducidad, su contingencia, su poder ser de otro modo, así como la arbitrariedad de sus modos de aparecer (Lanfranconi, 2017:26), Korczak insiste en que sea usted mismo, busque su propio camino. Conózcase a sí mismo antes de querer conocer a los niños. Comprenda de lo que es capaz antes de comenzar a delinear sus derechos y responsabilidades (Korczak, 2008:8).

Gilles Deleuze y Félix Guattari permiten complejizar este análisis cuando mencionan que:

En cierto sentido, hay que empezar por el final: todos los devenires son ya moleculares. Pues devenir no es imitar a algo o a alguien, no es identificarse con él, tampoco es proporcionar relaciones formales. Ninguna de esas dos figuras de analogía conviene al devenir, ni la imitación de un sujeto, ni la proporcionalidad de una forma. Devenir es, 
a partir de las formas que se tiene, del sujeto que se es, de los órganos que se posee o de las funciones que se desempeña, extraer partículas, entre las que se instauran relaciones de movimiento y de reposo, de velocidad y de próximas lentitud, las más a lo que se está deviniendo, y gracias a las cuales se deviene. En ese sentido, el devenir es el proceso del deseo. Ese principio de proximidad o de aproximación es muy particular, y no reintroduce ninguna analogía. Indica lo más rigurosamente posible una zona de entorno o de copresencia de una partícula, el movimiento que adquiere cualquier partícula cuando entra en esa zona (Deleuze y Guattari, 1985:275).

Para ellos, las determinaciones temporales-espaciales no dan cuenta de un predicado o una condición, sino que son dimensiones posibles de la multiplicidad. De este modo, lxs niñxs no devienen adultxs, aunque ser niñxs es un devenir-joven de cada edad. En este escenario, no es posible presuponer atributos o caracteres a un sujeto-cuerpo sin conocer su potencia, o sin observar sus afectaciones en vinculación a las afectaciones de $-\mathrm{y}$ conotros cuerpos, ya sea para oponerse en relaciones de dominio o destrucción, para intercambiar, y/o para componer cuerpos más potentes. En cualquier caso, niñerear no habla de impostar una posición otra o de representarse simbólicamente una figuramolde, sino de las fugas posibles en los modos de devenir otrxs.

En concordancia con estas operaciones, Fernand Deligny (1967) propone atender no ya a la trama, sino al tramar, pues allí lo simultáneo acontece no como producción o producto, sino como una forma de existencia que procura un modo de ser inespecífico y en red. Establece así la necesidad de un pensamiento arácnido, que es un pensamiento abierto y en permanente movimiento, explicitando que, aunque se diferencia del reino animal en su posibilidad de producción colectiva, conserva de su origen la multiplicidad de modos de tejer. Asimismo, la confección de una trama implica un proceso de dilución, no necesariamente en la reconversión de una materialidad a otra, sino más bien, en un proceso de asimilación y proyección.

Las posibilidades de la red no transitan sobre alternativas únicas, puesto que sus soportes pueden desaparecer en la misma medida en que pueden institucionalizarse, y por ello resulta importante atender a lo que aparece como brecha y/o falla. Así, lo arácnido se construye en -y con- los huecos que el tramar produce, y por eso Deligny se pregunta: Si gracias a esta práctica de trazar los trayectos aparece lo arácnido de las lineas de errancia, que son los trazos de los trayectos de los pibes cuyo proyecto se nos escapa, ¿vamos a ser capaces de respetar como corresponde esa vecindad? (Deligny, 1967: 45). 
Podemos acordar que, todas estas posiciones participan de la idea de que es impresc indible suspender analíticamente aquello que delimita o conforma, para pensar en los puntos de contacto y confluencia nacidos de afectaciones, tramares $\mathrm{y}$ movimientos, que no pueden ser cercados -en la materialidad de un cuerpo- en su potencia y devenir. Fernand Deligny lo reflexiona así:

¿Dónde está el autor en todas estas maniobras? Desaparece, borrado como se borra la idea de que el arte es representar. Me atrevería a decir que se trata de exponer, lo cual a menudo es cierto, ¿pero que hay entonces de la música? Se trataría más bien de acordar, palabra que no sabemos muy bien si se origina en corazón o en cuerda. Pero entonces acordar tendría que significar crear un acorde, y no un consentimiento, una conformidad, sino más bien una discordancia desde la cual van a vibrar relaciones de frecuencia (Deligny, 1967:155)

Por ello, la intención de profanar el pensamiento generacional, se sostiene sobre la posibilidad de crear discordancias que repongan en lo simultáne o y múltiple de aquello que nos constituye molecularmente, tramando sobre las operaciones posibles del devenir.

\section{Sum ario del Capítulo: Obra negra}

Este Capítulo pone el foco en eso que constituye lo subterráneo de todo proceso de construcción, y que no puede ser limitado a un conjunto de materia les y procedimientos, sino que más bien habla acerca de las condiciones necesarias para que ciertas producciones se establezcan, de los territorios donde ello es posible, y de los insumos sobre los que se construyen sus bases o cimientos. También da cuenta de las excavaciones realizadas, y de los procedimientos necesarios para avanzar en la excavación.

En este sentido, sostuve un interés particular por explicitar las condiciones en vinculación con las cuales considero que se crean marcos perceptivos y materiales a partir de los que construimos nuestras nociones sobre lo generacional, en ge neral, y sobre lo adulto, en particular. Entiendo que ello no es comprensible por fuera del anális is del modelo adultocéntrico concibiéndolo como sistema que se articula sobre la imposición del dominio, y por ello desarrollé aspectos que hablan sobre su sistematicidad, interés y direccionalidad.

Un elemento fuerza que acompaña esta narrativa es la percepción respecto de que 'lo adulto' -además de quienes material y posicionalmente ocupamos el lugar de adultxs-, 
actúa como principio regente de las formas de organización socio-política que conocemos, colocando a una serie de sujetos, percepciones, trayectorias, posiciones y modos de vinculación intergeneracional, en el orden de lo 'ya dado'. Estas relaciones de poder han de leerse en clave macropolítica (Preciado, 2021), ya que no se trata de una afectación únicamente en el orden del discurso, sino que también da cuenta de los modos en los que nuestros cuerpos son producidos.

Sin embargo, no hablamos de una relación única, sino de una constelación o conjunto de sistemas de poder y dominación que constituyen y moldean nuestra experiencia vital. Entendiendo esta complejidad me he valido de las perspectivas sobre interseccionalidad tanto para el anális is de estas formas de organización del poder, como para comprender la simultaneidad en las que el ejercicio del privilegio y la experienc ia de la desigualdad se articulan en trayectorias no excluyentes. Asimismo, considero que dentro de esta constelación de poderes, la relación entre adultocentrismo y patriarcado merece ser singularizada y complejizada, en tanto ambos sistemas se estructuran en torno a la utilización de datos de la biología humana y de la producción de corporalidades específicas, para crear modelos de dominio y subordinación amparados en cualidades innatas e ina movibles de ciertos sujetos.

Ahora bien, para que la generación de un tipo de sujetos sea efectiva no solo en su dimensión productiva, sino fundamentalmente, en su condición de reproducción, resulta imprescindible organizar formas de ser de acuerdo con la condición generacional asignada, homologando las adulteces hegemónicas a las adulteces deseadas. Sobre esta condición se crean los mandatos de la adultez y se refuerzan los microadultismos que resitúan a lxs adultxs en las trayectorias diferencia les.

Este Capitulo habla además sobre las asociaciones ilícitas que produce nuestro pensamiento generacional, comprendie ndo que el amalgama y homologación de ciertas nociones, la indiferenciación de características materiales y condiciones de valor socioproducidas, y la fijación de relaciones sobre parámetros de lo natural, refuerzan la producción diferencial de cuerpos y posiciones, reafirmando sistemas que se amparan en la desigualdad como condic ión ineludible. Por ello es que insisto al afirmar que las cualidades o características que poseen los sujetos en vinculación con sus experiencias corporales y sus posiciones de mundo deberían sernos indiferentes, si ello no se encontrara afectado por sistemas de separación, valoración y jerarquización que producen experiencias de la desigualdad concretas. 
He partido de considerar que edad y generación son nociones performativas que producen cuerpos y significados, es decir, entiendo que la adultez no es una condición temporal e irrenunciable de ciertos sujetos, sino más bien, una forma de producción performativa tanto de nuestras trayectorias, percepciones y posiciones, como de nuestros cuerpos mismos. En este marco, recupero los aportes de Agamben para analizar las construcciones comunicacionales y de sentido asociadas a lo generacional, a partir de establecer similitudes y distancias con su anális is respecto de los procesos de profanación, trabajando fuertemente sobre la concepción de secularización.

Consecuentemente, también desarrollo el modo en que este anális is se vincula con el pensamiento Benjaminiano que promueve la construcción de teorizaciones recuperando las concepciones de simultaneidad y copresencia, advirtiendo que se trata de un pensamiento que insiste en la necesidad de desestructurar las relaciones de poder existentes. Enlazo este análisis a las propuestas desarrolladas por Janusz Korczak, quien explora las posibilidades de habitar generaciones múltiples, y despliega una serie de propuestas y experiencias que cuestionan los modelos adultos conocidos. También me valgo de los planteos de Gilles Deleuze, Félix Guattari, y Fernand Deligny, para rastrear las potencias que otorgan las perspectivas que trabajan sobre el devenir y el tramar como mode los de comprensión e interpretación de eso que aparece como otro. 


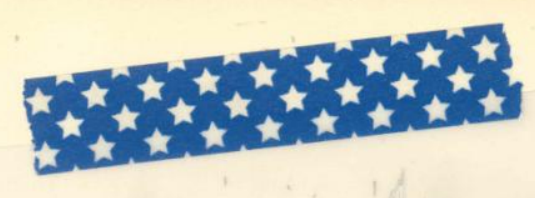

\section{CONSERVE}

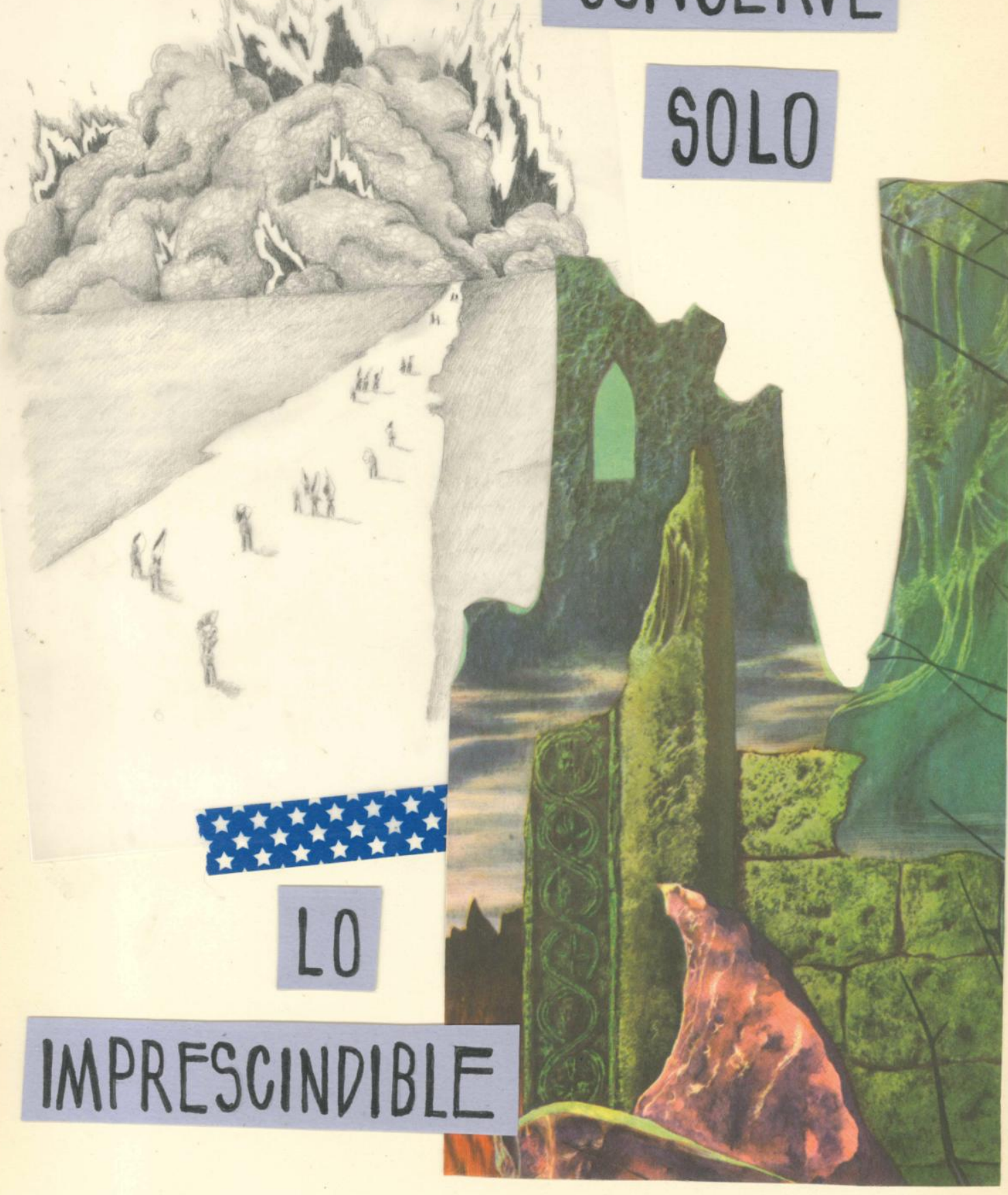




\section{Capítulo III: Zona Franca}

No siempre es fácil determinar si lo que nos amenaza tiene más influencia sobre nosotros que lo que nos seduce.

La propia naturaleza de esas dos cosas a veces no es contrapuesta sino casi indistinguible.

República Luminosa Andrés Barba

Hacer algún tipo de cálculo para establecer la distancia óptima con el observable es, a esta altura, un sinsentido. Aún así, entender los vínculos de proximidad e implicación, tampoco equivale a relativizar todas las ópticas de visión o a tildar de intrascendentes los mecanismos de visualización. A mitad de camino entre ambos enfoques, la necesidad de crear conocimientos situados emerge nuevamente como una alternativa que repara en la importancia de la rigurosidad para la construcción de posiciones ética y políticamente comprometidas.

Encontrar lo común en un territorio que es propio, implica, entre otras cosas, un movimiento continuo de aproximación y distanciamiento. Es decir, al mismo tiempo en que la proximidad permite divisar eso que no es explícito o localizable, y que aparece en el orden de lo percibido, sospechado y sentido, y/o de lo transmisible a partir de ejemplos o experiencias compartidas, la separación se vuelve imprescindible para recuperar perspectiva e incorporar aquello que fue ignora do o minimizado por la propia posición en el espacio. Construir un instrumento -en este caso, un formulario digitalque contemplara ambas necesidades fue dificultoso, puesto que apostar a la profundidad de las respuestas, evitando la conductividad en las preguntas, implicó pruebas y revisiones de las que participaron agentes diversos. En este mismo sentido, proponer una interlocución no directa, fue una estrategia de vigilancia para favorecer la obtención de respuestas más honestas y desprejuiciadas, reconfigurando las lógicas del distanciamiento en la apuesta por construir otros modos de proximidad.

La idea sobre la que se sustentó esta propuesta de indagación fue originada por un ensayo que, hace algún tiempo, me propuso una niña en una entrevista. Ella lo explicaba de esta manera: cuando estoy enojada y no sé si algo está mal o es que solamente me molesta porque lo dice alguien, cierro los ojos y cambio a la persona de lugar. Ponele, vos me decís algo que me hace re calentar, cierro los ojos, y me la imagino a Juli diciendo lo mismo. Si todavía me sigue molestando, es porque tengo razón. Casi 
siempre funciona, porque así podes ver lo raro, y también te podes dar cuenta cuando sos vos la que está mal. Por tanto, el cuestionario sobre el que se realiza el anális is buscó replicar, recuperando la sugerencia de esa niña, el movimiento de abrir, cerrar, y volver a abrir, intentando descubrir si lo que aparecía en ese segundo tiempo se acercaba, al menos parcialmente, a mis supuestos y sospechas acerca de los modos de sentirse y percibirse de ciertos sujetos en el espacio social.

Las preguntas que estructuraron la indagación se dividieron en dos grandes grupos: 1) un conjunto de interrogantes dirigidos a conocer las trayectorias, percepciones y posiciones acerca de la experiencia que ciertxs adultxs tienen sobre si mísmxs en el espacio social, y, 2) un conjunto de interrogantes sobre las experiencias, creencias y consideraciones que esxs mismxs adultxs poseen sobre el vínculo que construyen con niñxs y jóvenes en sus espacios socio-ocupacionales. Todas ellas fueron orga nizadas en torno a una misma inquietud cognitiva: ¿Cómo se construye la noción de lo adulto y cuáles son las afectaciones que esto provoca en las formas de construcción de vínculos intergeneracionales?

\section{Universo}

La encuesta fue completada por 155 personas que son y/o se perciben a sí mismas como adultas, y que desarrollan prácticas vinculadas a niñxs y jóvenes dentro del SPPDNNA. Si bien tuvo carácter anónimo, se solicitó a lxs participantes que dieran cuenta de algunos aspectos que ayudaran a comprender, a grandes rasgos, el tipo de población alcanzada. Contemplando la multi-opción como alternativa -atendiendo a las condiciones de pluriempleo-, fue posible conocer que la mayoría de estas personas desempeñan actividades en el sector público (82\%), mientras que, en menor proporción, la muestra también se compuso por actores y actrices de organismos privados (10\%), y de ONG's y Movimientos Sociales (8\%). Del total de encuestadxs tan solo el 16\% ocupa lugares jerárquicos en alguno de estos espacios.

Un dato de relevancia fue el alto índice de feminización de la población que constituye el universo de análisis y que se corresponde con el elevado nivel de feminización de las actividades vinculadas al acompañamiento y asistencia de niñxs y jóvenes en general. Hemos de convenir que, la feminización, no solo afecta a la dimensión doméstica del cuidado sino que permea los espacios laborales que se encargan de actividades asociadas a la asistencia y acompañamiento, tanto en la vinculación entre tareas y 
clivajes de género, como en la remuneración diferencial y/o en la asignación de tareas no pagas -que son presentadas como una condición inherente al desarrollo de ciertas funciones-. En este caso en particular, quienes se perciben mujeres representan el $81 \%$ de la muestra, mientras que el 4\% no se identifica con ningún género, $1 \%$ son lesbianas, $0,6 \%$ Queer, y $13,4 \%$ varones.

Respecto de las actividades que realizan en vinculación con niñxs y jóvenes, un grupo mayoritario estuvo integrado por personas que desempeñan actividades de promoción y protección de derechos (29\%), y de asistencia y acompañamiento (34\%). Las actividades educativas y docentes ocuparon el tercer lugar (14\%), mientras que aque llas vinculadas al acceso a la justicia se situaron cuartas (7\%). En un rango menor, pero en números relativamente equivalentes entre sí, se ubicaron actividades lúdicas, recreativas y deportivas (4\%), de alojamiento y convivencia (3\%), de investigación (5\%), y de participación, militancia y/o activismo $(3,7 \%)$. Las tareas vinculadas a la promoción y gestión fueron prácticamente inexistentes, representando tan solo el $0,3 \%$.

Cabe destacar que esta pregunta también fue considerada de opción múltiple, entendiendo que lxs agentes de este campo frecuentemente realizan tareas diferenciales, no solo respecto de la diversidad de empleos, sino, también, en el desarrollo de una misma función.

\section{Percibirnos adultxs}

Algunos años atrás, en el acompañamiento de la situación de una joven, yo me sentí perpleja al enterarme un aspecto absolutamente relevante de su historia que había sido falseado por ella misma a modo de resistencia, y sobre el que se habían pensado innumerables -y equivocas- estrategias de trabajo. Intentando evitar las opiniones que reforzaban la idea de que esta piba es terrible, decidí preguntarle cómo había conseguido burlar tan sistemática y eficazmente al Sistema. Sobre su respuesta, en el registro de mi entrevista anoté: Hay algunas preguntas que la gente que te atiende no te quiere hacer, porque les da lo mismo o porque les da vergüenza que ya te lo hayan preguntado mucho. En ese momento si vos aprovechas y les haces creer que ya se los contaste y son ellos los que no se acuerdan o que es algo obvio y bardeas un poco porque te preguntan siempre lo mismo, entonces no necesitas decir nada más. Yo escuché cuando decían que faltaba mi legajo que es algo que nunca me quisieron 
contar, entonces después cada vez que me preguntaban yo les decía que ya lo había dicho y que se fijaran en mi legajo.

En ese momento aprendí que la pregunta sobre lo que presuponemos es una pregunta impresc indible, no cuando ello acontece con intención de reiteración, de constatación o de evaluación, sino cuando aquello que es presupuesto como conocido es una estructura sobre las que nos posicionamos antes de llegar al encuentro más que una resultante del intercambio. Bucear en los lugares obvios y repreguntar lo conocido por todxs, fue, entonces, el puntapié inicial para indagar en aquello que creemos que concierne a lo inherente e identitario de las experiencias adultas. En este caso, poner el acento en el punto en que la frontera se ha constituido -dividiendo aquello que es adulto de lo que no lo es-, tuvo por objetivo conocer las apreciaciones respecto de las cuales nuestra posición de mundo se transforma, permitiéndonos transicionar a otra generación.

Así, el énfasis estuvo puesto en aquello que habla de las percepciones, observables en la adscripción a la adultez como producción posicional más que como devenir de la experiencia corporal, intentando diluir marcaciones materiales para centrar el interés en aquellos procesos por los cuales consideramos que nuestra experiencia de mundo se ha constituido generacionalmente. Jorge Huergo repara en la importancia que esto tiene para los procesos comunicacionales mencionando que:

Si trabajamos en procesos comunicacionales, necesitamos considerar al otro como un interlocutor (alguien que no es mero "destinatario" de nuestras propuestas, sino alguien que es capaz de pronunciar su palabra y de comunicarse de diferentes modos): necesitamos conocerlo sistemáticamente, metódicamente. $\mathrm{Si}$ los otros son nuestros interlocutores, para generar procesos y desarrollar proyectos de comunicación con ellos (o en sus ámbitos) necesitamos reconocer sus "marcos de referencia": las relaciones directas de la población, las concepciones, valoraciones, estereotipos, expectativas y creencias que a diario comparten los distintos actores y sectores de una comunidad. (Huergo, 2001: s/p)

En este marco, ¿Desde cuándo usted se considera adulta/o? fue la pregunta que inauguró el cuestionario. Por una cuestión del orden de lo metodológico -enfocada fundamentalmente en la sistematización sobre una base de parámetros equivalentes-, se propusieron una serie de alternativas, dejando abierta la posibilidad a construir otras explicaciones o re latos en caso de que lo contemplado no fuera descriptivo de la propia trayectoria. Asimismo, evitando sesgar las respuestas con valoraciones univocas, lxs encuestadxs podían señalar la cantidad de opciones por las que se sintieran 
representadxs. De este modo, se obtuvieron 318 respuestas, dando cuenta de que la mayoría de las personas consideró necesario recurrir a la articulación de más de un núc leo explicativo-discursivo para situar el origen de su adultez. Esto nos coloca frente a la idea de que existe una percepción multi-causal sobre la génes is, contribuyendo a la creencia de que la adultez no es la resultante de una marca biológica, sino que ella se ubica en el orden de la producción de sentido, incluso cuando esto no sea nominado de ese modo.

Si observamos la Figura 1, podremos divisar que la opción que repuso el inicio de la adultez Desde que toma decisiones con libertad, realiza elecciones de forma autónoma, y asume por sí mismo/a compromisos y responsabilidades, fue la más utilizada por lxs participantes como descriptor, siendo una alternativa representativa para el $62 \%$ de la población. He de destacar que esta premisa fue construida sobre una narrativa que destacaba las tres nociones fuerza asociadas a la adultez: libertad, autonomía y responsabilidad, por lo que, esta marca experimental, contribuye en el análisis de los modos en que algunas nociones hegemónicas son percibidas como condiciones inherentes a ciertas generaciones, convirtiéndose, en muchos casos, en el sustento de creencias, mandatos y microadultismos.

Las alternativas que siguieron en rango a esa afirmación fueron: Desde que obtuvo independencia económica de otras personas (38,7\%), Desde que estableció proyectos/necesidades/deseos diferentes de los de su familia y/o grupo de origen (29, 7\%), y Desde que dejó de convivir con su familia de origen y/o cambió su centro de vida (26,5\%). Así, la percepción -material o simbólica- de separación del grupo originario y/o de independencia respecto de otrxs, también se convirtió en una marca de relevancia al momento de pensar el inicio de la experiencia adulta, en consonancia con aquello que menciona Bauman (2007) respecto de que toda estructuración de frontera requiere de la construcción de parámetros de diferencialidad capaces de generar distinciones entre producciones generacionales de mundo.

Por el contrario, hubo una serie de opciones que ocuparon lugares minoritarios, entre las que se destacaron aquellas que daban cuenta de la realización de las tareas de cuidado tanto con ascendientes como con descendientes-, y que fueron seleccionadas tan solo por el $12 \%$ de la población. Esto es muy interesante, ya que a pesar de que la idea de que lxs adultxs nos hacemos cargo de todo permea frecuentemente nuestros discursos y prácticas, la asociación entre inicio de la adultez y desarrollo de tareas de cuidado y crianza no fue particularmente significativa en el anális is de las trayectorias propias. La 
ocurrencia de eventos sociales y/o hechos significativos tampoco apareció como elemento de relevancia (4.5\%), incluso cuando varias de las observaciones hechas por quienes incorporaron marcadores propios refirieron a estos procesos. Asimismo, 12 participantes $(7,7 \%)$ aseveraron que no podían describir el inicio de su adultez a partir de hechos o procesos de relevancia.

\section{(Figura 1)}

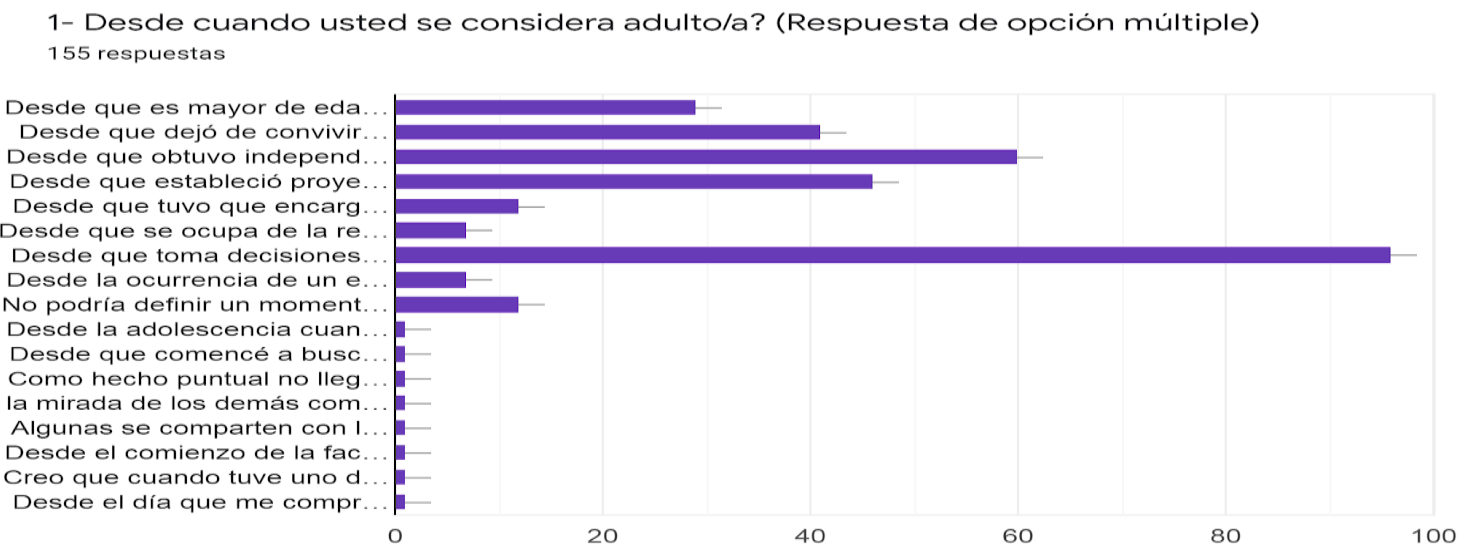

Por su parte, la opción Desde que es mayor de edad legalmente -que se ubicó quinta en orden de elección- requiere de un anális is particular y combinado, considerando su peso material y simbólico. En este caso, solo 1 de cada 5 encuestadxs (18,7\% del total) marcaron como significativa la mayoría de edad para situar su transición generacional, incluso cuando esa condición supone marcos de habilitación y censura para la población con la que trabajan. Es decir, que si bien la condición etaria asociada a los marcos normativos y legales aparece como idea fuerza en las localizaciones que hablan sobre las trayectorias de niñxs y jóvenes, la utilización del mismo sistema de medición resulta relativa al momento de pensar la adultez. Así, las trayectorias propias desmienten empíricamente la presunción etapista de las generaciones en vinculación directa con agrupac iones o estamentos etarios.

En correspondencia con esto, se solicitó a lxs encuestadxs que respondieran qué edad aproximada tenían cuando estos hechos o procesos acontecieron, intentando hacer un camino inverso a nuestro sentido común según el cual, frecuentemente, ubicamos primero la razón numérica para luego dar cuenta de algún tipo de capacidad o condición. En un rango que va de 13 a 36, lxs encuestadxs dieron cuenta de una asombrosa diversidad de trayectorias (ver figura 2). Si bien los 18 años ocuparon el 
segundo lugar como marca numérica, su incidencia en el total de respuestas fue incluso menor que en la pregunta anterior (13\%). Estas respuestas, además, nos alientan a pensar que cuando las trayectorias vitales son situadas, es posible desandar las fijaciones que establecen relaciones direccionadas y uni-causales entre edad, generación y capacidad.

(Figura 2)

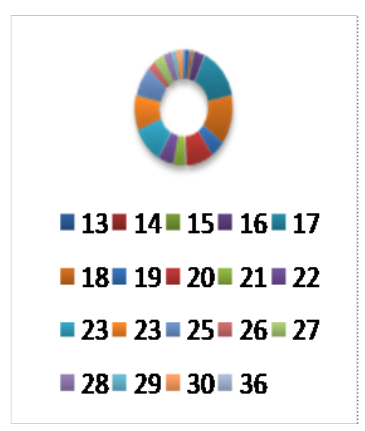

Si hacemos este ejercicio a partir de un ejemplo práctico vemos que: en la primera pregunta la opción Desde que toma decisiones con libertad, realiza elecciones de forma autónoma, y asume por sí mismo/a compromisos y responsabilidades fue elegida como marca significativa para 96 personas; sin embargo, si quisiéramos agrupar a esta población de acuerdo con la segunda pregunta, ello no podría ser absorbido por una única marca etaria. Aún si esa respuesta se hubiera concentrado mayoritariamente en cierto grupo, sería necesario agrupar rangos extensos como de 13 a 23 años o de 19 a 36 años.

Al liberarnos de algunas presunciones que nos estructuran, en este caso, abriendo a la posibilidad de separar una posición vital de la cronología que a nuestros cuerpos les es asignada con el nacimiento, emerge como potencia la importancia de entender a lo etario y lo generacional como construcciones performativas variables. Si volvemos sobre las respuestas obtenidas, no me encuentro en condiciones de afirmar que -para las personas alcanzadas por la muestra-, la adultez acontezca según una relación temporal fija o estática. Por el contrario, he observado que, al proponer un ejercicio que sitúa experiencias concretas, la adscripción a una generación ha estado vinculada a ciertos fenómenos y/o procesos, en un rango temporal que sibien es restringido, también posee gran amplitud. 
Intentando profundizar en estas percepciones, se solic itó a lxs encuestadxs nombrar tres características que consideraran propias de la adultez. Si bien la respuesta era abierta es decir, no construida en base a opciones-, la mayoría de las argumentaciones fueron coincidentes, enfatizando fuertemente en nociones como responsabilidad, autonomía, libertad e independencia. Muchxs pusieron el eje en aspectos tales como la posibilidad de tomar decisiones respecto de sí mismxs y de otrxs, obtener más y mejores experiencia y saberes, contar con más conocimientos, asumir compromisos, trabajar y percibir un salario. Interesantemente, varixs utilizaron el modismo hacer lo que quiero con... para referirse a la posibilidad de decidir y elegir con autonomía y/o libertad sobre asuntos puntuales. Como contracara de ello, minoritariamente, hubo quienes describieron a la adultez como tediosa, patética, aburrida, acrítica, impune y sin sentido. Este código invisible de ciudadanía adulta aparece fuertemente internalizado, y, a pesar de que lxs adultxs alcanzadxs por la muestra podían elegir las cualidades que quisieran libremente, la similitud en las respuestas también habla sobre ese sentido compartido fuertemente arraigado, que enuncia posiciones al mismo tiempo en que da cuenta de cómo se edifican mandatos. Así, por ejemplo, el 63\% de la población consideró a la noción de responsabilidad como descriptor predominante, mientras que las opciones que siguieron en rango de elección fueron independencia (32\%), autonomía (27\%) y libertad (25\%). Respecto de las cualidades que podríamos nominar como restrictivas, la idea de obligación es la única que ocupó un lugar significativo (18\%), y si bien se sitúo por debajo de las antes mencionadas, con frecuencia fue utilizada en forma complementaria a los descriptores libertad y responsabilidad.

\section{Hablar de privilegios}

A pesar de que, progresivamente, la concepción de desigualdad en los vínculos intergeneracionales ha ganado visibilidad a partir de las perspectivas de derechos y de participación o protagonismo infantil, aún hablamos más de aquello que niñxs y jóvenes deben ganar y legitimar, mientras que lo que lxs adultxs deberíamos perder o reconfigurar, cuando emerge, es enunciado como secundario o anexo. En este marco, el poder que requiere ser deconstruido o diluido suele aparecernos como difuso, considerando que su enraizamiento en las formas de organización del lazo hace que no nos observemos a nosotrxs mismxs como detentorxs de privilegio y/o que percibamos esa diferencia como condición inevitable del vínculo. 
Con ese argumento, realicé una serie de preguntas que buscaban conocer los modos de percibir y significar esas trayectorias diferenciales. La primera de ellas interrogaba de forma directa a lxs participantes acerca de si se consideran en una situación ventajosa respecto de otrxs (Ver figura 3), mientras que las que le siguieron, por el contrario, preguntaron por sus experiencias y trayectorias respecto de acciones o procesos que ocurren de modo diferencial y/o que frecuentemente acontecen como experiencias de clausura o condicionamiento para niñxs y jóvenes. La articulación de las preguntas no tuvo como objetivo tender una trampa a lxs encuestadxs sobre sus propias respuestas, sino, que, por el contrario, lo que intentaba conocer es cuan arraigadas se encuentran algunas condiciones de diferencialidad en las trayectorias de lxs agentes: sin que esto sea necesariamente percibido como una forma de ejerc ic io de la desigualdad.

(Figura 3)

4- Alguna vez sintió que lo trataban de forma privilegiada o ventajosa por ser adulta/o? 155 respuestas

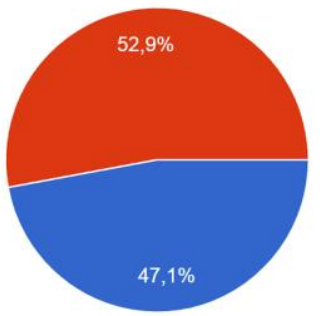

Ni

Al preguntar de forma directa respecto del uso de privilegios, solo la mitad de lxs encuestadxs admitió haber transitado por situaciones en las que su posición y/o corporalidad le otorgara algún tipo de primacía sobre otrxs. Que es otra manera para decir que uno de cada dos adultxs que trabaja con niñxs y jóvenes no se percibe, a priori, reafirmando y/o reproduciendo trayectorias de la desigualdad. Este dato ha sido para mí un hallazgo, puesto que si bien da cuenta de aquello que motiva el anális is general y que reafirma la hipótesis sobre la que se estructuró esta indagación, noté, al ver los resultados del muestreo, que al diagramar esa pregunta yo portaba un presupuesto de relevanc ia que no había sido puesto en juego. En este caso, asociado a la creencia de que el vínculo directo con niñxs y jóvenes necesariamente nos devuelve interrogantes acerca de nuestras formas de transitar el mundo: y que por ello estimaba que serían menos lxs adultxs que, trabajando con esa población, nunca se hubieran percibido en una situación ventajosa. Por el contrario, antes de iniciar el cuestionario, me inclinaba a pensar que existía una percepción mayor respecto de la utilización de 
prerrogativas, pero que estxs agentes no consideraban posible o necesario su cuestionamiento.

Al reflexionar sobre esta omisión visualicé que, como parte de mis propias consideraciones respecto del modo en que acontecen ciertas relaciones, aún me permea la resistencia a considerar que, frente a hechos y fenómenos en los que se evidencian condiciones claras de diferencialidad, algunxs adultxs pueden no percibir ciertas experiencias como productoras de desigualdad. En este sentido, entiendo que la importancia de romper los pactos adultos y/o encontrar fugas a estas experiencias, requiere necesariamente de ejercicios de visualización.

Por el contrario, a lxs entrevistadxs que habían respondido afirmativame nte sobre el uso de privilegios, les pregunté respecto de cómo resolvían esas situaciones en las que se encontraban involucradxs y sobre las que advertían poseer posiciones de ventaja y/o condición de privilegio. En este marco, si bien se trataba de una respuesta de opción múltiple, la mayoría de las personas argumentaron que Intento ser reflexiva/o y no reproducir situaciones que puedan ser desventajosas para otras/os (63\%), respecto de lo que el 9\% advirtió que Prefiero retirarme de esos espacios y/o dejar de participar de esas situaciones cuando ocurren, mientras que el 30\% consideró que Cuando lo advierto por lo general hago algo por revertir esas situaciones inmediatamente. Algunxs (23\%) enunciaron que aunque intento no formar parte de esas situaciones o de mediar entre las personas, no siempre puedo evitarlo, a diferencia de quienes hacen uso de esas situaciones según mi interés o necesidades (5\%).

En un universo diferente de respuestas podríamos agrupar las de quienes, si bien advierten una situación diferencial, no necesariamente consideran que eso suponga un tipo de desigualdad. Así, respecto del mismo interrogante, el 17\% de las personas señalaron que entiendo que hay una diferencia natural entre adultas/os, niñas/os, y viejas/os, y no por eso me siento en una posición superior o privilegiada en mi vida cotidiana. Un $9 \%$ sostuvo que Por lo general no tengo a priori una valoración positiva o negativa respecto de esos hechos, y suelo darme cuenta con posterioridad, por lo que no desarrollo ninguna acción específica en ese momento, mientras que otro 9\% aseveró que Lo tomo como algo excepcional, no creo que pueda generalizarse como un modo de vínculo sino que depende más de ciertos hechos o situaciones específicas.

De este modo, es posible encontrar en estas respuestas dos elementos de distinto orden, pero igualmente relevantes: por un lado, respecto de quienes asumen algún tipo de incomodidad en esas trayectorias diferenciales, se advierten diversas estrategias de 
vigilancia (muchas de las cuales se encuentran, tal vez, más asociadas a la reflexión, el dialogo o a evitar la participación en ciertos espacios, que a la ejecución de acciones directas que modifiquen esas experiencias en el momento en que ocurren). Por otro lado, es importante señalar que, dentro del universo de personas que asumieron la existencia de trayectorias o vivencias diferenciales, hay para quienes la idea de ventaja o privile gio no supone necesariamente una condición de desigualdad respecto de otrxs.

En vinculación con este último punto, y, recuperando eso que advertía al inicio del apartado acerca la naturalización e invisibilización de las experiencias que para lxs adultxs aparecen como cotidianas y libres, pero que usualmente se constituyen en espacios de clausura para niñxs y jóvenes, se incluyeron una serie de interrogantes que buscaban conocer cómo acontecen estas trayectorias diferenciales, no ya a partir de la indagación en el vínculo, sino como percepción de la experiencia adulta misma. Con este objetivo se preguntó a lxs encuestadxs: Alguna vez se sintió discriminadalo y o tratada/o injustamente por ser adulta/o? (figura 4); Alguna vez se le impidió opinar sobre algún tema o problema por ser adulto/a? (Figura 5); y Alguna vez se le demandó asistir acompañada/o a alguna institución por ser adulta/o? (Figura 6). ${ }^{5}$

(Figura 4)

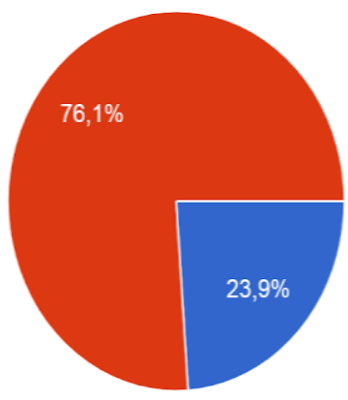

(Figura 5)

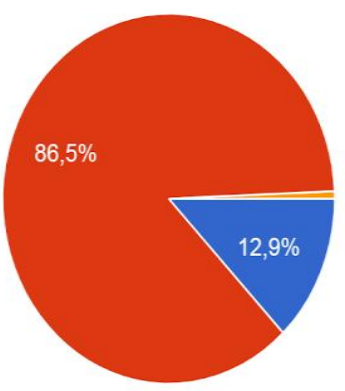

(Figura 6)

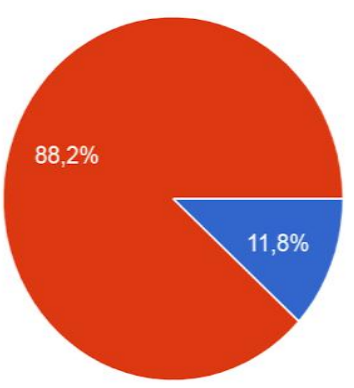

En una visualización rápida a estas respuestas, es posible advertir que en todos los casos, quienes se han visto impedidxs, imposibilitadxs, y/o consideran que han sido tratadxs de forma discriminativa por ser adultxs, constituyen una minoría en el universo total de encuestadxs. Esto acrecienta la percepción de que, como adultxs, poseemos menos barreras de legitimación, en e sentido de que nuestras narrativas obtienen, $a$

\footnotetext{
${ }^{5}$ En todos los casos, el color Rojo representa la opción 'NO' y el Celeste la opción 'SI'
} 
priori, mayor relevancia; además de que, materialmente, no presentamos mayores dificultades u obstáculos para el tránsito social. Alguna de estas preguntas, cuando las pensamos de forma a is lada rozan con lo absurdo, tal como acontece con el interrogante respecto de si alguna vez se le demandó asistir acompañadola a alguna institución por ser adulta/o; sin embargo, cuando establecemos su relación con otrxs tránsitos, su relevancia es significativa.

Así, por ejemplo, en la segunda parte del cuestionario, se preguntó a lxs encuestadxs si Niñas/os, adolescentes y jóvenes pueden transitar sin acompañamiento adulto por el espacio/organización/institución/proyecto en el que usted desarrolla sus actividades? (Ver figura 7), lo que aportó un hallazgo significativo, puesto que la posibilidad de transitar sin restricciones resultó ser limitada.

(Figura 7)
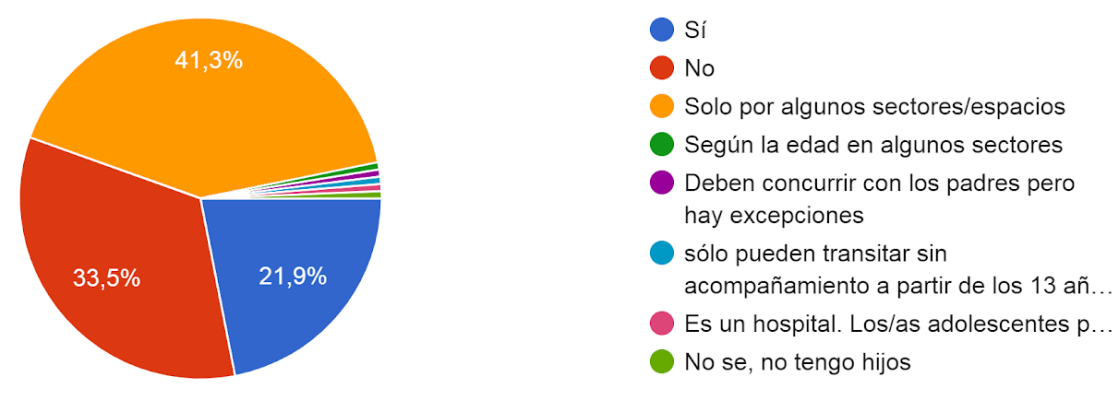

Lo cierto es que transitar por una institución sin necesidad de ser acompañadxs no constituye en sí mismo una condición de desigualdad; pero, si consideramos que en esta sociedad la posibilidad de circular libremente le es restringida a una amplia proporción de la población, entonces debemos admitir que eso que significamos como una acción natural y cotidiana en nuestras trayectorias, es imposible de ser desarrollada, en este orden de cosas, sin la apelación a cierto tipo de privilegios. Si pensamos de forma comparativa ambos gráficos, estamos en condic iones de afirmar que mientras que 1 de cada 10 adultxs dice que se le ha demandado compañía para el acceso y/o permanencia a ciertas instituciones, en un orden inverso, solo 2 de cada 10 niñxs y jóvenes han podido transitar sin ningún tipo de restricciones en ciertas instituciones $u$ organizaciones. Acerca del último gráfico, lo correcto es señalar que, en la mayoría de los espacios, lo que se propone son tránsitos regulados, respecto de actividades específicas y/o de acuerdo con rangos etarios situados. 
Asimismo, mientras que a lxs adultxs se les preguntó acerca de sus experiencias en el tránsito social general -es decir, en los distintos espacios en los que transcurre su cotidianidad-, al momento de responder sobre el tránsito de niñxs y jóvenes, el recorte establecido fue la institución y/u organización de la que forman parte, situando estas trayectorias en organizaciones dirigidas al trabajo con niñxs y jóvenes. Esta distinción es importante porque, cuando establecemos la diferencialidad de trayectorias, la imposibilidad total o parcial de transitar sin acompañamiento adulto, no fue medida sobre el universo total de instituciones - lo cual de seguro hubiera ampliado la brecha-, sino que se ubicó en aquellas organizaciones que se supone que entienden a niñxs y jóvenes como sujetos centrales de esos procesos de asistencia y/o acompañamiento.

En articulación con este último señalamiento, en la primera de esta serie de preguntas, y a propósito del relevamiento sobre situaciones de desigualdad que hubieren afectado a lxs encuestadxs en su condición de adultxs, se pidió a quienes consideraron haber experimentado situaciones de este tipo que desarrollaran los elementos más significativos de esas vivencias. Aquí también se buscó conocer aquello que es compartido en la percepción sobre las experiencias de la desigualdad por las que somos afectadxs, y que creemos que se encuentra relacionado con nuestras posiciones y corporalidades generacionales. Sobre estas respuestas, es curioso que muy pocxs adultxs situaran condicionantes directamente vinculados a su posición generacional en un sentido más estricto, señalando como significativas otras afectaciones interseccionales entre las que resultaron preeminentes aquellas vinculadas a la identidad de género (32\%), al aspecto físico y/u otra dimensión corporal particular (36\%), a la participación y/o adscripción política (24\%), y a la pertenenc ia de clase (19\%). Otras afectaciones tales como el territorio, las creencias y religiones, y las condiciones de capacidad-discapacidad resultaron minoritarias. Un grupo ínfimo de adultxs $(2,4 \%)$ mencionó que se sintió tratado injustamente cuando se le impidió realizar actividades lúdicas y recreativas que se consideraban propias de niñxs y jóvenes, y cuando fueron excluidos de grupos con el criterio de priorizar a personas más jóvenes.

Una explicación a esto, en línea con la posición que he desarrollado, tie ne que ver con la dificultad para delimitar en nuestra cotidianidad eso que aparece como difuso e ilocalizable de la experiencia generacional adulta; y, que frecuentemente, se vuelve observable o localizable a partir de su asociación con otros marcadores o clivajes (considerando, asimismo, que analíticamente se propone una disección de dimensiones vitales que en la experiencia concreta aparecen enlazadas e interproducidas). Este 
argumento no agota el análisis, puesto que es necesario pensar esos movimientos en relación con los procesos de naturalización que normalizan ciertas acciones y procesos, ubicándolos en la órbita de lo necesario o inevitable. De este modo, cuando se le preguntó a lxs partic ipantes respecto de si otras personas han tomado decisiones sobre su vida adulta sin consultarle, más de la mitad de lxs encuestadxs respondió afirmativamente, haciendo notar que la relativización de la propia participación y la toma de decisiones sin necesidad de consentimiento, también permean las experiencias adultas.

Al indagar sobre las dimensiones y argumentos respecto de los que se prescindió de la participación para la toma de decisiones, las cuestiones vinculadas a asuntos laborales $(63 \%)$ y familiares $(64 \%)$ fueron preeminentes, aunque aparecieron otras argumentaciones igualmente significativas, tales como las relacionadas con decisiones económicas (30\%), amorosas y/o sexo-afectivas (27\%), sexuales (16\%), de participación en espacios políticos $(22 \%)$ y de vinculación con amigxs o grupos de pertenencia $(17 \%)$. La concentración de la toma de decisiones en estas áreas no es casual si consideramos que las características de inclusión en los espacios laborales y familiares soportan formas de flexibilidad tendientes a reconfigurar vínculos $\mathrm{y}$ participaciones, a partir de experiencias o situaciones delimitadas a posteriori de la adscripción de los sujetos en esos espacios. Asimis mo, frecuentemente asumimos que se trata de espacios de participacion y pertenencia condic ionada y diferencial, es decir, en las que se espera algún tipo de intercambio como requisito implícito y/o explícito de inclusión y permanencia, y sobre las que se construyen sistemas de roles, funciones y jerarquías.

Atendiendo a estas coordenadas de análisis, podríamos arriesgar que las relaciones familiaris tas y los espacios soc io-ocupacionales son, en las trayectorias adultas, sitios de tránsito predominante, dando cuenta, espacialmente, de los lugares comunes a partir de los que se construyen parámetros de pertenencia, valoración y separación. A pesar de ello, no es posible asumir que estas experiencias se edifiquen, necesariamente, sobre criterios de reciprocidad y acompañamiento. Considerando esto, se pidió a lxs encuestadxs que dieran cuenta de quienes eran esxs otrxs relevantes en sus trayectorias vitales -y con quienes pensaban la construcción relacional sobre criterios de reciprocidad-, señalando, en este caso, por quienes considera que debe ser acompañada/o para transitar su vida adulta. 
A partir de esta respuesta fue posible visualizar cómo, los vínculos construidos a partir de intercambios laborales, a pesar de ser frecuentes, no resultan del todo representativos en términos de acompañamiento y reciprocidad, situándose quintos en orden de jerarquía, por debajo de todos aquellos construidos en asociación a alguna forma de afectividad, e incluso de los que se conforman a partir de intereses o actividades compartidas. Las relaciones construidas a partir de lazos familiares $(86,5 \%)$, de amistad (84\%), y amorosos o sexo-afectivos (75\%), resultaron, tal como era de prever, las más representativas. Por otra parte, una de las opciones preveía la negativa a considerar que la adultez es una posición $\mathrm{y}$ experiencia que requiere de acompañamiento $\mathrm{y}$ reciprocidad, aunque solo el $4 \%$ de la población alcanzada por la muestra pensó que transitar en compañía de otrxs era algo innecesario o irrelevante.

Dentro de estas formas de vinculación, es interesante destacar la significativa presencia e importancia que comportan las relaciones de amistad, ya que allí se juegan los lazos de pares y/o construidos íntegramente a partir de criterios de elección y/o deseo. Este tipo de vínculo, si bien también resulta significativo para otras experiencias generacionales, no revis te simbólicamente el mismo tipo de importancia al momento de evaluar sistemas de reciprocidad y acompañamiento en los espacios institucionales que trabajan con niñxs y jóvenes. Así, por eje mplo, cuando pensamos en referentes afectivos para este colectivo, restringimos la búsqueda a aquellos que, además, son adultxs. Lo mismo que ocurre cuando, frente a situaciones que acontecen como problemáticas, naturalizamos la inmediata incorporación de familiares o representantes legales.

Respecto de esto, se pidió a lxs participantes que hicieran un ejercicio hipotético que les permitiera pensar a quien solicitarían ayuda $y / o$ asistencia frente a un evento problemático puntual, utilizando como base las mismas opciones vinculares incorporadas en la pregunta anterior. Interesantemente, el 50\% de lxs encuestadxs mencionó a sus amigxs como alternativa, siendo ésta la opción que obtuvo mayor preponderancia. También es importante reconocer que los lazos familiares $(37,4 \%)$ y los vínculos sexo-afectivos $(36,8 \%)$ fueron señalados como significativos.

No debemos naturalizar que elegir a quien acudir es una condición no contemplada para todas las experiencias generacionales, puesto que para algunxs de nosotrxs, contar con representación y/o mediación se ha convertido en una exigencia necesaria e ineludible para transitar en casi todos los espacios de sociabilidad. En este universo de análisis, un número relativamente importante de personas $(25 \%)$ consideró que preferiría no convocar a tercerxs, prescindiendo del acompañamiento de otrxs. 
En base a todos estos interrogantes, al finalizar la primera parte de este cuestionario, se incluyó una pregunta de respuesta abierta dirigida a conocer si estas personas valoraban necesario transformar alguna condición, percepción y/o dimensión en sus trayectorias y experiencias de la adultez. Una de cada dos personas -es decir, el 50\% de lxs encuestadxs- aseguró que no cambiaría ningún aspecto de su adultez, resulta do que se condice con las percepciones sobre las trayectorias diferenciales y la utilización de privilegios. Asimismo, sospecho que la inexistencia de experiencias de clausura, restricción y/o regulación de la libertad, contribuyen en el pensamiento de que nada problemático acontece en nuestras experiencias adultas.

A diferencia de este conjunto, la mitad restante de la población alcanzada por la muestra reflexionó en torno a las transformaciones posibles y/o deseables. Para muchxs la idea de tener menos responsabilidades, y gozar de mayores libertades o poseer más autonomía resultó importante. Varixs señalaron que desearían trabajar menos, ser menos estructurados, realizar menos actividades obligatorias, y/o tener más tiempo libre. De formas interesantes, y apostando a la construcción de narrativas diversas, muchas de estas personas argumentaron que desearían encontrarse con su deseo, poder reconocer y respetar sus sentires, y poder construir vínculos que recuperaran como central la dimensión de lo afectivo. Otrxs, a modo de pregunta, se interrogaron sobre si era posible ser más reflexivxs y esponta nexs. Volver a jugar y recuperar la dimensión lúdica apareció como una actividad asociada a otra generación pero que a algunxs les interesaría recuperar.

Muy pocxs encuestadxs, incorporaron algún aspecto asociado al modo en que lxs adultxs nos vinculamos con otrxs y/o a la forma en la que nos construimos corporal y posicionalmente. Respecto de la dimensión relacional, solo ocho personas pensaron en que mejorarían su vínculo con ascendientes o descendientes, o que ayudarían a quienes más lo necesiten. Acerca de las críticas a las posiciones adultas, tres personas aportaron observaciones reflexivas y deconstructivas de los lugares asignados y asumidos, mencionando que: Transformaría todo lo que lleve a imitación de estándares de otras adulteces que responden a poses inútiles, Intentaría deconstruir la asimetría generacional en los vínculos que construyo, y Supongo que cambiaría la estructura ceñida de la adultez. Es decir, la anulación de todo cuanto se corra de los límites del deber ser adulto que anula alternativas. 


\section{Abrir al vínculo}

En la segunda parte de este cuestionario, intenté profundizar en las formas de percibirnos adultxs y de construir posiciones respecto de la adultez a partir de los modos de relacionarnos con otrxs. Por este motivo, se solicitó a lxs encuestados, que respondieran las restantes preguntas cons iderando el vínculo que construyen y sostienen con niñxs y jóvenes en sus espacios socio-ocupacionales. Adentrandome en el sobre qué es posible o no dialogar con niñxs y jóvenes, se solicitó a lxs entrevistadxs que mencionaran si consideran que hay información que solo debe ser manejada por adultas/os, y que en caso de creerlo así, desarrollaran brevemente los temas o contenidos que les acontecían como problemáticos. En este contexto, el 52\% de la muestra entendió que no existe ninguna información que no pueda ser incorporada al dialogo con niñxs y jóvenes, aunque varixs realizaron salvedades respecto de las edades, y las formas y estrategias comunicacionales de acuerdo con la que esos dialogos se organizan. Es de destacar que la adecuación del mensaje y la adaptación del contenido estuvo fuertemente asociada a las cualidades asignadas a las personas recepcionantes, es decir, a la capacidad de entendimiento, a su lenguaje, a su edad y crecimiento, a su madurez, y/o a su desarrollo físico y mental, entre otras cuestiones.

Respecto del 48\% que opinó que cierta información debe permanecer bajo la custodia exclusiva de lxs adultxs, los argumentos temáticos-problemáticos que mencionaron fueron diversos, efatizando en aspectos vinculados a la sexualidad, al trabajo, a ciertas experiencias de violencia extrema, y a la participación en espacios políticos. Ha sido interesante que, muchxs encuestadxs, en lugar de definir un núcleo problemático o un tipo de información en particular, describieron los efectos posibles que ciertos conocimientos podrían provocar en niñxs y jóvenes, resaltando que evitarían toda aquella información que pudiera ser traumática, angustiante, que genere padecimiento, que cause dolor, que pueda perjudicar a los menores (sic), que lxs afecte emocionalmente, que provoque incertidumbre, y/o que afecte de cualquier manera a un niño, entre las más significativas. Un número menor -pero no insignificante- de entrevistadxs expusieron opiniones más rígidas y/o conservadoras sobre los diálogos que involucran a adultxs y niños, utilizando argumentos tales como: Un adulto puede manejar todo tipo de información, sin embargo los niños no, y/o debería evitarse toda la información privada que no es relevante para un niño. 
A este interrogante se enlazó otro, dirigido a conocer la percepción de estxs adultxs sobre la toma de decisiones, poniendo a jugar en forma de pregunta el presupuesto de que existen decisiones que deben ser tomadas únicamente por adultos. En ambas preguntas se suspendió la posibilidad de optar entre alternativas, promoviendo la elaboración de respuestas propias, que dieran cuenta de trayectorias singulares. A pesar de ello, la mayoría de las narrativas resultaron similares, no solo en relación al mensaje, sino también, al tipo de enunciaciones a las que recurrieron. Al diferenciar estos interrogantes, busqué separar dos elementos que frecuentemente se presumen como una unidad del campo, que son, por un lado, la posibilidad de ser escuchadxs y de que la propia opinión sea tenida en cuenta, y, por el otro, la participación real en la toma de decisiones. Sin dejar de lado que, en los procesos de toma de decisón, las formas de organización y distribución del poder son absolutamente relevantes para comprender los procesos de hegemonía y subalternidad.

De hecho, si nos detenemos a observar comparativamente ambas preguntas, es evidente que la única diferencia entre ellas fue el reemplazo de la palabra información por la de decisión, obteniendo, a partir de esa modificación, resultados significativamente diferentes respecto de la percepción. De esta manera, el 31\% de los encuestados persistieron en la consideración de que no existen decisiones que sean propiedad del mundo adulto, siendo este un porcentaje veinte puntos inferior al que consideraba que no existe información que solo deba ser manejada por adultxs. Esto quiere decir que mientras que, para 5 de cada 10 encuestadxs la información que poseemos es deseable y/o posible de ser compartida con niñxs y jóvenes sin restricciones, solo para 3 de cada 10 adultxs los procesos de toma de decisiones de ninguna manera pueden prescindir de la participación de los sujetos a los que se dirigen.

A quienes consideraron que existen una serie de decisiones que competen únicamente a lxs adultxs (69\%), se les pidió que enunciaran brevemente sobre qué temas, problemas, fenómenos o procesos consideraban que no era necesaria y/o deseable la participación infantil. Acerca de ello, los aspectos vinculados a la dimensión corporal-sexual de los cuerpos niñxs, así como las decisiones económicas y/o que involucran al trabajo infantil fueron las que adquirieron mayor relevancia. Al hablar de la dimensión corporal-sexual no solo me refiero a decisiones vinculadas a la realización, conocimiento y/o participación de ciertas experiencias sexuales y/o de goce, sino a las formas de habitar el propio cuerpo -incluyendo su transformación-, a la realización de terapeuticas, y a las pautas de cuidado personal y a limentación. Respecto de las consideraciones que exluyen 
de la participación a niñxs y jóvenes en la toma de decisiones vinculadas a aspectos económicos, si bien se observó una marcado rechazo a las formas de trabajo infantil, las resticciones respecto del uso y distribución del dinero, de la participación en la economía familiar, y de la compra y venta de productos, también ocuparon un lugar de relevancia.

Al igual que en la pregunta anterior, dentro de este subgrupo varixs encuestadxs no señalaron situaciones o problemas específicos que supusieran una restricción en la toma de decisiones, sino que aproximaron percepciones de espectro general sin localización específica, tales como: todas las decisiones que pongan en riesgo la vida o integridad de un niño/a o adolescente; todas aquellas que lo expongan a responsabilidades y efectos o consecuencias para las que no se encuentra emocional y físicamente aún en condiciones de asumir; todas las situaciones de vulneración de derechos a nnya; todas las que se tomen en el marco de una urgencia; todas las que impliquen la separación; y todas las que afecten a la vida; entre otras.

La marcación etaria asociada a la toma de decisiones, si bien apareció como un señalamiento para algunas de estas personas, no fue particularmente relevante, ni es posible situarla con una relación mayor a cualidades o condiciones específicas. En la mayoria de los casos, incluso, se utilizó a modo de argumento para dar cuenta de la imposibilidad de niñxs y jóvenes para comprender la relevancia o la pertinencia de ciertos temas/problemas. Aún reconociendo las condiciones de estructuración y disposición del poder en estos espacios, no es posible pensar en la toma de decisiones únicamente bajo lógicas de negación e imposición. Por tanto, y advirtiendo la alta capacidad de agencia directa de niñxs y jóvenes, fueron incluidas una serie de preguntas orientadas a pensar aquello que acontece en circunstancias donde, nuestras acciones y percepciones, son puestas en cuestión por esxs otrxs del espacio.

Si bien es posible encontrar diversos argumentos para dar cuenta de las posiciones de lxs agentes que pueden desempeñar su trabajo sin la inclusión de lxs sujetos a lxs que sus acciones se dirigen, lo cierto es que estas respuestas también dejan entrever un núcleo fuertemente problemático, y que frecuentemente se aloja en el orden de lo presupuesto. A saber, la certeza de que muchas de las instituciones que se dirigen al trabajo con niñxs y jóvenes pueden seguir funcionando sin ellxs, y que esa certeza, no necesariamente se constituye como problemática. Considerando estas cuestiones, deconstruir la experienc ia adulta resulta aún más complejo, puesto que el modo en que 
nuestras formas de percibir, experimentar y posicionarnos incide sobre otrxs, frecuentemente reside en zonas de opacidad difíciles de localizar y desentramar.

Siguiendo este hilo argumentativo, se incluyó una pregunta dirigida a conocer aquello que acontece cuando ni siquiera es posible pensar en el diálogo como forma de encuentro y/o espacio de participación. En este caso, el eje estuvo situado en las percepciones adultas respecto de la imposibilidad de establecer códigos comunicativos comunes, no ya por una negativa del interlocutor, sino más bien, por la dificultad para construir una narrativa compartida. Si bien en las respuestas anteriores, la falta de comprensión, la ausencia de conocimientos, o la imposibilidad para entender la relevancia y/o pertinencia de ciertos hechos o fenómenos, fue situada en el orden de lo infantil, es incorrecto presumir que estas cualidades y condiciones asignadas a los cuerpos niñxs alcancen para explicar lo que sucede cuando, en el marco de un encuentro, el diálogo emerge como algo imposible de construir.

La mayor parte de lxs encuestadxs se inclinó a pensar en la multiopción dependiendo las situaciones y características del encuentro. Respecto de quienes arriesgaron alguna alternativa para dar cuenta de su trayectoria, un porcentaje singificativo de personas (36\%) refirió que, cuando se encuentra en situaciones como la que se propone, opta por modificar su forma de hablar o el modo de establecer la comunicación. En vinculación con esto, e130\% mencionó que recurre a la utilización de técnicas que no requieren de la utilización de la palabra, mientras que un $14 \%$ explicó que se vale del uso de tecnología. Otras personas, ante esta misma situación, consideraron que prefieren acudir al acompañamiento de otros adultos que intenten mejores pautas comunicativas (16\%), e incluso, que optan por hablar con la persona adulta que acompaña a esxs niñxs y jóvenes $(23 \%)$.

\section{Todxs lxs de mi tipo}

A pesar de que la adultez es una posición en la que también me reconozco, usualmente me resulta dificultoso responder al interrogante acerca de lo que es propio en los modos experienciales de ser, percibir y transitar esta posición generacional, y por eso, cada vez que alguien me señala actitudes o comportamientos que reponen en aquello que debería hacer o poseer en espacios y situaciones particulares, me siento, de una o varias maneras, ficcionando un papel difícil de sostener. Entonces, como descreo de las propie dades y cualidades innatas de lo adulto y supuse que ese podría ser un gran sesgo 
a mi propio pensamiento, opté por consultar a esos otrxs con quienes se supone que participamos de un mismo tipo o clase de sujetos, cuales son sus observaciones acerca de nuestras trayectorias adultas. Este ejercicio experimental fue situado y dirigido, por lo que cuando digx todxs lxs adultxs, no lo hago con la pretensión de abarcar al número total de individuos incuídos en este colectivo, y/o con la intención de presumir un conocimiento acabado del campo: sino que utilizo como puntapié una serie de trayectorias y posiciones concretas y localizables, para hablar de zonas o espacios donde se ubica lo común y compartido de ciertas experiencias vitales.

A partir de la implementación de este cuestionario, me fue posible comprender que, si bien para muchas personas es posible situar marcas corporales y prácticas concretas y localizables, existe, tendencialmente, una inclinación a considerar que la adultez acontece a modo de proceso, que articula múltiples dimensiones y tramas, y que frecuentemente se organiza a partir de ciertas circunstancias que recuperan condiciones hegemónicas de producción de narrativas y sentidos, como así también experiencias asociadas a marcas materiales-espaciales definibles. Aunque la noción de lo etario sobrevoló y compuso explicaciones y argumentaciones, al hablar de la propia trayectoria, en vinculación a experiencias y observaciones situadas, fue posible desandar fijaciones y direccionalidades que establecen asociaciones univariables para la relación edad-generación-capacidad.

He de confesar, que ha resultado un hallazgo para mi descubrir que la mitad de lxs adultxs con los que trabajo no considera que exista una posición de privilegio en las adulteces a las que representamos y adscribimos, no solo porque observo que la utilización de prerrogativas es sistemática, arbitraria y totalitaria, sino también porque, me acontece como dificultoso pensar que ciertas experiencias de separación, valoración y jerarquización, puedan ser negadas u omitidas en el diálogo cotidiano con otrxs que se sitúan en condiciones desiguales respecto de nosotrxs. Por eso, a partir de esta lectura, me advierto que, eso que yo nomino y ubico en el orden del ejercicio del privilegio, es entendido y/o simbolizado por uno de cada dos adultxs a lxs que conozco, como una característica o condicion natural de ciertas experiencias corporales-temporales.

Aún así, es importante tener en cuenta, que lxs adultxs poseemos menos barreras para que nuestros discursos y narrativas obtengan relevancia y/o legitimidad, además de que, materialmente, nos encontramos con menos restricciones y/o regulaciones para transitar en los diversos espacios sociales. Esto no elimina la afectación que otrxs clivajes o marcadores producen sobre nuestras posiciones y corporalidades, sino que habla del 
modo en que estas articulaciones se producen, provocando movimientos de visibilización e invisibilización de acuerdo con nuestra posición en el sistema de relaciones. Por este motivo, he de señalar que aquello que acontece como difuso en la experiencia adulta, suele volverse observable y/o localizable a partir de su interjuego con otros marcadores o clivajes.

Según el relato de lxs participantes, el sentido compartido sobre el que se estructuran nuestras adulteces está caracterizado predominantemente por nociones como responsabilidad, autonomía, libertad e independencia. Y si bien estas condiciones y cualidades por momentos nos constriñen -tal como fue señalado por varixs encuestadxs cuando tuvieron que pensar aquellos aspectos de sus adulteces que transformarían-, con mayor frecuencia resultan ser organizadores fuerza para la construcción de los modos de saber ser y saber transicionar generacionalmente. Asimismo, resulta relevante analizar los desplazamientos por los que ciertas narrativas ocupan zonas de hegemonía, produciendo atributos y adjetivaciones que percibimos como inherentes a ciertas generaciones. Sobre estas creencias y supuestos, también se edifican los mandatos de la adultez.

Aunque la idea de que, cuando somos adultxs podemos hacer lo que queremos. atraviesa la construcción de discursos y diálogos, al pensar en trayectorias situadas, es posible observar cómo la relativización de la propia participación y/o la toma de decisiones sin necesidad de consentimiento, también resulta significativa en los tránsitos adultos. Sin embargo, al indagar acerca de quiénes son esxs otrxs con los que es posible y/o deseable construir relaciones de intercambio y reciprocidad, la mayoría de las personas señalaron como significativos aquellos vínculos construidos por elección y afinidad, además de las relaciones devenidas de sistemas familiaristas y/o de parentesco. Así, a pesar de que los sistemas familiaristas continúan siendo un pilar a partir del que se edifican las formas correctas o aceptables de transitar la vida social, lo cierto es que, para lxs adultxs, la posibilidad de elegir los vínculos sobre los que se establecen relaciones de acompañamiento y reciproc idad, resulta impresc indible.

Coincidentemente con estas observaciones, la mitad de lxs adultxs consultados no cree que sea necesario y/o deseable transformar algún aspecto significativo de su posición y experiencia adulta. Esto resulta bastante lógico si atendemos, por un lado, a que la mayoría de ellxs no se encuentran impedidxs para realizar actividades y/o expresar opiniones en su condición de adultxs, y, por otro, a que no consideran que las 
diferencias, valoraciones y jerarquizaciones que se producen en el vínculo con otrxs produzcan experiencias de la des igualdad.

Al momento de pensar cómo se producen y reproducen nuestras adulteces en el vínculo con niñxs y jóvenes, fue posible observar los modos en que la atribución de principios y propiedades a ciertos sujetos y cuerpos, es puesta en juego en los procesos de construcción de lazo social. De esta manera, si bien la mitad de las personas consultadas entendió que no existe información que no pueda ser compartida, un número mayoritario de adultxs consideró que era necesario crear sistemas específicos de codificación, adecuación, decodificación, y comunicación, utilizando como argumento las condiciones y cualidades de las personas recepcionantes. Es decir, para muchas de estas personas, aquello que hace al sentido y contenido de lo comunicable, se encuentra en directa relación con lo que esas otras personas son y/o representan, y que en el caso puntual de niñxs y jóvenes, se expresan bajo premisas tales como: capacidad de entendimiento, edad, madure z y desarrollo.

Asimismo, es importante considerar que la mitad restante de estxs encuestadxs consideró que existen temas y/o asuntos que deben permanecer en la órbita de lo adulto, colocando, como era de esperarse, a los aspectos vinculados a la sexualidad, al trabajo, a ciertas experiencias de violencia extrema, y a la participación en espacios políticos, en ese conjunto. Teniendo en cuenta que la frontera de separación entre lo adulto y lo niño estuvo dada, para la mayoría de esta población, por la posibilidad de construir espacios de autonomía y libertad, no es extraño que, permanezcan perceptivamente en espacios de clausura, aquellos asuntos que podrían trastocar esa barrera.

Esta idea se refuerza si observamos que el poder de decisión permanece preeminentemente en el espacio de la posibilidad y agencia adulta. No podemos pasar por alto que, la variación entre ambas respuestas, deja entrever que la participación es percibida en asociación a la posibilidad de recepcionar información -y, en el mejor de los casos, a intercambiar respecto de ella-, más que a la potestad para tomar decisiones. Hemos de recordar que mientras que, para 5 de cada 10 personas la información que poseemos es deseable y/o posible de ser compartida con niñxs y jóvenes sin restricciones, 7 de cada 10 adultxs consideran que existen decisiones y problemas que, aunque involucran a niñxs y jóvenes, deben ser interpretados, agenciados y resueltos únicamente por ellxs.

Cabe destacar, para comprender la importancia de estas percepciones, que al hablar de información y decisiones, me remito específicamente a aquella que se supone que 
involucra, como sujetos centrales, a lxs niñxs y jóvenes que forman parte de nuestrxs procesos de trabajo. Es decir que, por ejemplo, cuando se le preguntó a estxs adultxs acerca de la información que consideran deseable o no compartir, no se hizo referencia a aspectos referidos información 'propia' o 'privada', sino a aquella que involucra de forma directa e indirecta a los sujetos a quienes acompañamos y asistimos. Esto mismo ocurrió al recuperar la percepcion y experiencias vincula das a la toma de decisiones.

Si analizamos las condiciones de estructuración y las características de funcionamiento de las instituciones y organizaciones en las que niñxs y adultxs se encuentran, no quedan dudas de que la participación de lxs primerxs no es una condición impresc indible para el acceso a la información y/o la toma de decisiones, reforzando la diferencialidad en tránsitos y experiencias. No hay aquí nada demasiado de novedoso, pues diversos estudios del campo (Chaves, 2014; Duarte, 2012; Pavez Soto, 2013; Carli, 2007, González Céllis, 2018; Cussianovich, 2012; Liebe1, 2012; Llobet, 2014; Magistris y Morales, 2018) han realizado significativos aportes para desenmascarar y problematizar las formas institucionales en las que se producen y reproducen estas experiencias generacionales de la desigualdad. Sin embargo, en un sentido inverso, esta caracterización también nos sirve para advertir y problematizar la imposibilidad que poseemos para cuestionar, revisar y reconfigurar los modos en que nuestras formas de ser adultxs imponen y delimitan modos de ser, no solo para nosotrxs mismos, sino, fundamentalmente, para otrxs que son generacionalmente diferentes.

En este sentido, en el discuro adultx, la apelación al diálogo y la reflexión, apareció en reiteradas oportunidades como alternativa y estrategia para la resolución de situaciones conflictivas. Sin embargo, en asosiación con ello, también muchxs de estxs adultxs reconoc ieron que esos procesos de reflexión e interpelación no necesariamente suponen una modificación en las propias percepciones y prácticas. Solo una pequeña proporción de lxs encuestadxs consideró que la falta de encuentro, acuerdo, y participación de niñxs y jóvenes, imposibilita completamente el desarrollo de su trabajo.

\section{Sum ario del capítulo: movimientos pendulantes}

Si inic io nuevamente el ejercicio pendulante sobre el que se construyó este Capítulo, en compás al movimiento de abrir, cerrar y abrir, debería admitir que cuando diagramé este cuestionario, creía que lo que me proponía era una observación minúscula y contextual, orientada más a establecer una pauta de vigilancia respecto de mis propias trayectorias, 
percepciones, posiciones y corporalidad, que a descubrir, a partir de experiencias situadas, los modos de configuración y extructuración de ciertas adulteces. Por fortuna, advertí esta equivocacion cuando la guía aún era un ensayo, lo que me permitió reconfigurar, suprimir e incorporar interrogantes. Sin prejuicio de ello, luego de su implementación, también observe la pregnancia de algunos presupuestos que habían logrado colarse a ese ejercicio de revisión.

Quienes participaron de la encuesta que se ha utilizado como herramienta operativoinstrumental para la construcción de estos conocimientos, son en su mayoría mujeres, que se desempeñan predominantemente en instituciones y organismos públicos, y cuya tarea central es la asistencia, acompañamiento y protección de derechos de niñxs y jóvenes. La escritura fue acompañada de un interrogante central que operó a modo de resonancia y directriz: ¿Cómo se construye la noción de lx adultx y cuáles son las afectaciones que esto provoca en las formas de construcción de vínculos intergeneracionales? Para su abordaje me centré en dos dimensiones de dialogo: por un lado, en las trayectorias y experiencias que son consideradas como inherentes a las vivencias adultas $-\mathrm{y}$ por tanto, atraviesan y son comunes a los distintos espacios sociales en los que nos desenvolvemos-, y por el otro, a aquellas acciones, prácticas, perspectivas, creencias y consideraciones que estxs adultxs articulan y despliegan, en el vínculo con niñxs y jóvenes en sus espacios de trabajo.

Los conocimientos cimentados utilizando como recurso la información brindada por lxs participantes podrían ser agrupados, a grandes rasgos, en tres ejes o procesos de localización: uno que nuclea y delimita elementos que hablan sobre la concepción de la adultez en tanto experiencia temporal-corporal singular y situada; otro que profundiza en las percepciones y trayectorias vinculadas a los modos de significar y agenciar experiencias y vivencias diferenciales; y finalmente, uno que, recuperando las dimensiones anteriores, habla sobre las formas de construcción de un tipo de vínculo intergeneracional específic o desde una perspectiva adulta.

Dentro del primer eje, fue particularmente relevante -y singularmente visible- la posibilidad de establecer una distancia entre marcadores nominales-etarios $y$ representaciones de la adultez. Sobre las posiciones construidas, las nociones de responsabilidad, independencia, libertad y autonomía, resultaron marcadores preeminentes para caracterizar las trayectorias propias. Al pensar las condiciones y características que asumen estos modelos identitarios -y que están contenidas en el segundo de los ejes-, fue evidente que, para un gran número de personas, transitar de 
manera ventajosa respecto de otrxs, no se corresponde, perceptivamente, con la utilización de privilegios, y que por tanto, existe un tipo de experiencia de la desigualdad que continúa considerándose como del orden de lo naturaly dado. Respecto del último de los ejes, para la mayoría de lxs participantes la interacción o vínculo con niñxs y jóvenes no necesariamente supone formas de reciprocidad y/o equivalencia, manteniendo fijas las localizaciones de separación, visibles, sobre todo, en aquellos aspectos que dan cuenta delacceso a la información, y a los procesos de participación y toma de decisiones. 


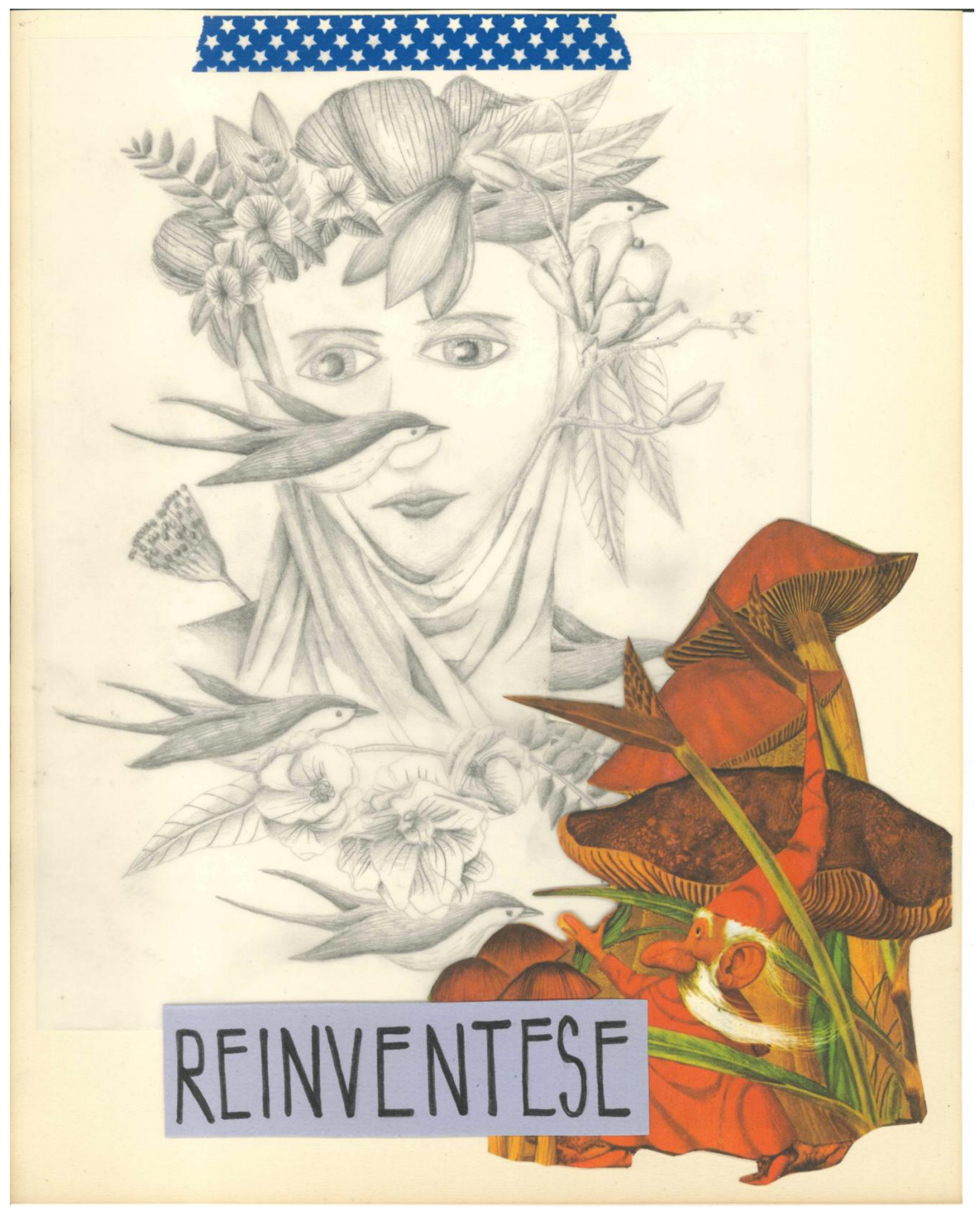




\section{Capítulo IV: Profanxs}

¿Pero cuanto tiempo hizo falta para que algunos hombres
adviertan que ese hacer estaba a su alcance?
Es fácil imaginar el temor experimentado
ante el fuego surgido repentinamente.

$Y$ hay que hacer intervenir una curiosidad bastante intensa

para atravesar ese temor.

Lo arácnido

Fernand Deligny

A inicios de 2019, llevaba yo algunos años acompañando a una niña que venía de una trayectoria de conflictividad que se incrementaba aceleradamente, y respecto de quien habíamos fracasado sistemáticamente en gran parte de las estrategias de asistencia propuestas. Por ese tiempo, la mayoría de los agenciamientos que desplegaba involucraban situaciones donde se ponía en juego su propia vida, y que acababan en la atención de urgencia. Quienes trabajabamos con ella andábamos con una sensación permanente de alerta y desolación, y transmitíamos un enojo indisoluble nacido de la impotencia por no poder pensar alternativas que dieran respuesta a sus deseos y necesidades. En ese contexto, una noche recibí un llamado de la Comisaría Novena pidiendome asistenc ia urgente porque esa niña estaba en el hall central rompiendo todo y amenazando a los oficiales que le habían impedido dormir en una plaza.

A una cuadra de la Comisaría ya era posible observar el montaje de escena: ella, impostada en la puerta impedía el ingreso de personas, a quienes les gritaba que por favor no entraran porque en esta Comisaría desaparecen gente, que lxs policías eran todxs golpistas y asesinos, y que si algo le pasaba buscaran su remera y llamaran a esas personas que iban a saber qué hacer. Solo cuando logré aproximarme me dí cuenta que la remera que tenía estaba marcada con dos nómbres y dos teléfonos, y que cuando se refería a esas personas hacía alusión a la anotación escrita con fibron. Uno de esos nombres era el mío. Probablemente, si solo hubiera sido una espectadora casual, esa postal me hubiera parecido un acto de justicia poética. Sin embargo, a esa altura, estaba yo muy contrariada, y solo pude cuestionar su accionar interrogandola acerca de, si de casualidad, no se le habían ocurrido estrategias menos riesgosas para alcanzar sus objetivos. Estuvimos largo rato hablando en la puerta hasta que acordamos un lugar donde pudiera dormir, más por mi insistencia que por su deseo. En el camino, yo, que seguía molesta, hice un comentario muy irónico sobre los nombres escritos en la 
remera, a lo que ella muy seria me respondió: Esto no es un chiste, cuando sos una persona como yo, necesitas siempre tener una lista de adultos a los que vas a poder llamar si te pasa algo.

Desde que empecé a pensar en las personas a las que deseaba entrevistar para poner a jugar mis ideas y percepc iones sobre las adulteces que representamos, esa conversación suena como un loop en mi cabeza. De alguna manera, yo también me siento escribiendo una remera, ahora con una lista propia, de lxs adultxs que creo que todxs necesitamos para habitar el mundo. No hablo aquí de transitar el mundo acompañadxs del mismo modo en que las personas adultas establecemos vínculos de afectividad a los que, más allá de las particularidades, podríamos renunciar si así lo quisieramos. Por el contrario, me refiero a esos que aparecen como condición de habilitación o mediación para transitar espacios y experiencias para quienes, en estos sistemas adultocéntricos, habitan posiciones generaciona les subalternas.

Sobre el criterio de selección podría decir varias cosas, pero prefiero enfatizar en dos cualidades distintivas que creo que los sujetos de mi lista tienen: 1) una urgencia ética por repensar los lugares que ocupamos, en los espacios que compartimos con niñxs y jóvenes, instalando la pregunta acerca de lo que es posible transformar para abandonar nuestras posiciones de privilegio; y, 2) la honestidad para abrirse a pensar en lo impensado, con la convicción de que si las formas que conocemos no alcanzan para reconfigurar esas relaciones sociales, entonces, es imprescindible inventar lo que todavía no existe. Encuentro en sus perspectivas y prácticas, una aspiración profana por devolver al uso libre y común aquello que nos han hecho creer que pertenece al orden de lo sagrado y diferencial, y es esa fuga la que me alienta a pensar que aún podemos, colectivamente, devenir otrxs.

Por una decisión profundamente política, si bien esta Tesis trabaja sobre aquello que se ha vuelto problemático en las construcciones adultas que habitamos -y que contribuye en la reproducción de los sistemas de dominación que conocemos-, he pensado que la mejor forma de atacar esa compacidad (Lanfranconi, 2017), es partir de las excavaciones y profanaciones que existen, y que han logrado desarmar o diluír algunas de estas estructuras, ensanchando las grietas por las que se cuelan otros modos de habitar el mundo. Entiendo que el pensamiento adulto que conocemos, despojado de toda capacidad imaginativa, se ha vuelto por excelencia un pensamiento de la carencia, la imposibilidad y la falta, y que eso atenta contra nuestra curiosidad inventiva. Debemos, entonces, ser capaces de sorprendernos como niños (Korckzak, 1918), 
permitiendo a nuestros agenciamientos recuperar la posibilidad de experienciar tiempos y espacios diversos y dinámicos, que repongan en la simultaneidad y singularidad en las que la vivencia colectiva puede ser devuelta al uso libre, desde una potencia equivalente.

Por este motivo, si bien la idea de que una Tesis es un producto individual me parece, en términos generales, una ficción funcional y organizada, decir que este Capitulo podría haberse contruido sin el diálogo colectivo, sería además, un engaño. He de distinguir entonces, que existe una motivación y organización individual e interesada de acuerdo con los objetivos e hipótesis propuestos en esta investigación, pero que el diálogo que aquí se recrea es integramente de producción colectiva, basado en conversaciones que mantuve con personas que poseen experiencias tan singulares como anónimas, y que comparten la curiosidad y la valentía para preguntarse sobre lo impensado e indecible de las posiciones de mundo que habitamos. Así, esta pruducción multiforme, es la resultante de una polifonía de voces de la que también participaron Lucía Belaunzarán (LB), Manuel Rodriguez (MR), A lejandra Quintero (AQ), Mariano Girini (MG), Marina D’Alonzo (MD), Esteban Julián Fernández (EJF), Luisina Corrales (LC), Silvina Fuentes (SF), Sofía Porta (SP) y Gustavo Docters Fontana (GDF) ${ }^{6}$.

He optado por una escritura hilvana da y contínua de ideas y diálogos, la mayoría de los cuales se produjeron en encuentros individuales, pero que aquí se enlazan en una narrativa colectiva, recuperando el ejercicio arácnido de tramar sonidos, silencios, enlazamientos y deslizamientos, construyendo un pensamiento en red de lo que compartimos y tejemos, así como de lo que aún nos queda por descubrir e inventar. Al hablar de la importancia de tejer colectivamente Fernand Deligny explicaba que:

De hecho -y en el mejor de los casos- los miembros de una red no se conocen del todo entre sí, y de ese hecho sorprendente depende la solidez de la red; donde se ve que lo humano puede perfectamente prescindir del modo de ser subjetivo, lo cual, dada la inflación galopante del susodicho modo de ser, ameritaría que uno se detenga allí un poco. (Deligny, 1967;77)

\footnotetext{
${ }^{6}$ Lucía forma parte del Programa Niñez, DDHH y Políticas Públicas y Manuel acompaña a jóvenes en Casa Joven, ambos comparten su trabajo con niñxs y jóvenes en el PRIEC City Bell. Alejandra y Silvina recuperan es as experiencias a partir del encuentro con Niñxs y jóvenes en el Hospital de Niñxs Sor María Ludovica, mientras que Luis ina lo hace en el Hospital Garrahan. Mariano conoce y acompaña a niñxs en el Hospital Gutiérrez y también en un espacio interdisciplinario en el que recibe consultas particulares. Julián se encuentra con el mismo colectivo en talleres de ESI, escuelas y espacios de formación universitaria. Sofía acompaña estas trayectorias desde el Área de Niñez de la Comisión Provincial por la Memoria, y conoce y comparte experiencias con niñxs y jóvenes en el Hogar del Padre Cajade, espacio que también Gustavo co-construye junto a jóvenes. Marina, por su parte, se encuentra y acompaña la trayectoria de niñxs desde una Escuela Pedagógica.
} 
He utilizado el montaje literario (Benjamín, 2005) como método para tramar hilos y enlazar tejidos, ensayando una narrativa que se centra en el mostrar como modo de decir, puesto que allí donde acontece lo pequeño es posible observar la sabiduría entretejida en los materiales de la vida vivida (Benjamín, 1991: 11). Así, bucear en las experiencias mínimas y subterraneas, es también un modo de resistencia: porque en el orden de lo adulto, tendemos a considerar que todo lo que es pequeño carece de potencia, capacidad y valor. Construir historias a partir de la composición de fragmentos -dejando a la vista huecos y detenciones-, tiene por sentido esclarecer que todo pensamiento es un diálogo inacabado, $\mathrm{y}$, por tal, ha de ser pensado en relación con los enlazamientos aún no producidos.

Aunque entiendo la dificultad que el pensamiento impregnado de racionalismo posee para leer lo inconcluso y colectivo, insisto en este ejercicio, ya que considero que transformar los modos de relacionarnos y asir el mundo implica, necesariamente, desafiar los marcos de comprensión y las ópticas de visualización sobre las que nuestras experiencias y representaciones se producen y son producidas. Es fácil observar cuando trabajamos con niñxs, que lo hablado sobre las personas, con frecuencia, tiene más poder que lo que las personas dicen de sí mismas, y, por ende, la posibilidad de invertir ese canon comunicativo, se encuentra profundamente enlazada a la honestidad para reponer en ciertas narrativas, tal y como estas han sido enunciadas por los sujetos que las producen y significan. Atendiendo a esto, abandonar el principio de autoridad deviene fundamental para construir posiciones adultas no jerarquizadas y diferenciales, enfatizando en aquello que une a la experiencia singular cotidiana y el conocimiento compartido.

\section{Encontrarnos}

Podemos imaginar a priori las muchas formas del vínculo intergeneracional, pero lo que nace de encontrarnos es una potencia que no cabe en delimitaciones anticipadas. Es en ese entre de dos o más posiciones, donde aquello que conocemos y percibimos es recreado de un modo singular, entendiendo que no solo se ponen en juego las experiencias y afectaciones del yo, sino que también emerge lo que asignamos y nos permitimos para con otrxs. Para muchos de nosotrxs, además, encontrarnos y hablar con niñxs y jovenes ha supuesto un ejercicio de desmantelamiento que hace explícitas estas 
implicancias, puesto que aunque ninguna posición se construye a solas, no todas nos demandan la misma honestidad y capacidad de revis ión.

Podriamos acordar aquí que algunas fugas se producen cuando nos permitimos abandonar parámetros y estándares de comprensión, en sentido de diluir las estructuras de saber sobre las que nos sostenemos, para adentrarnos y explorar en esas otras formas de experienciar, conocer y construir que nos proponen lxs niñxs con quienes nos vinculamos. Usualmente, hablamos de comprender una trayectoria, a modo de encastrar lo que le pasa a otrx de acuerdo con nuestras formas de asir el mundo, sin embargo, estos ejercicios de mirar en subterraneo, suspendiendo las delimitaciones que en lo aparente deben ser resguardadas por las posiciones que nos son asignadas, permiten deconstruir ópticas de visión parciales e individualistas, para ensayar nuevas formas de mirar que se enrraicen en lo colectivo y compartido. Hemos de proponernos entonces, componer a partir de lo que nos encuentra.

No hay que naturalizar que hasta el primer encuentro somos todxs desconocidos, y entonces preguntarle a esx niñx por qué sabe o cree que llegó hasta ese espacio es fundamental (SF). Al decir que es importante saber lo que nos encuentra, en el por qué alguien está ahí, no me refiero a la linealidad de enunciar lo que a vos otra persona te dijo que era su problema, sino, si esx niñx está participando en el 'de qué va la cosa' (LC). Mucho de lo que acontece en esos primeros diálogos se centra en la información, ya que termina siendo una dimensión central de la participación de chicos y chicas en los procesos. ¿Qué información? Poder presentarse, en sentido de poder nombrar quiénes somos y que hacemos, aunque después haya que reforzar eso, que sepan por qué te encuentran en ese lugar, y en qué vas a poder acompañar y en qué no (SP). Cuando, además, se vuelve necesario despejar algunos presupuestos de policiamiento y control social, terminamos hablando más de para qué no estamos que de para qué estamos, y también es importante preguntarle al otrx qué es lo que opina sobre eso (MR).

Todxs lxs pibxs llegan con una historia, y las historias que traen son una más difícil que la otra, son historias que están atravesadas por la pobreza, por la miseria, por la violencia, por situaciones de vulnerabilidad. Y todo eso se nota en la dificultad para poder confiar, para poder abrirse, para apostar al lugar que estamos proponiendo. Cuando alguien llega, me parece importante que cada quien diga quién es. Hay distintas formas, yo por ejemplo, siempre les propongo que juguemos a la play, los invito al juego no a una charla especifica, y nunca necesité a lxs pibxs pedirles que me 
cuenten, siempre hay un momento en el que se da, quiebran, abren, confían y te cuentan. A veces una excusa sirve para eso, para que alguien se sienta cómodx para contarte su historia. Juntarnos a tomar mate, jugar a la play, son cosas que sirven para eso, para conocerse, para saber cómo estamos, como nos sentimos (GDF).

También nosotrxs poseemos historias y trayectorias que nos han colocado en esas confluencias temporales y espaciales, y ese es un tipo de sensibilidad común que necesitamos permitirnos poner en diálogo. Contar quienes somos, es más que hablar de los lugares que ocupamos y las funciones que tenemos en las instituciones para las que trabajamos, y tiene que ver con la capacidad para permitir la emergencia de lo singular y colocar en el orden de lo hablado aquello que traemos y aportamos cada vez que nos pensamos en esos vínculos. Estos movimientos son los que posibilitan hacer lugar a los modos en que las trayectorias y experiencias de niñxs y jóvenes nos irrumpen en tiempo presente.

Para 'llegar a alguien' hay que tomarse el tiempo de hacerlo (LB), porque cuando estás muy apuradx hay cosas que no estás escuchando (MG). Una entrevista no es todo lo que vos querés todo el tiempo, y por eso es sustancial centrarse en lo que se produce en el diálogo más que en la información que querés conseguir (AQ). A veces es importante reconocer también cuando no es el momento para ese encuentro, porque me parece que muchas veces empezamos una entrevista porque nos urge a nosotrxs algo, pero no es el tiempo de la persona. Es importante poder respetar eso (LC), o incluso, si la persona considera que no hay nada que podemos hacer en ese momento, que tenga en claro que el espacio va a permanecer abierto por si en otro momento entiende que algo de acompañamiento que hacemos puede servirle (LB).

No debemos olvidar que hay muchas circunstancias que impactan significativamente en la vida de las personas, y, que, usualmente, es en esas coyunturas en las que se producen nuestros intercambios, por eso es significativo considerar las cosas que son importantes desde la perspectiva del otrx para poder ser lo más respetuosxs que logremos (AQ). Por más terrible que sea una situación, debemos poder ejercitar la capacidad para hablar, también, sobre lo que nos gusta, para reponer en lo viviente del diálogo, que es lo que compartimos y nos acerca (MD).

Al partir de lo que nos encuentra, es relevante instalar preguntas sencillas pero que puedan hablar de lo que es común, por ejemplo, yo a veces les pregunto cuál es su color favorito, y buscar localizar ese color en este espacio que es extranjero, y pensar en qué otros lugares que le son familiares lo encuentra, y jugar un poco en esa 
reterritorialización las posibilidades de habitar espacios que son ajenos a nuestra cotidianidad. Además, preguntas como esa, que no tienen una única respuesta y pueden ser contestadas por todas las partes, nos habilitan a pensar que todxs tenemos gustos, deseos y preferencias que pueden ser diferentes (EJF). En este punto, es imprescindible establecer una distinción elemental: por más que ese encuentro se origina las más de las veces por la necesidad de otrxs, eso no quiere decir que, una vez que estás en la escena, lo que vaya a pasar no puede ser reconfigurado y habitado por nosotrxs (SF). Entonces que aparezca el diálogo con otrx es fundamental. En el PRIEC por ejemplo, cada vez que salimos, estamos vestidos con ambo, barbijo y máscara, que es algo que ya distancia, no solo representativa sino materialmente; entonces, lo básico del encuentro es, por ejemplo, entablar una conversación a la altura de la persona, si esa persona mide un metro menos que vos, agacharte o sentarte, buscar que la mirada esté a la misma altura. Usar vocabulario sencillo, no técnico, pero al mismo tiempo, no omitir lo que nos interesa (MR). Desde un punto de vista similar, pero en un espacio distinto, pienso en las alternativas que tenemos, y que también dan cuenta de lo que va a ser posible o no en el diálogo, como rotar los lugares, por ejemplo. O sacarme el guardapolvo, porque en el hospital el guardapolvo es un objeto de poder y distinción. Cuando te ve un niñx con guardapolvo y llora, es claro que ve ahi la fuerza de todo lo que vos representas, y vos vas y les decís 'no te voy a revisar' como si se limitara a eso. Cada vez que te sacas el guardapolvo, material y simbólicamente, sos otra persona, y los chicxs valoran eso (AQ).

Ser respetuosxs de los relatos y narrativas que otrxs nos confían -y que hacen referencia a sus propias experiencias o trayectorias-, no solo implica resguardar aspectos sensibles o que le generan sufrimiento a las personas, sino que también habla sobre la necesidad de pensar los modos en que estas vivencias inciden en las posiciones construidas. Cada vez que nos permitimos ser irrumpidxs por estas formas singulares de percibir el mundo, la necesidad de construir narrativas ficcionales respecto de otrxs -y que en este caso, anticipan nominaciones y discursos de lo que niñxs y jóvenes son, hacen, o quieren- se vuelve obsoleta.

Hay que evitar dar por sentado cosas, por ejemplo, ¿dónde queres que hablemos?, bueno eso tiene que ser una pregunta, porque entonces no es lo mismo, hay chicxs que prefieren charlar caminando, otros arriba de una estructura que hay en la placita, o hay quienes eligen la oficina del equipo porque es un lugar donde 'nadie los va a escuchar'. Hay que entender que no es solo el diálogo, sino sentirse cómodxs para 
charlar. O la pregunta sobre cómo les gusta que lxs nombren, porque a veces nos pasaba que nos llegaba un nombre de legajo doble, y terminábamos llamando a la persona con un nombre que no le representa. En esa sola pregunta, para nosotrxs, se abrió un universo increible, porque hay chicxs que nos empezaron a decir bueno, ya que me preguntas y puedo elegir, llamame $X^{\prime}$ (SP).

Cuando la palabra no es posible, o tal vez, cuando no acontece como el hilo central a partir del que se establece un diálogo, el intercambio está más desde el respeto de lo corporal. Por ejemplo, en mi formación me habian enseñado que siempre hay que revisar enterx al niñx, y con el correr de la residencia, entendi que el abordaje del cuerpo es un diálogo. Hay que preguntar sobre la revisación. Me pasa un montón, que muchxs adultxs insisten en las revisaciones, y yo tengo que explicar esta cuestión del respeto por el cuerpo ajeno. De hecho, por lo general, la primera vez que nos encontramos en un consultorio, priorizo no tocarlxs, para que encuentren en ese espacio un lugar en el que se sientan respetadxs. [...] Aunque mayoritariamente me encuentre con bebes, la anticipación del lenguaje es algo re importante, aunque eso vaya acompañado por la mirada y por las formas de tocar, más que por las palabras que uso. [...] Lo fundamental es no abordar el cuerpo sin preguntar primero, y sin que haya un acuerdo sobre eso, sin que esté en claro para qué es importante o necesaria mi práctica $(\mathrm{MG})$.

En cualquier caso, qué contás, qué preguntas y cómo te acercás, es algo que está en proceso constante de desarrollo, un poco porque cada encuentro es algo a construir. También hay algunas cuestiones que emergen como fundamentales, una de ellas es pensar cómo vamos a construir confianza con esa persona, utilizando algunas estrategias que recreen lo menos que logremos posiciones adultocéntricas. Pensando que el adultocentrismo se nos cuela incluso desde lugares copados, que después decantan en formas de paternalismo o proteccionismo. (MR). Para eso, hay que prestar atención a cómo la persona se siente en el lugar, a veces hay mucha incomodidad, y aunque a vos te puede parecer que es muy importante que alguien esté ahí, si la persona te demuestra que no quiere permanecer con vos, me parece importante entender que hay un límite, que la participación no es una obligación ni una imposición (LC). Cada uno pone su historia en el cuerpo como puede. Y lxs pibxs también ponen en el cuerpo como pueden la historia que vivieron, y eso conlleva a que a veces no puedan manejar sus emociones, sus enojos, que cierren puertas, que no se abran, que 
no permitan que lxs acompañes, o que no quieran permanecer donde vos estás, y nosotrxs debemos poder ser capaces de comprender eso (GDF).

También hay que poder pensar, de manera amplia, en las condiciones generales en las que se produce el intercambio: cuando llegas a un espacio en el que alguien no tiene ropa o zapatillas y donde no hay ni para comer, vos no podes caer y como si nada preguntarle a alguien si consume o qué consume, porque se vuelve una conversación obscena. [...] En trayectorias de tanta soledad, abandono y arrasamiento, tenes que poder ser capaz de entender que lo que vos vas a acompañar ahí, no es ese consumo puntual, sino una trayectoria de sufrimiento que excede la demanda que alguien te hizo, $y$ de la que ese consumo es, en el mejor de los casos, una expresión (LB). Por ese motivo, todo el tiempo debemos recordarnos que el encuentro con otrxs es, también, abrir a otros espacios y a otras experiencias (MG).

A veces, al revés, el encuentro no empieza con una pregunta tuya, sino con una pregunta que ellxs traen, y poder contestarla con honestidad, en sentido de lo que quieren conocer de vos me parece que es fundamental, porque eso es crucial, y habla de lo que vos vas a proponer para lo compartido. Me parece que si vos inicias engañando u ocultando, ya estás marcando una pauta de relación que no está buena (MD). Por eso, me parece que, a veces, más difícil que elegir contar algo, es cuando lxs niñxs te plantean una duda puntual sobre vos, porque en este mundo, saber contestar con honestidad implica ser valientes y romper con nuestros propios prejuicios (EJF). Creo que hay que acercarse a lxs pibxs y poder compartir con ellxs, en mi caso, yo vivía con lxs chicxs, entonces armábamos proyectos compartidos, y como ellxs estudiaban yo también estudiaba al lado de ellxs. O para cocinar por ejemplo, cocinábamos juntxs. No creo que sea necesario situarse en un lugar en el que te medís con el otrx y les das órdenes. Me parece que el laburo es codo a codo, y que si vos esperas que el otrx sea transparente, vos tenes que ser transparente también (GDF). En ese escenario, muchas veces te encontrás con que hay chicxs que saben más de vos que vos mismx, porque ellxs también ponen a jugar otras cosas, gestos, posiciones, modos y con eso leen la realidad (MD).

Creo que en general no abrimos mucho por una cuestión más, en este caso, por ejemplo, de la idea de las disciplinas, no sé, como un deber ser profesional, donde todo el tiempo hay algo del orden de regular lo personal, de no abrir a lo propio. Yo al principio tenía altos mambos con algunas acciones, si eso estaba bien éticamente o no, incluso en términos de condiciones laborales o de responsabilidades. Van apareciendo 
un montón de encrucijadas de ese tipo en las que una también va eligiendo. Yo suelo elegir con algo, que no sé si es garantía de algo, pero que a mí me parece fundamental, que es la importancia de priorizar el intercambio y lo que se abre en el encuentro cuando conocen quien sos más allá del lugar que ocupas (SP).

Atendiendo a esto, debemos ser capaces de traccionar los presupuestos de acuerdo con los que ciertos encuentros deben ser producidos, en mi caso, una pregunta que me estoy animando a incorporar es si se animan a preguntarme algo que creen que no se podría preguntar en ese espacio. Me parece que, sobre todo en esa coyuntura que trabaja la ESI desde lo escolar, una cuestión genuina, transparente, honesta, desde la curiosidad y la libertad, implica justamente decirles, que las preguntas más valiosas son esas que creemos que en el espacio no se pueden decir (EJF). Y en esa coyuntura debemos poder incomodarnos, porque cuando abrís también hay un lugar donde sos más vulnerable a lo que pasa. Bueno y hay que bancarse eso, porque hay una vulnerabilidad que genera encuentros, pero también te genera muchos cuestionamientos de otro tipo. Yo no creo que la vulnerabilidad necesariamente cuestione la autoridad o la posibilidad de brindar 'pautas adultas del mundo', pero de seguro te abre a otras cosas (SP).

De este modo, no presuponer la existencia de diálogos allí donde no existe vínculo resulta un elemento que, si bien respecto de otras relaciones podría parecer del orden de lo obvio, aquí se vuelve necesario explicitar. Tensionar la idea de que las fronteras son deseables y necesarias implica, también, encontrar nuevos lenguajes y nuevas formas de acercamiento que horizontalicen las posibilidades, condiciones y características de la participación de los sujetos en el espacio: para lo que acceder a las mismas fuentes de información acontece como fundamental. La posibilidad de situar experiencias y posiciones a partir de lo que nos encuentra, en lugar de exaltar lo que nos separa, resulta en este contexto un desafío imprescindible para pensar formas del vínculo que se centren en lo que emerge del intercambio.

\section{Ensanchar grietas}

No todos nuestros conocimientos y percepciones se transforman a partir de interrupciones, incomodidades o encuentros particulares, pero es importante reponer en que hay intervenciones que abren una brecha, transformando mucho de lo que conocíamos antes de que el cruce de nuestras trayectorias se produjera. De esta manera, hay hechos y fenómenos que permiten descubrir la cristalización del acontecimiento 
total en el análisis de los pequeños momentos particulares (Benjamín 2005; 496). Muchas veces, son las experiencias singulares y situadas las que nos advierten el modo en que nuestro pensamiento se transforma, permitiéndose ensayar sobre lo imprevisto e impensado. La síntesis de ese movimiento, aunque sea enunciada de manera individual, es siempre una resultante de la experiencia compartida.

Recuperando esto que decíamos sobre las preguntas que son disruptivas cuando te abrís al diálogo, un día me encontré con un pibe que, en el marco de mi trabajo, me preguntó si yo tomaba alcohol. Si bien pude elaborar una respuesta sin demorarme tanto, internamente se me jugó el hecho de que iba a ser crucial, para la continuidad de la conversación la posibilidad, de ser honesto en lo que dijera: sabiendo que a mí se me cruzaba la cuestión de lo moral, o sea, de cómo de alguna manera modula esa información la posibilidad de repensar la idea de la transparencia. Es decir, vos podes contestar que si o que no a la pregunta ¿tomas alcohol?, pero eso no dice nada si es problemático o no ese consumo, en qué ocasiones tomas, o incluso cuando nos la hemos puesto nosotros tomando. En esa circunstancia estaba con una compañera de trabajo que también se vio afectada por la pregunta. Entonces, en esa trama fue importante en un punto, no adelantarnos a nada y priorizar la honestidad, contestar que sí, que tomamos, y que si le interrogaba saber algo más sobre eso. Eso fue súper habilitante para el pibe, porque suspender la moralidad y el mandato de lo que corresponde o no conversar con un niño permite cosas. Me parece que en ese caso, Jonathan nos devolvió esa pregunta sobre la transparencia, que es algo que frecuentemente les demandamos a ellxs, y a lo que es importante responder con una forma de la verdad. Ese aprendizaje, luego se volvió estructurante porque incorporás otros enfoques posibles, aunque no los vayas a replicar linealmente en todas las intervenciones (EJF).

Hay que romper el miedo que existe a conversar con niñxs. Digo, está mega difundido este derecho del niñx a ser escuchado, pero hay mucho miedo cuando tenés un niñx enfrente, y bancarte todo lo que puede llegar a enunciar (EJF). Si te paras un cachito a pensar, te das cuenta que todxs lxs pibxs que conoces te irrumpen de una u otra manera. En general me parece que hay un momento de quiebre claro, y que pasa muy a menudo, que es cuando logras entrar en confianza y lxs pibxs te cuentan una perspectiva del mundo que no tiene nada que ver con lo que vinieron a denunciar lxs adultxs que te demandan. Cuando podes escuchar desprejuiciadamente te das cuenta que todos los relatos tienen otra versión de lo que llega a las instituciones como 
'problema', y yo creo que esos otros relatos no aparecen en casi ningún lado; que, en todo caso, es la versión real de lo que le pasa a un pibe (LB).

Hace algún tiempo, yo lo estaba llevando a Pedro a un Jardín con una mirada re piola de aprendizaje activo, que es una institución privada que yo pago todos los meses, y nos cruzábamos un carro con un señor y un niño que entiendo que era su hijo. Yo vi una asimetría social muy zarpada en esas dos situaciones, y entonces yo le cuento la situación y en el relato le armo como una especie de vulneración de los derechos del niño: ¿¿ves? Ese niño no está yendo al jardín porque tiene que ir con su papá a trabajar, tiene que juntar cartón todo el día para poder comer'. Como con esta idea de generarle empatía a Pedro con lo social. Y Pedro ahí me desarmó todo, porque me mira y me dice: 'QQué bueno! A mí me re gustaría un día acompañarte al trabajo'. $Y$ ahi me pregunté, por qué presupuse que ese pibe la estaba pasando mal solamente porque no está en la escuela. Yo entiendo que la escolaridad es algo a lo que hay que prestar atención y demás, y que si me la cuentan de entrada yo también digo bueno, veamos qué pasa, y entiendo que está buena la escuela en un montón de cosas, pero la mirada normalizada jerarquiza, y dice que uno la está pasando bien y el otro mal. Y el niño al que yo conocía, en realidad también quería ir conmigo a trabajar' [...] Está esto de creer que cuando se termina la incorporación del lenguaje hay uno solo, y que si decimos las mismas palabras estamos hablando en el mismo lenguaje, y no sé si todxs nos representamos lo mismo con las cosas que decimos (MG).

Es importante entonces, reponer en los modos a partir de los que en ciertas nominaciones hay un convertir en un problema algo que es la trayectoria de una persona, la idea de las niñas-madres por ejemplo. Cada vez que salgo de una entrevista en la que eso que me contaron de un niñx y lo que esx niñx me cuenta que pasa son dos cosas totalmente diferentes, pienso en cómo ficcionamos la realidad por no hablar con las personas, todo lo que uno se imagina del otrx sin ir a preguntarle, y lo peligroso que es que eso tenga un lugar tan relevante. Creo que lo hacen otrxs y nosotrxs también, porque es mentira que porque ocupas otro lugar no construís presupuestos sobre ciertas cosas. Y siempre pienso 'quizás era más fácil preguntarle a esx niñx' y eso te ahorra mil cosas. Pero bueno, tomarse el tiempo de hablar con el otrx también es una decisión política de lo que creemos que hacemos en los lugares que ocupamos. Se encubre mucho en esta economía del tiempo, porque la verdad es que interconsultar, llamar y escribir la solicitud, insume más tiempo incluso que acercarse a la persona y preguntarle. Capaz aún así el acompañamiento es necesario, pero te podes enfocar en 
lo que realmente la persona quiere o necesita. Utilizamos muchas categorías para lo que no podemos definir pero sabemos que tiene que quedar sujeto a algún control o forma de observación (AQ).

Hace unos años, en Casa Joven estábamos preparando la marcha El Hambre es un Crimen, de la que habíamos participado como organización en reuniones de adultxs, entonces surge esta discusión de que teníamos que armar algo con lxs pibes porque la marcha es para ellxs pero la estamos armando nosotrxs. Entonces yo pedí ocuparme de esa parte, que era lo que más me interesaba. Yo en Casa Joven participé siempre del espacio de recreación, que es el único espacio en el que van pibes y pibas de todas las edades, y que es el único día que pueden ir niñxs más pequeñxs. Estábamos ahí con un afiche, pensando en las demandas, trabajando un poco sobre qué es solicitar al Estado, y todo lo que había aparecido hasta ahí-esto lo pensamos después-tenía más nuestra impronta que la de lxs pibxs, porque estaba: más trabajo para los padres, más comida, mejores escuelas. Entonces paso Marito, que tendría unos 5 o 6 años, vino a mirar, y cuando le preguntamos qué le pediría al gobierno, nos dijo 'más postre'. Y ese terminó siendo el slogan de la marcha. Nunca a ningún adultx se le hubiera ocurrido pedir eso. Nos hizo dar cuenta que es importante pensar, no solo las respuestas, sino también las demandas, asumiendo otras posiciones (MR).

A veces pienso que si nos orientamos solo en función de la palabra adulta terminaríamos vinculándonos con esxs niñxs con mucho prejuicio, y que de alguna manera, es lo que pasa. Si solo escuchamos a las personas adultas, la verdad es que nos acercamos a lxs niñxs con mucho temor. Después en el encuentro, te das cuenta que la realidad es mucho menos terrible cuando unx tiene la posibilidad de conversación directa con lxs niñxs, porque muchas veces eso que aparece como dramático para lxs adultxs, lxs niñxs aportan otras formas de procesamiento y lo que en un primer momento parece un problema abrumador, al animarte a hablar, vas encontrando puntos de los que agarrarte para construir alternativas. Si queres resolver algo de la manera más sencilla, tenes que primero ir a hablar con lxs pibxs (EJF).

Me pasó, por ejemplo, con unas nenas con las que hacíamos un chiste, porque yo les decía que eran un grupito de brujitas porque andaban siempre juntas y de reunión, y entonces ellas también me decían bruja a mí, y jugábamos un poco con eso. Y un día vienen unxs más chiquititxs, y me dicen ahi está la bruja señalándome porque estaban con ellas. Y ahi fue como un choque, porque una cosa era ese juego compartido con ellas, que era situado y que tenía que ver con un intercambio muy específico, y otra es 
la narrativa que se socializa, que atribuye condiciones y que señala fijando cosas en lugares, y que de repente eso sea el registro de otrxs niñxs ajenos a la escena me asustó. Entonces me senté y conversé esto con las nenas, establecimos la diferencia entre un juego compartido y una atribución identitaria, en este caso, en esa idea de que ahora otrxs nenxs iban a señalarnos como brujas, y que no sabemos muy bien qué es una bruja o qué nos provoca ese señalamiento cuando lo hacen otrxs con otras intenciones. Me parece que incluso en esas situaciones, lxs nenxs te dan la oportunidad de permanecer en el diálogo (MD).

Cuando cambié de lugar, empezar a desarmar todo lo que se había armado fue difícil. Cuando empecé a vivir con lxs pibxs fue todo nuevo [...] y una de las primeras cosas que me pasó es que empecé a notar que David se levantaba muy temprano, hacía cosas a escondidas y yo no entendía muy bien. Después me di cuenta que se hacía pis, que tenía miedo que yo lo retara, y entonces lo que hacía era ir a lavarse las sábanas rápido en un balde, y después las volvía a poner húmedas, para que no lo notáramos. No las dejaba que se sequen ni nada, estaba tan apurado que las estrujaba y las ponía así. Lo mismo hacía con la ropa. El día que me di cuenta, no le dije nada, y al otro día me levanté más temprano y cuando fui, lo encuentro lavando, entonces él me mira asustado, y yo sin decir nada, me puse al lado y empecé a lavar con él. Y ahí le expliqué como poner la ropa en el lavarropas, y le enseñe como podía hacerlo si quería lavar el solo. Y estábamos en esa tarea, yo no había dicho nada, simplemente estaba acompañándolo en la tarea, y el ahí me dice 'perdón', y yo le pregunto por qué, y él me responde 'perdón por mearme'. En ese momento yo le dije 'no David, vos no tenés que pedirme disculpas a mí por algo que te pasa, hay a quienes les cuesta más que a otros, pero vas a ver que de a poco vamos a poder resolverlo'. Hice eso por varias semanas. Se levantaba, yo le preguntaba si se había hecho pis, y entonces le pedía que me alcanzara las sábanas y las poníamos a lavar, le pedía que se bañara mientras tanto para que estuviera cómodo, y ahí, entre día y día empezamos a charlar. Y entonces él me empieza a contar que no venía durmiendo bien, porque cuando dormía, revivía las situaciones de abuso con su papá, y que revivía cuestiones muy especificas. Cuando empezamos a trabajar con el equipo pudimos situar lo que pasaba, y notar que no era todo lo mismo, que le estaban pasando cosas muy particulares, en momentos muy especificos, y que es importante atender a eso [...]. Después de un tiempo, David empezó a hacerse pis solo tres veces por semana, después dos, y en un momento dejó de hacerse pis. $Y$ en ese punto, vinieron otras educadoras a preguntarme cómo había 
hecho, y yo les dije que no había hecho nada en específico, que solo me había ocupado de que él dejara de ser humillado por esa situación, que dejara de sentir culpa por lo que le estaba pasando, y de que pudiéramos hablar sobre cómo nos sentíamos (GDF). Por el contrario, hay momentos en los que tenés que poder reconocer cuando hay que pegar un giro y arrancar otra vez, porque a veces, cuando te encontrás con ciertxs pibxs descubrís un mundo, y lo que creías que sabias o lo que te habían contado, no te sirve para nada. Es decir, a veces te pasa que lees, y empezas el encuentro, y desplegas toda una escena, que no sirve para nada, y la otra persona te cuenta algo que nada que ver y te quedas ahí pagando. Me parece que ahi hay que darse la oportunidad de reiniciar (SF). Como cuando trabajamos con Sofía por ejemplo, que era una niña que sufría todo tipo de violencias en una situación que nos fue presentada de un modo, pero rápidamente nos dimos cuenta que el problema estaba en otro lugar. Me parece que lo rescatable fue la rapidez y la posibilidad de encuentro, en la decisión de poder correr a su mamá. En generar las condiciones para que ella pudiera hablar y contarnos lo que le pasaba. En el momento la situación fue muy violenta porque intervino la policía y porque tampoco es fácil ir contra la idea de lo familiar, pero inmediatamente después ella se acerca, nos abraza y nos dice 'gracias'. Y recién ahí se pudo producir un encuentro en serio, y ella nos empezó a contar lo que le pasaba. Eso es fundamental, el dar el espacio a lxs chicxs para que hablen. Después estuvo todo lo demás, en términos de la estrategia y de brindarle protección, pero lo fundamental fue esa apuesta. Este es un caso extremo y explicito, pero después te das cuenta que esa negación es algo cotidiano. De hecho era una niña que había pasado por muchísimas instituciones, pero nadie le había preguntado a ella 'qué te pasa'o 'por qué venís con polera a la escuela en diciembre'. Eso me recontra hizo pensar en lo que pasa con lo institucional, porque esta no era una niña que estaba encerrada en su casa. Y a veces, cuando eso pasa, ya llegamos tarde, tuvo que pasar una situación grave que afectara su integridad para poder decir 'che, hay que correr a esta adulta y hay que hablar con ella sola'. ¿A nadie se le ocurrió antes? No creo que sea eso, no fuimos ningunas iluminadas, creo que es más otra cosa, es ese vínculo con lo adulto que no podemos romper (AQ).

En este sentido, me pasa que siento mucho asombro, porque te encontrás después de un diálogo con un montón de relatos que no caben en un informe, y que no aparecen en ningún lado. Y me produce también mucho enojo, porque observo mucha injusticia en esa situación. Qué palabras priman sobre otras, porque yo no creo que sea en nuestros encuentros la primera vez en la vida que alguien logre contar qué le gusta o qué quiere, 
pero alguien decidió que eso era menos importante que otras cosas (SP). Tengo un recuerdo muy claro de mi ingenuidad no tanto con una persona sino más con una situación, que fue lo primero que me descolocó un poco cuando empecé a trabajar con niñxs y me hizo pensar mucho en mis idealizaciones y presupuestos, y que tiene más que ver con lo institucional y del hacer de las instituciones de niñez. En una ocasión puntual en la que, en medio de una situación tremenda, yo pedi intervención a un Servicio Local re convencida que todo iba a suceder como vos pensas que funciona el Sistema: tipo trabajo en equipo, interdisciplina, coordinación, escucha, mucha participación... y bueno, nada de eso pasó. No sé en qué pensaba. Yo estructurada, creyendo que había algo del procedimiento que si estaba enunciado formalmente iba a suceder así. Me sentí muy ingenua, pero además me di cuenta que la intervención pasa por otros lugares. Me dio una cachetada de realidad, tipo dale querida, los Reyes Magos son los padres. A veces se generan exigencias creadas sobre idealizaciones que nos hacemos, y ese es un lugar muy separado de la vivencia, para bien y para mal, porque tendemos a fijar relaciones que son de mucho movimiento, y ahi le erramos (LC).

Bastante seguido me pregunto sobre las cristalizaciones que nosotrxs hacemos de las personas, cómo te armás la idea de que alguien es de una única manera porque conoces una partecita de su vida, o porque con vos siempre fue de un modo. Me recuerdo una situación, en la que llego a hablar con una piba, que en ese momento estaba teniendo un aborto y que no sabía lo que le estaba pasando a su cuerpo, no sabía que estaba embarazada y por tanto tampoco sabía que lo que le estaba pasando era un aborto. Una piba que ya había estado muchas veces en el Hospi y que era conocida porque desde pequeña tenía una situación de consumo muy complicada, y que en una milésima de segundo supo que le estaba pasando algo en su cuerpo pero que no lograba entender qué era. Todavía me moviliza mucho, porque era una piba armada en un montón de situaciones y que todxs la veíamos así, como fuerte e impenetrable, y que en ese momento era un ser tan frágil y desprotegido, que fue arrasador para ella y para mí, porque hasta ese momento yo habia tenido una forma de vincularme con ella que cambió completamente a partir de ese encuentro (SF).

Otras veces, por más conocimiento y voluntad que tengas, la realidad te plantea situaciones de tal complejidad, que a una se le acaban las ideas (AQ). Una vez pasó, que estaba con una piba que se hacía muy responsable de que había denunciado a su familia, y sentía mucha culpa por las cosas que habian pasado en su casa, o por el 
hecho de que los demás hermanos estaban en Hogares, todo creía que era muy por su responsabilidad, y nosotrxs lo trabajamos, una, dos, mil veces desde la palabra. Siempre desde la palabra. Y aunque lograba verlo, siempre, en algún punto volvíamos a la primera charla. [...]. Una de las veces, yo ya no sabía más cómo conversar, y me dejé acudir por un movimiento más expresivo e improvisado, y entonces me paré delante de ella y empecé a darle vueltas diciendo 'no depende de vos'. Y a pesar de que después volvió mil veces a esta cuestión de la culpabilización, ahora cada vez que nos vemos me dice a modo de chiste 'no depende de vos'. Y hoy, si pienso en el impacto que eso tiene, creo que me hubiera gustado decirle otra cosa, porque de hecho es con una piba con la que hablo un montón sobre su protagonismo, y el mensaje que yo le di, es 'no depende de vos', cosa que en ese marco es horrible. Pero bueno, en esa situación ayudó a estructurar un montón de cosas, y lo traigo como ejemplo de que a veces, usamos estrategias disruptivas, que nos recontra desorganizan a nosotrxs también, y que esa incomodidad posterior habla sobre lo que nosotrxs también necesitamos aprender de esos encuentros (SP).

Creo también que hay una resistencia muy grande a desorganizar el propio cuerpo para encontrarse con otrxs. Eso no quiere decir que todo lo que hagas así es siempre exitoso, pero sí te abre a la posibilidad de pensar en las múltiples dimensiones en las que podemos encontrarnos (EJF). También me doy cuenta que la mayoría de las prácticas que tenemos no tienen nada que ver con lo que dicen en la Facultad que es el Trabajo Social, pero que todas esas 'locuras' son las que nos abren camino para hacer otras cosas (LB).

Una vez me paso con un pibe que vivía atrás de Mafisa, arriba de un basurero, él y un montón de otros pibes en una fila de casillas, y ese pibe se iba de la casa y se drogabay la madre estaba completamente desbordada porque el pibe le traía muchos problemas. Cuando hablamos con él, quinientas veces hablamos, porque llegar a un acuerdo no es algo que vas a hacer de una vez, nos dimos cuenta que lo que él quería era estar ocupado, hacer deportes, tener actividades, pero él vivía en un lugar que cuando llovía no podía salir ni para ir a la escuela. Entonces cuando le preguntamos qué quería, él nos dice que quería estar en un lugar donde todo le quedara más accesible. Bueno, pedimos otro espacio habitacional, y rebotamos como unos campeones, entonces le explicamos que la otra alternativa que conocíamos era una institución en la que pudiera estar un tiempo, donde puedas estar más tranquilo, mantener el vínculo con tu familia y hacer estas cosas. Vamos al Servicio Local, y ahi nos dicen que el pibe no 
tenía los derechos vulnerados porque la familia no lo violentaba, y que por tanto una medida de abrigo no era posible. Entonces le explicamos lo que nos decían, y le propusimos que asistiera él mismo para que le explicaran directamente que 'lo que él quería no se podía hacer porque no hay una figura jurídica que contemple como argumento el deseo de un niño'. En el camino le digo: ¿vos sabes lo que es la burocracia? Son todos los obstáculos que te vas a encontrar cuando lleguemos para que vos no puedas lograr tu objetivo, entonces tenes que pensar una estrategia, y en lo que vos propongas te vamos a acompañar. Hacemos todo el recorrido de entrevistas, y no sé como hizo, pero logró lo que quería. Nunca perdió el vínculo con su familia, se pudo laburar todo lo que queríamos, ¿y eso por qué? Porque logró que respetaran su deseo. Y se quedó ahí hasta que decidió volver. Pero bueno, hay mucho miedo con lo que los pibxs desean (LB).

Aunque no sea la única forma de transformar una trayectoria, el desvío que producen algunos imprevistos e impensados, nos alientan a pensar que la posibilidad de dejarnos irrumpir por esos otrxs modos de percibir y componer el mundo, permite suspender las valoraciones de lo que corresponde que seamos con la posición y corporalidad que se supone que representamos. En este ensayo, a lgunas pistas contribuyen en esa búsqueda: la necesidad de escuchar, la importancia de ser honestxs en el intercambio, la oportunidad de permitirnos permanecer en el diálogo y habitar nuestras incertidumbres, el recaudo por generar las condiciones para que encuentros y diálogos sean posibles, la sensibilidad para ser capaces de adoptar otros pensamientos y formas de comprender la realidad y el desafío de suspender las barreras impuestas por los modos de ser adultxs que se nos demandan.

\section{Hacernos cargo}

Pensar en los modos en que las adulteces que representamos pueden hacer lugar a las necesidades y deseos de esxs otrxs con los que nos encontramos a diario, implica, necesariamente, inmiscuirnos y ensayar hipótesis y visualizaciones en relación con eso que creemos que niñxs y jóvenes requieren de lxs adultxs que somos. Este interrogante de ninguna forma ha de pensarse a modo de cancelación o reemplazo de los intereses y propuestas que esxs niñxs traccionan y nos demandan, sino que más bien habla de la permeabilidad respecto de las trayectorias, posiciones y percepciones que entendemos 
que permiten hacer lugar a esas otras formas de comprender y habitar el mundo. Dice Judith Butler que:

...la pregunta sobre ¿Quién Soy? Es una pregunta que cambia su todo y forma dependiendo el contexto político en el cual es movilizada. Así por ejemplo, puede ser preguntada desde una posición de supuesta ignorancia ("eres tan diferente de mi que no puedo entender quien eres"), o puede ser formulada como una invitación a la escucha de algo inesperado y con el objetivo de revisar las presuposiciones culturales o políticas de sí mismo, o incluso cambiarlas drásticamente. (Athanasiou y Butler, 2017:125)

Con frecuencia creemos que debemos construir posiciones que nos sitúen de modos diferenciales frente a ciertos vínculos, en lugar proponernos deconstruir hábitos y percepciones que colocan fronteras, delimitan trayectorias y excluyen posiciones. En los procesos de acompañamiento y trabajo con niñxs y jóvenes, esa pregunta suele instalarse a partir de otros emergentes, y frecuentemente nos sitúa frente a nuestro deber ser. Entonces, hemos de pensar que podemos vincularnos con esxs otrxs reafirmando las identidades supuestas, o, por el contrario, podemos acercarnos al diálogo reflexionando acerca de los modos en que las posiciones que asumimos podrían contribuir a pensar relaciones no excluyentes.

A mí me pasaba, por ejemplo, que en ese momento, cada vez que iba a la Salita me hacía como un monólogo en el que me preguntaba a mi mismx: Y entonces, ¿Quién soy yo?, ¿Cuál es mi tarea?, ¿dónde está el pediatra acá?, ¿si yo cuestiono todo, y no puedo entender lo que le pasa, qué hago? Tenía una necesidad muy fuerte de volver a algunos marcadores para reafirmarme en esa situación en la que me tambaleaba todo. Mucho tiempo después, me di cuenta que te podes acercar a eso que te preocupa de otros modos, en este caso, a partir de la pregunta: ¿cómo puedo acompañar yo en esta situación?, o ¿qué movimiento necesito hacer para que esa persona se sienta incluida? (MG).

Me parece que además de una escucha desprejuiciada, lxs pibxs necesitan que nosotrxs abramos y liberemos los espacios. Muchxs niñxs ya están institucionalizadxs en lo formal porque su nombre figura en historias clínicas, matriculas de escuelas, o causas judiciales, pero esa inclusión no es democrática, porque esas personas no necesariamente saben lo que hay escrito sobre ellas o los diálogos que se producen en su nombre, o, incluso, qué es lo que conoce sobre ellxs gente que no lxs vio nunca. Hay que democratizar eso, porque no hay justicia en que yo sepa lo que dice una 
trabajadora social sobre X, si X no sabe lo que están diciendo sobre él o ella, o peor, si X nunca se cruzó con esa trabajadora social ni pasó por esa institución (LB).

En ese sentido, es importante que nos interesemos en los encuentros. Un interés que vaya más allá del motivo por el cual esa institución te encuentra con ese sujeto. Me parece que así como lxs pibxs están interesados en nuestras vidas, también te piden que vos te intereses en serio. Creo que es necesario que admitamos que hay cosas que no sabemos y que ellxs son una fuente donde puede existir una respuesta. Que nos animemos a incorporar sus formas de percibir, de pensar, de construir alternativas. Blanquear que hay cosas que no sabemos y cosas en las que nos podemos equivocar, me parece que hay temor con eso porque parece como si perdiéramos autoridad, pero yo creo que eso genera un movimiento interesante, porque ellos están esperando sentirse autorizadxs también, esa vulnerabilidad es la que habilita otros puntos de vista y desarma la idea de autoridad (EJF).

Una vez, en la formación viene una maestra, que era una de las precursoras de esta modalidad de enseñanza, y nos dijo algo que a mí me quedó muy marcado, y que es que para poder trabajar con chicxs, tenés que tener la flexibilidad para poder volver a ese centro de la infancia y salir, moverte en los dos mundos, porque de lo contrario no es posible conectar con lo que está sintiendo el otro en ese encuentro. Yo eso lo re siento siempre. Los chicxs se dan cuenta cuando vos sos honestx, y entonces cuando jugas, tenés que poder meterte en el juego, no hacer como de cuenta que, porque tu capacidad imaginativa ahi es muy finita, y entonces si viene una nena, agarra un bloque y te llama por teléfono, es importante que en ese momento, vos agarres lo que tenés al lado y contestes esa llamada, y hables en serio, porque así se construye lo compartido. Si te vienen a contar algo, detenés lo que estás haciendo y lxs escuchas, y entonces así, cuando es al revés, vos también podes pedir esa reciprocidad en la escucha. El ejercicio de comprensión empieza por uno (MD).

Lxs pibxs necesitan ver ejemplos de lo que después les proponemos como modo de vivir, en sentido de ejemplos de ternura, de amor, de compromiso, de solidaridad. Yo creo que lxs pibxs necesitan que los retes o que les digas que no estás de acuerdo cuando crees que algo es de otra manera, pero que también los abraces. Que podamos enojarnos, pero después de eso, que también seamos capaces de sentarnos, de revisarnos, y de terminar llorando juntxs, como me ha pasado con muchos pibes. Ser transparentes con otros, para que otros sean transparentes con nosotros. Construir desde la ternura, pero nosotrxs también construyendo desde la ternura, tienen que 
vernos a nosotrxs alojar y cuidar, y para eso se necesita que aprendamos a convivir, y a manejar nuestros enojos y frustraciones. Me parece que hay un desafio ahí con esta posición adultocéntrica de quienes creen que la tienen más clara, y que haber vivido una experiencia particular, sirve para explicar la experiencia de todxs. Eso es lo que me enseñaron a mi lxs pibxs. Lxs pibxs nos enseñan mucho más que lo que nos enseñan lxs adultxs, y encuentran una multiplicidad de alternativas diferentes frente a situaciones de mucho dolor y violencia (GDF).

Yo creo que lo que necesitan son encuentros genuinos que construyan un vínculo. $Y$ creo que como en muchos otros procesos el camino para lograr ese vínculo es una meta en sí mismo. Y lo digo porque creo que para que se den encuentros genuinos con niñxs necesitamos entrar en esa 'frontera indómita' de Graciela Montes, algo que solo lograremos si empezamos a remover todos los obstáculos, todo el ruido que impide que lxs niñxs digan todo lo que tienen para decir. Que se escuche su voz es el camino y la meta al mismo tiempo. Solo así ellxs podrán construir quiénes quieren ser de pequeñxs (MG).

Por eso, es fundamental que lxs escuchemos y dejemos de suponer cosas. Dar el espacio que a veces no es fácil, porque cuando digo escucharlxs lo digo como un proceso profundo, tomarnos el tiempo, pensar en el lugar, en cómo se produce el encuentro. En lo que tenemos que hacer para que una persona sienta que ahí puede contar algo. Escuchar también nos implica ser creativxs, conocer otros lenguajes, desarmar las formas que conocemos. Escuchar en serio, con esa escucha que te desarma y te obliga a repensar todo. Eso es lo fundamental. Y después, que eso no se puede pensar por fuera de qué es lo que hacemos con lo que la persona nos cuenta, que son las decisiones que hablan de nosotras y de nuestras adulteces. Porque a veces hacemos como que lxs escuchamos, pero después a la hora de la decisión te das cuenta que no, que nosotrxs tomamos las decisiones por lo que nosotros creemos. Hacer un como si en la escucha queda hermoso, y nos es cómodo (AQ).

También necesitan que invirtamos tiempo, las cosas piolas surgen cuando no andas apurada, o no sé si es apuro la palabra, porque a veces sí necesitas que ese tiempo tenga otra velocidad. Lo digo en sentido de poder acompañar el tiempo de otrx. No podemos pretender sentarnos, y que en ese momento, nos resuelvan el objetivo final de la intervención misma, porque lxs adultxs tampoco lo hacemos así en nuestras vidas. Es la necesidad de comprender que existen otras temporalidades del encuentro que no se rigen bajo la lógica pregunta-respuesta. También necesitan que no los subestimemos, 
de preguntarnos y preguntarles otras cosas posibles. A veces sobreestimamos y eso puede no estar bueno, porque en última instancia, eso tampoco es la persona. Pero por lo menos me parece importante hacer lugar y tomarse el tiempo para que las posiciones de cada quien puedan emerger (SP).

A veces siento que no hay lugar para todas las variaciones, en ciertos espacios y circunstancias nos comportamos de un modo y en otras nos comportamos diferente, o por ejemplo, con algunas personas tenemos mejores diálogos que con otras. Eso está súper naturalizado en el mundo de lxs grandes, pero, sobre lo mismo, a lxs niñxs se los prejuzga mucho, o se los encasilla en personalidades o formas de ser (MD). Creo que si les hiciéramos la vida un poco más fácil, eso sería una gran contribución. Hay cosas sencillas para eso, por ejemplo, que podamos ponernos en su lugar y hacer un ejercicio de comprensión y de pensar desde otro lugar. Poder entender qué le pasa a una persona ya es un montón, pero si además podemos pensar que en las situaciones que nos encuentran, lo que nos cuentan lo usamos para mejorar cosas o situaciones aunque sean pequeñas, creo eso ya ayudaría mucho. A veces es solo saber estar, saber escuchar y saber acompañar (LC).

Por eso, dos cosas me parecen imprescindibles: 1-que no subestimemos todo el tiempo a la persona con la que te encontras y el saber que tiene; y 2-Que no confundamos protección con imposición o ahogo (SF). Hay mucha ansiedad de lxs adultxs respecto de lo que un niñx puede o no puede, se genera toda una cosa en torno a esta idea de la capacidad medio asociada a ciertos parámetros. $Y$ a veces toda esa carga de expectativa y exigencia es muy frustrante para lxs chicxs. Alguien que por ejemplo llega a la escuela sin comer, o a quien no le preguntan en su casa como le fue, es la misma persona que tiene que poner todo su cuerpo y capacidad para responder a lo que una institución le demanda. Por eso me parece que el saber acompañar, poder compartir con amor, y poder comprender es fundamental. Tratar de ponernos un poco en el lugar de esxs niñxs es algo que cuando somos adultxs nos cuesta mucho trabajo hacer (MD). Si tuviera que arriesgar una respuesta diría que necesitamos destruir el mundo tal como lo conocemos, pero mientras lo logramos, más Políticas Públicas en Niñez, más y mejores, más programas de inclusión, recreativos, artísticos, que se territorialicen yo creo que ayudaría bastante. Abandonar la idea de que el Sistema es algo punitivo o de control social. No es tan difícil darse cuenta que invertir ahí es desinvertir en otros lugares que son punitivos (MR). Y me parece que, fundamentalmente, necesitamos gente que quiera compartir el mundo, que se siente en el piso, que se suba a los 
arboles, que no sean ellxs los que tengan que adecuarse todo el tiempo a nuestras lógicas y a nuestras formas de compartir. Necesitan también que lxs escuchemos más. Que confiemos, que seamos capaces de creer y de apostar a lo que proponen como alternativas. Necesitan de adultxs que puedan construir otras formas de ser adultxs. Entiendo que hay algo del orden del límite que es necesario pero que hay que repensar como forma de relación social, y que también implica que haya adultxs que se dejen poner límites. Y que nos hagamos cargo, que si construís un vínculo no te podes borrar después (SP).

Recuperamos de nuestras experiencias mejores oportunidades en los diálogos y encuentros de los que participamos cuando nos permitimos escuchar desprejuic iadamente admitiendo las cosas que desconocemos, haciendo lugar a nuestras incertidumbres y sensibilidades. Reponemos en la importancia de interesarnos en esos vínculos, de respetar las posiciones que emergen del intercambio, de experienciar vivencias y diferencias comprendiéndolas en su singularidad, y de componer aquello que nos es común a partir de las afectividades y sensibilidades que son conmovidas cuando nuestras historias se encuentran con otras.

\section{Desarmar ejércitos}

Dice Rebecca Solnit (2020:27) que aquello que desconocemos por completo suele ser lo que necesitamos encontrar, y encontrarlo es una cuestión de perderse. Y entonces explica que la etimología de la palabra perdidx, halla su origen en el nórdico antiguo, y se construye sobre el sonido de la palabra hablada los que hacía referencia a la disolución de los ejércitos, más precisamente, al momento en que las personas rompían filas para hacer una tregua con el mundo. En este sentido, la posibilidad de producir interrupciones y proponer otras formas de habitar el mundo, muchas veces, se encuentra enlazada a la valentía para desarmarnos y desertar de esos espacios colectivos en los que, enfrentarnos a otrxs, aparece como una condición necesaria para el encuentro.

Cuando, además, obtenemos condiciones ventajosas en esos territorios en disputa, para disolver las posiciones no alcanza con dejar de dominar espacios, sino que también resulta necesario abandonar las construcciones y estructuras que valoran, distancian y jerarquizan. El proceso de desarme, en este contexto, si bien se adviene a negociaciones y reconfiguraciones, también suele reservarse espacios de resistencia. Hacer enunciable 
aquello que nos cuesta construir de otros modos es un ejercicio imprescindible para imaginar mutaciones y transformaciones posibles.

Considero que lxs adultxs, cuando nos vinculamos con niñxs y jóvenes, tenemos una tendencia a asumir una posición de guardianes de algo que no sabemos bien qué es, pero que creemos que le asegura a esas personas condiciones mínimas de habitabilidad y de vida. Sobre esa premisa creamos sistemas de resguardos, habilitaciones, protecciones, circulaciones y tránsitos. Sin embargo, tener una llave propia -en el mismo sentido en que Virginia Woolf tenía un cuarto propio- respecto de mis necesidades, intereses y deseos, tanto como de las formas de percepción, configuración, experiencia y/o resolución, ha sido para mí la ventaja mejor valorada de mi adultez. A pesar de eso, he observado que, incluso desde lugares políticamente afectivos, frecuentemente me encuentro reproduciendo esas posiciones que antes me constriñeron, advirtiendo que, en esas situaciones, mantengo una resistencia por pensar otros modos posibles. Es difícil pensar en abandonar o reconfigurar ciertos poderes porque un poco te quedas pensando sin saber bien para dónde salir, y porque también es muy fácil encontrar una excusa que te deje en tu posición (LC).

A mí me parece muy difícil negociar el poder de tomar decisiones. Esa barrera que ponemos en el 'hasta dónde', que me parece que se nos juega a veces en esta cosa de la responsabilidad pero que tiene que ver mucho con nuestras creencias. El tomar decisiones por los otrxs, me parece que resignar eso es lo más difícil. Sobre eso tengo más preguntas que respuestas. ¿Cuáles son las formas de esto sin imponer un poder de decisión? Entiendo que es porque vemos en lxs niñxs 'sujetos más vulnerables', y entonces te aparece hasta disfrazado como una duda ética ¿¿cómo no vamos a proteger a los más débiles aunque eso implique tomar decisiones por ellos'?, hay un imaginario que es: ¿cómo no voy a hacer nada si estx niñx está en peligro? y ahí te contestas, bueno, yo lo voy a ayudar, como si además eso es algo que haces vos, y volvés también a los lugares de los que te vas a escapar, tipo, que va a saber, si es un niñx (AQ).

Si lo pienso, creo que siendo adultx me costaría mucho a mí renunciar al poder de tomar decisiones completamente por mí mismo. Aunque veo que siendo pibx, una de las cosas que más nos reclaman ellxs, es que a pesar de que toman decisiones por su cuenta, están al cuidado de un adultx que termina respaldando o no esa decisión. Y en un punto es así, aunque ellxs tomen sus decisiones lxs adultxs estamos para decirles que nos parece qué está bien, qué nos parece que está mal. Y muchas veces eso hace que tomemos decisiones y que ellos no puedan hacer completamente lo que quieren [...] En 
última instancia, somos siempre lxs adultxs lxs que construimos la norma, y, a veces, en ese contexto, apelamos a mejorar las condiciones, a escucharlxs, a que se sientan cómodxs en el espacio, pero también terminamos hablando por lxs pibxs sin involucrarlxs (GDF).

Es difícil abandonar el prejuicio de que porque somos más grandes tenemos más claro por donde pasan las cosas, y lo que lxs pibes necesitan. Creo que eso tiene todo que ver con algo que me pasa a veces, que es darle más entidad a las formas en las que pienso que hay que cuidar, a lo que unx pibx me está diciendo que necesita (LB). Ceder al concepto de la razón es lo más difícil. A la idea de que podemos comprender y saber qué hacer. Pensar que la fragilidad no implique o que no vaya de la mano con algo negativo o con una especie de carencia. En sentido de que lxs adultxs podemos mostrar algo de nuestra fragilidad sin que eso suponga que seamos menos algo. Por lo general no somos subestimados por eso, al contrario, somos mas humanxs o sensibles. Pero cuando lxs pibxs te muestran más fragilidad, eso es un problema. En una generación es un valor y en otra es un problema (SF).

Creo que me parece dificil repensar el poder de la justicia. Me refiero a que desde el lugar de adultx tenemos la capacidad en una situación que consideramos de injusticia, de interceder y devolverla a lo que creemos que le daría equilibrio. Por ejemplo, si un pibx agrede a alguien, siento que tengo el poder y la capacidad de poner un límite solo apelando a mi condición de adultx. No quiero decir que no sea necesario intervenir frente a esa situación, sino que creo que la explicación no está en ser adultx o no, pero con eso alcanza. Ese poder de la inmediaticidad, de intervenir enseguida respecto de esa realidad que se está produciendo, cosa que no sé si siempre conviene o si es la única manera (EJF). Renunciar a esta especie de figura de autoridad es re complicado, porque te sentís medio en bolas en la aproximación con otrx. Viste como cuando te preguntas: ¿y bueno yo quien soy para decirle algo?', y ahi medio que te la respondes en el orden de que sos una persona adulta, que tiene más experiencia, que sabe cosas porque vivió más, y ese es un significante que se completa solo. Como en apelación a la experiencia acumulada (MD).

Que la última palabra sea la mía. Para mí eso sigue siendo muy difícil porque me ha pasado en situaciones, yo proponer que el otrx elija, y que el otrx me diga no, yo quiero que vos me digas qué tengo que hacer. Y por otro lado que cuando el otrx hace algo distinto a lo que estoy planteando, a mi me incomoda un montón, y siento que generar las condiciones para que otro decida sigue siendo para mí un desafío en desarrollo. 
[...]Hay algo de lo adulto que se explicita ahí cuando pensamos en cosas como 'habilitar' la palabra, y no nos ponemos nunca en otras situaciones lúdicas o de juego ya que se supone que para eso deberíamos 'ser habilitados' [...] cómo se juega la palabra de lxs pibxs, me lo sigo preguntando porque entiendo que siempre sigue estando el final en lx adultx, la resolución de la charla parece que siempre se da en la conversación con lxs adultxs' [...] la necesidad nuestra de entrar ahi, para ver que esté todo bien, en lugar de pensar en compartir espacios de disfrute (MG).

Se me hace dificil pensar las formas cuando alguien ya no quiere trabajar conmigo, onda 'en este momento de mi vida no quiero hacer algo con vos', en sentido de dejar de participar en la trayectoria de alguien para quien una creía que ocupaba un lugar. Cuando no hay consentimiento en establecer un vínculo con el otro, aparece de alguna manera lo autoritario en la obligación de que esa persona trabaje con vos independientemente de su voluntad, ya sea porque igual crees que tenés que hablar con esa persona, o porque hay una obligación de mantener ese intercambio (SP). Me parece importante saber que nosotrxs, muchas veces estamos para lxs pibxs en un momento de su vida, y después se van o hacen otras cosas, y no por eso le quitan importancia a lo que hicieron con vos en un momento. Pero cada uno toma su rumbo también. A mí me costó mucho tiempo entender eso, porque en algún punto es muy loco que generas un montón de afecto en un momento, te encontras en una coyuntura muy complicada, y después de repente no sabes nada mas de esa persona. Y saber eso, que fuiste importante en un momento puntual, de la misma manera en la que ese pibe fue importante para vos en un momento puntual, que fue un acompañarse, pero que ahora la persona está en otro proceso (GDF).

Es difícil renunciar al ego, que sejuega de muchas formas; pero, por ejemplo, cuando algo se da de una manera diferente de la que vos planteas y fracasa, y vos ahí señalas algo. Y no es solo eso, sino que además creemos que si fracasó la alternativa de otrx también fracasó la persona, y resolvemos, bueno, que lo intente y cuando fracase vemos, como si ya hubiera determinación, o como si unx lo hiciera de una manera diferente. Creo que muchas más veces de las que creemos caemos en ese sesgo, y tenemos una dificultad para dejar hacer a las otras personas según lo que consideran mejor aunque no estemos de acuerdo (LC).

También me hace mucho ruido la disposición a ceder todos los poderes, me pregunto si está del todo bueno. A ver, yo en general tengo una posición que es 'muerte a lxs adultxs', y suelo creer que lxs que estamos mal somos nosotrxs, pero necesariamente 
me hago la pregunta, porque de alguna manera ceder todo es una forma de no poner nada de uno. Me pregunto si no hay ahi, en esas polarizaciones, un adelantarse a toda necesidad (SP). Sin embargo, me parece que a veces se nos crea la ficc ión que renunciar a un tipo de poder o de condición de ventaja es como negarse a uno mismo en un sentido de inversión de la norma. Reconfigurar una lógica de relación necesariamente va a suponer perdernos de una o varias maneras, pero decir que algo es desconocido no es sinónimo de decir que no hay nada. Finalmente, no habrá vínculo en una experiencia unilateral. Se nos hace difícil pensar un vínculo en el que no sea imprescindible 'lo adulto' como forma. Ahora, si lo pensamos en la inversión de toda norma, y. sí, yo también tendría miedo de que lxs niñxs se comportaran con nosotrxs como nosotrxs nos comportamos con ellxs.

Incluso cuando nos preguntamos por nuestras adulteces, asumiendo lo problemático de las posiciones de mundo que ocupamos, todavía no sabemos cómo es ser de otros modos. Entendemos que persistir en la pregunta y reafirmar la necesidad de transformación es imprescindible, pero pensar en un mundo sin lo adulto todavía aparece como fantasmático. Dice Alejandro Cussianovich en una conferencia (2019: $\mathrm{s} / \mathrm{p})$ que para entendernos en esta relación asimétrica entre adultxs y niñxs no hay formulas, por eso hay que hacer un ensayo, un ejercicio de reflexión sin fórmulas pero en permanente aprendizaje de la condición humana. Tal vez se trate entonces de arriesgarnos a participar de relaciones en las que las asimetrías no sean una condición para el establecimiento de vínculos.

\section{Sum ario del Capítulo: Arriesgar}

Usualmente, cuando dudo sobre una observación o una acción, o simplemente cuando necesito otro punto de vista, hablo con mi sobrino Lorenzo. Por lo general, él tiene la capacidad de retraducir pensamientos complejos a análisis simples, y eso me permite despejar supuestos y prejuicios. Realicé el guión de estas entrevistas con su ayuda, porque cuando una lleva algún tiempo siendo adulta, tiende a natura lizar la ocurrencia de fenómenos y procesos significativos en la forma de vivenciar trayectorias,

percepciones y posiciones. Él cree que la adultez se produce en el momento en el que el pensamiento de una persona cambia, no importa cuántos años tengas. Y, por ejemplo, frente a algo que ya te pasó, vos te das cuenta que elegís de una forma diferente. $O$, por ejemplo, cuando te pasa algo -como trabajar o irte a estudiar-y alguien te fuerza a que 
vos cambies de opinión, o también cuando te dicen, a partir de ahora tenés que ser responsable por tus cosas. Además asume que en esa experiencia la gente empieza a pensar mucho más en sí misma, y se olvidan que vos sos otra persona, y te empiezan a mandar o se piensan que vos no entendés las cosas.

En este escenario, y poniendo en común lo que a cada quien le preocupaba de las adulteces que conocemos, discutíamos respecto de cuáles son lxs adultxs que nos ayudan a pensarnos de otros modos, y ambxs consideramos que nos caen mejor lxs adultxs que insisten en hacerse preguntas, y que se permiten dudar y decir que no saben cómo resolver algunas cosas. Como siempre, él lo explica de una forma más precisa: $s i$ una persona hace lo que dice, y si vos ves que se siente bien consigo mismo y con lo que hace y no necesita buscar la falta en otrx, entonces, aunque se equivoque, esx es un adultx al que te podes arriesgar a conocer.

Lxs adultxs sobre los que yo arriesgo, han hablado en estas páginas sobre las preguntas y observaciones que ellxs se hacen a partir delvínculo con niñxs y jóvenes, y por eso he considerado importante reponer en los modos, consideraciones y experiencias a partir de los que se producen esos encuentros, en la forma en la que esas trayectorias otras han irrumpido en sus parámetros para construir percepciones y posiciones, en los análisis que realizan respecto de la permeabilidad de nuestras adulteces para hacer lugar a experiencias de mundo diversas, y, fundamentalmente, a la posibilidad de desarmar las estructuras que nos arman en fijaciones identitarias que separan y disgregan. Es que cuando no nos sabemos las respuestas, es importante, por lo menos, poder permanecer en las preguntas $(\mathrm{MG})$.

El montaje como método, permite la fusión entre lo individual y colectivo, haciendo posible la emergencia de la trama como movimiento de relevancia. E1 análisis de lo pequeño y cotidiano, por su parte, posibilita hablar de lo común asociado a la sabiduría que emerge de la experiencia presente (Benjamín, 1991). Finalmente, el ejercicio de no subtitular o sobre-interpretar los diálogos desarrollados, ha sido una apuesta por comprender que cuando la palabra de otrx habla con claridad sobre las trayectorias que compartimos, no son necesarias autorizaciones o traducciones. Los huecos que todavía quedan, son la invitación a un dialogo aún no producido, alentan do la potencia de lo que acontece en el cruce de trayectorias desconocidas. 

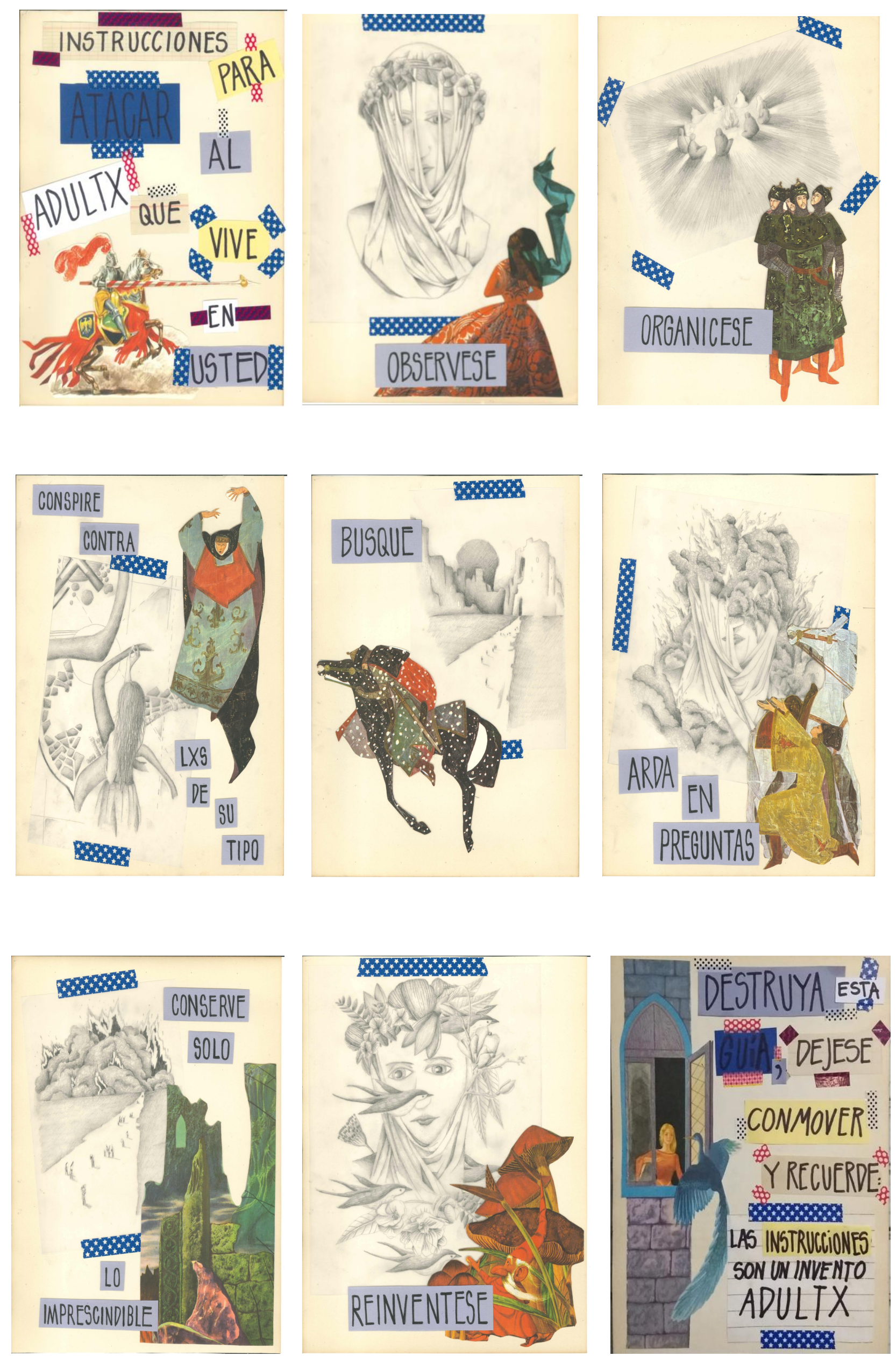


\title{
Aproximaciones finales: afectaciones extrañas
}

\author{
Debería haber, pensé, \\ un ritual para nacer dos veces: \\ remendada, reparada, y con el visto bueno \\ para volver a la carretera \\ La campana de Cristal \\ Sylvia Plath
}

Llevo una década entera trabajando en un Hospital, y aún así -o quizás por eso-, todavía mantengo una relación permanente de reconocimiento y rechazo por las Guardias. La última vez que tuve algo que pudiera considerarse una urgencia -porque cuando una transita cotidianamente por instituciones de salud, sabe que las Guardias son solo para urgencias reales e impostergables-, llevaba tres días sin poder levantarme de la cama, con un registro de fiebre que se mantenía por largas horas en $40^{\circ}$, y me había terminado la última tableta de paracetamol que había en mi casa. Mis amigxs se turnaban entre acompañarme y amenazarme para que hic iera una consulta, y arrastrarme hasta ese receptáculo de seres urgidos de diagnósticos y tratamientos de emergencia les pareció que era una contribución seria a mi sistema de cuidado. Decir que tenía fiebre no me dio ninguna prioridad de asistencia, porque, al parecer, antes de la existencia del Covid-19, la fiebre era un recurso común para describir el malestar.

Sin embargo, cuando se inició el circuito de la atención, eso que inicialmente era una afectación menor y desdeñable, se convirtió en un verdadero problema de salud por el que debí haber consultado mucho tiempo antes. Tuve que completar varios anális is, hacer un repaso minucioso y detallado de todas mis actividades del día cero, someterme a interrogatorios y revisaciones de varios especialistas, y quedarme en observación hasta que pudieran acordar el tratamiento a seguir. Según mi interlocutor, era posible que estuviera experimentando una enfermedad medieval erradicada, a partir de una infección extraña y muy poco común causada por la bacteria del Streptococcus. Entonces, además del tratamiento riguroso con dosis altas de penicilina, tenía que permanecer en aislamiento total por diez días, debiendo concurrir de urgencia si los síntomas persistían en las siguientes 48 horas. Antes de irme, varias personas pasaron a ver ese fenómeno tan poco frecuente en el que me había convertido.

Cuando finalmente volví al Servicio en el que trabajo -que vale la pena recordar, se dirige únicamente a la atención de niñxs-, algunas de mis compañeras intrigadas por 
esta narrativa fantástica del desarrollo de una enfermedad medieval hicieron un ateneo improvisado con los estudios y el regis tro de mis actividades. Rápidamente llegaron a la conclusión de que había tenido escarlatina, y que había contraído esa infección de un niñx con el que había compartido gran parte de la mañana del día cero. Entre risas, una de mis compañeras me explicó que no era una enfermedad extraordinaria, sino que la fiebre escarlata es una enfermedad que ocurre de forma muy excepcional en adultxs, y que por tanto, muchxs médicos generalis tas creen que está extinta. Que efectivamente era una rareza singular que mi cuerpo poseyera la capacidad de contraer esa bacteria de niñxs, puesto que luego de los diez años, por lo general el organismo adquiere ciertas defensas, pero que, en todo caso, la pérdida o adquisición de defensas tampoco podía ser medida temporalmente en términos absolutos.

Como este hay miles de ejemplos inhóspitos y curiosos sobre las fronteras que se establecen entre cuerpos y posiciones a partir de lo generacional. Es siempre claro, que alternar posiciones o desafiar algunas delimitaciones corporales-temporales, se nos presenta como un fenómeno extraordinario o una rareza singular que ha de ser sujeta a revisión. En este contexto, la tendencia nos mueve a reafirmar y consolidar, en lugar de deconstruir y diluir, los marcadores identitarios y posicionales sobre los que nuestros cuerpos y posiciones se edifican. Por este motivo, he ensayado en esta Tesis un ejercicio que implica un movimiento doble y enlazado: por un lado, indagando respecto de los marcadores y observables que hacen que lo adulto pueda ser enunciado como posición de mundo, quitándole el manto de invisibilidad dominante y permitiendo ensayos de localización y reterritorialización, y, por el otro, inmiscuyéndome en aquellas trayectorias y experiencias que, advirtiendo aquello que acontece como problemático y diferencial en las adulteces que representamos, producen fugas y diluciones que permiten pensar formas de vinculación no jerarquizadas y/o desiguales.

Analizar las posiciones dominantes en relación con las experiencias de resistencia y transformación, resulta fundamental para comprender los procesos sociales a partir de las potencias y agencias que los sujetos ponen en juego en sus vínculos colectivos. Esa trama de producciones y afectaciones que componen y configuran las experiencias de mundo son construidas sobre modelos de implicación múltiple e interconectada, que hacen que vivencia singular y experiencia colectiva formen parte de una misma trama, a la que es posible aproximarse desde movimientos y tejidos diversos.

Al iniciar esta producción insistía en que, lo que me acontece como verdaderamente problemático de los sistemas adultocéntricos en los que vivimos, es que quienes 
detentamos posiciones de privilegio hayamos omitido tan sistemática y eficazmente la pregunta respecto de nuestras propias afectaciones en estos sistemas que se estructuran en base a la desigualdad. Si bien observo que el uso de ventajas y prerrogativas es sistemático, entiendo que para que el análisis y revisión de un tipo de relaciones adquiera valor y potencia en el diálogo colectivo, con antelación, ha de poder ser nombrado y narrado tal y como acontece. Por ese motivo, entendí que era imprescindible iniciar la indagación realizando un ejercicio de reterritorialización, considerando que lo adulto, aunque siempre presente y directivo, aparece en la narrativa común a partir de enunciaciones opacas y difusas, y/o, es hablado a partir de su vinculación con otros marcadores interseccionales, y/o a los roles y funciones ocupados en los espacios. Dos interrogantes sirvieron de guía a este movimiento: ¿Qué constituye el territorio común de las adulteces desde la percepción y experiencia de lxs adultxs? y ¿cuáles son las afectaciones que estas posiciones provocan en las formas de construcción de vínculos intergeneracionales?

Utilicé como observable y organizador para el análisis una constelación categorial conformada por la relación entre trayectorias, percepciones y posiciones, puesto que entiendo que ello permite suspender algunas estructuras del deber ser generacional sustentadas en premisas normativas y en discursos dominantes, para enfocar en lo sentido y narrado que emerge de las trayectorias y experiencias concretas y situadas de lxs agentes. Hemos de recordar aquí, que las experiencias, saberes, sentidos, sentires, afectaciones y localizaciones que han sido repuestas, hablan sobre una polifonía de nociones y prácticas, que ocurren de forma simultánea e interconectada, por lo cual las narrativas obtenidas no necesariamente responden a procesos tradicionales de construcción de discurso, sino que dan cuenta del modo en que ciertas composiciones comunicacionales se tejen allí donde acontece el cruce entre cuerpos y lenguajes.

Dice Washington Uranga que:

Cuando decimos procesos comunicacionales nos referimos a prácticas sociales atravesadas por experiencias de comunicación. Prácticas sociales factibles de ser reconocidas como espacios de interacción entre sujetos en los que se reconocen procesos de producción de sentido, de creación y recreación de significados, generando relaciones en las que esos mismos sujetos se constituyen individual y colectivamente. (Uranga, 2012: 24)

Si pensamos en las condiciones y características que asumen las prácticas y relaciones sociales descriptas a lo largo de esta investigación, en vinculación con los modos de 
procesamiento ético-político de las relaciones temporales-corporales, del interjuego entre marcadores biológicos y procesos de producción de sentido, y de los movimientos de opacidad y transparencia representacional, es fácilmente evidenciable que los debates propuestos se ubican allí donde persisten tensiones e interrogantes imposibles de ser saldadas en las formas del lazo social que conocemos. Resulta preciso recuperar aquello que se enuncia en como elemento de cruce entre perspectivas comunicacionales y enfoques de $\mathrm{DDHH}$, dejando entrever que lo que es crítico no es un conjunto de conceptos predefinidos como "temas" u "objetos" sino el tipo de preguntas que se plantean en términos de problemas y posiciones.(Programa Maestría en Comunicación y DDHH, 2011:13)

Me subyace una creencia que ha sido presentada en esta producción a modo de hipótesis general, y que se sustenta en la idea de que la mayoría de lxs adultxs no se perciben a sí mismos en condición de privilegio respecto de otras generaciones y/o entienden que establecer pautas de jerarquización, exclusión y disciplinamiento son aspectos inherentes e innatos de toda experiencia generacional, y, que, por lo tanto, si bien piensan formas de vinculación más respetuosas, no necesariamente ponen en cuestión los sistemas de desigualdad sobre los que se sostienen. Si bien contemplaba en esta idea fuerza dos movimientos diferentes (por un lado, el de quienes no advierten el uso de privilegios y/o la participación en relaciones de desigualdad, y, por el otro, el de quienes, aunque lo advierten, no creen necesarias y/o no conocen otras formas de vinculación), originariamente me inclinaba a pensar que la percepción respecto del privilegio era mayoritariamente visible para lxs adultxs que trabajan con niñxs y jóvenes, y que existía una dificultad y/o imposibilidad para considerar y construir otras formas de vincularnos.

Sin embargo, la información obtenida del cuestionario digital me ha obliga do a poner en duda esta creencia, puesto que unx de cada dos adultxs alcanzados por la muestra no considera que exista una posición de privilegio en las adulteces a las que representamos y adscribimos, y que por tanto, la forma en la que construimos vínculos intergeneracionales no les acontece como productora de desigualdad. Incluso dentro del subgrupo de personas que asumieron la existencia de trayectorias o vivencias diferenciales -es decir, el otro 50\%-, hay algunxs a quienes la idea de ventaja o privilegio no les acontece necesariamente como una condición de desigualdad respecto de otrxs. Esto resulta curioso, si consideramos que, esxs mismxs adultxs, también han mencionado que mayoritariamente no poseen barreras o impedimentos para que sus 
discursos y narrativas obtengan relevancia y/o legitimidad, que no se han sentido impedidos para transitar por espacios sociales, que poseen menos restricciones $\mathrm{y}$ condicionamientos para decidir por sí mismxs, y que por el contrario, saben o conocen que todas estas condiciones se producen de manera diferencial en las experiencias y trayectorias de lxs niñxs y jóvenes con lxs que trabajan.

En concordancia con esto, la muestra también se dividió en partes iguales entre aquellxs adultxs que no creen que sea necesario y/o deseable transformar algún aspecto significativo de su posición y experiencia adulta, y quienes, por el contrario, consideran impresc indible modificar algún e lemento de esa trayectoria. Respecto de este segundo grupo, es importante recuperar que, muy pocxs encuestadxs incorporaron como elemento necesario y/o deseable la revisión de algún aspecto asociado al modo en que lxs adultxs nos vinculamos con otrxs y/o a la forma en la que nos construimos corporal y posicionalmente, asociando la mayoría de las transformaciones a la posibilidad de obtención de más autonomía, más libertades y menos responsabilidades.

Esto resulta bastante lógic o si atendemos, por un lado, a que la mayoría de nosotrxs no estamos impedidxs para realizar actividades y/o expresar opiniones en nuestra condición de adultxs, y, por otro, a que hay quienes, desde posic iones similares, no consideran que las diferencias, valoraciones y jerarquizaciones que emergen del vínculo con otrxs produzcan experiencias de separación y exclusión. La idea de que formamos parte de una generación inefable, justamente, habla sobre esta imposibilidad para nombrar aquello que nos sitúa y compone, tanto en relación con las afectaciones propias, como también, a las que producimos y provocamos a otrxs, como modo de construir y sostenernos en los vínculos intergeneracionales. Somos todavía un constructo incomprensible amparado en la resistencia por trastocar las formas de existencia que nos sitúan en lugares de privilegio.

Considerando que enunciar la desigualdad no resulta suficiente para insta lar la pregunta sobre las posiciones diferenciales y/o de privilegio, nacen de este proceso nuevos interrogantes: ¿Cuáles son entonces las condiciones necesarias para que la pregunta sobre lo adulto pueda ser enunciada?, y ¿a partir de que narrativas las posiciones que ocupamos pueden formar parte de los modelos comunicativos compartidos, habilitando la emergencia de lo diferente? Todavía consevo la presunc ión de que hacer visibles las circunstancias sobre las que se producen sistemas de dominio incluyendo de manera directa a lxs actores que ocupan posiciones diferenciales, posibilita romper con la hegemonía representacional que naturaliza la ocurrencia de experiencias de la 
desigualdad asociadas a lo generacional como condición necesaria para la vida social, aunque ello no ha sido posible de ser probado o descartado, en su complejidad e implicancias, a partir de los resultados de la indagación realizada.

Respecto de la creencia de que un elemento legitimador de los sistemas adultocéntricos se vincula a la correspondencia exacta entre cronología, corporalidad y posición generacional, he de enunciar un hallazgo interesante: mientras que al hablar de otrxs en este caso de lxs niñxs y jóvenes con lxs que nos vinculamos en los espacios de trabajo a los que pertenecemos-, la asociación entre edad, generación y capacidad permaneció fija, alentando habilitaciones y restricciones de acuerdo con ello, y realizando observaciones respecto de las posibilidades y límites de los sujetos de acuerdo con estas atribuciones. Por el contrario, al recuperar la propia trayectoria adulta, esta composición de sentido fue relativizada y diluida, incorporando la dimensión de lo procesual, reponiendo en trayectorias singulares para dar cuenta de ciertas experiencias, $\mathrm{y}$, en muchos casos, prescindiendo de nominaciones etarias para hablar de posiciones generacionales.

En este sentido, al hablar de niñxs y jóvenes, la posibilidad de acceso a la información y la capacidad de participar en los procesos de toma de decisiones que lxs involucran, según la perspectiva de estxs adultxs, se encuentra sujeta a la posibilidad y pertinencia de establecer sistemas de codificación, adecuación, decodificación y comunicación, de acuerdo a condiciones y cualidades que aparecen como innatas y directamente asocia das a marcadores etarios. Mientras que, al hablar de la trayectoria propia, no es posible ni deseable totalizar marcaciones y/o unificar criterios respecto de la ocurrencia de fenómenos, tal como ocurrió en la asociación entre ciertas experiencias y percepciones que daban origen a la adultez y la asignación de marcaciones etarias. Asimismo, he podido evidenciar una relación inversamente proporcional respecto de la exaltación de cualidades que las personas a lcanzadas por la muestra consideran que son propias o inherentes a la adultez, y, en sentido opuesto, la necesidad de establecer restricciones y clausuras respecto de las trayectorias y experiencias de niñxs y jóvenes a partir del uso diferencial de tres nociones fuerza: responsabilidad, libertad y autonomía.

He enfatizado en estos procesos de asociación y construcción de sentido sobre todo en la dimensión teórica de la Tesis, dando cuenta de los mecanismos y andamiajes a partir de los que algunos significantes fuerza son utilizados como insumo para la reproducción y consolidación de los sistemas adultocéntricos en los que vivimos. Parto de considerar que lo adulto -además de quienes material y posicionalmente ocupamos ese lugar-, 
actúa como principio regente para la organización de las relaciones intergeneracionales que conocemos, y que esta idea fuerza atraviesa y produce afectaciones no solo en el orden del discurso, sino también, en los modos en que nuestros cuerpos son producidos. Entiendo que tanto la edad como la generación son nociones que han de comprenderse como producciones performativas de cuerpos y significados, y que por tanto, la adultez no puede ser pensada por fuera de los modos en que nuestras trayectorias, percepciones, posiciones y cuerpos, producen, se producen y son producidas. Sin embargo, aún no encuentro una pregunta común que habilite este debate en el espacio colectivo, puesto que observo, como resultante de lanális is, que la percepción de la edad como marcación total aún es difícilmente conmovida cuando es extraída y separada de la propia experiencia: es decir, cuando aparece como un atributo de habilitación o clausura para con otrxs. He de decir entonces, que prefiero conservar esta latencia que aún aparece como concepción difusa, para ensayar nuevas hipótesis e interrogantes sobre las conexiones que aún no han podido producirse.

En todas estas composiciones y construcciones de sentido, los sistemas comunicacionales -en tanto mediadores y co-constructores de las experiencias y percepciones socio-políticas-, juegan un rol central, cons iderando que en el orden de la producción del discurso las lógicas y estrategias de separación, jerarquización y valoración todavía aparecen como elementos estructurantes. Sobre este punto, me parece fundamental la constribución que Jesus Martín Barbero realiza, introduciendo la necesidad de tranformar nuestros marcos de interpretación de acuerdo con los nuevos modos de percibir y sentir que otras generaciones aportan. Esos sensoruims nuevos, en el pensamiento Benjaminiano, se enlazan a procesos de dilusión y profanación, por lo que he recuperado los aportes de Giorgio Agamben para analizar los sistemas comunicacionales en clave generacional, a partir de enlazarlos al estudio sobre los procesos de sacralización y profanación.

Así he llegado a la última de las hipótesis, que es la que se sustenta en la convicción de que existen una serie de perspectivas y prácticas profanas que se organizan proponiendo rupturas a los modelos generacionales que conocemos, y que se embarcan en procesos de deconstrucción y disolución para pensar en lo común-compartido, pero que ellas aún no han obtenido valor en el espacio colectivo. A pesar de que la información obtenida en la encuesta general habla acerca de un estado de situación del campo que resulta poco alentador respecto de la posibilidad de revisión y reflexión sobre las posiciones de mundo que habitamos, de manera minoritaria también existen 
perspectivas y prácticas que disputan los sentidos generacionales establecidos, a partir del cuestionamiento de la desigualdad como elemento natural del vínculo intergeneracional.

Estas perspectivas profanas pujan por devolver al espacio común aquello que aparece como propiedad diferencial de ciertos sujetos, insistiendo en modos colectivos de ser que no necesiten recurrir al uso de privilegios y/o al establecimiento de fronteras de valoración y exclusión. De hecho, si analizamos los diálogos producidos y recreados en el Capítulo IV en simultaneidad a los datos obtenidos en el Capítulo III, fácilmente podemos advertir las múltiples estrategias que proponen estxs actores y actrices para poner en jaque fijaciones que producen nominaciones y restricciones para la participación de niñxs y jóvenes en los distintos espacios.

Más allá de la fortaleza analítica que estos discursos y prácticas traen para repensar y reflexionar en torno a las percepciones y experiencias que dejan entrever el sentido común que permea las representaciones materiales y simbólicas del campo, estas posiciones avanzan sobre aquello que aún ocupa el lugar de lo inédito e impensado en las posiciones generacionales que conocemos, y allí radica la fuerza y la potencia de estos pensamientos. A lo largo de los distintos relatos emerge la insistencia por construir un código comunicativo común, abandonando la idea de adecuación de una matriz a otra, y reponiendo en la necesidad de componer un nuevo sentido compartido que se enraíce en la necesidad del encuentro y del diálogo como condic iones ineludibles para que aquello que emerge como común pueda ser explorado en su singularidad.

Este es un tipo de pensamiento que insiste en las preguntas sobre lo desconocido y que recupera la importancia de que la experiencia de lo diferente pueda ser alojada como otro modo de vida posible. Estas narrativas no omiten conflictividades y resistencias; por el contrario, las incorporan, entendiendo que en esos huecos y detenciones también existe posibilidad de reflexión. Aunque persiste la pregunta respecto de si es posible construir experiencias de la adultez desde posiciones que prescindan de la valoración y jerarquización como modo de vínculo, estas trayectorias y perspectivas insisten en tramar sobre las grietas en las que otros modos de ser transitan.

A pesar de que la dimensión comunicacional fue, a lo largo del proceso, un elemento que moduló y delimitó la indagación y producción, lo cierto es que fueron lxs actores y actrices comprendidxs en este recorte quienes exaltaron la necesidad de pensar narraciones y discurs os que adquieran fuerza y valor colectivo, posibilitando reflexionar en torno a los vínculos intergeneracionales a partir de lo que une la experiencia social 
colectiva, prescindiendo de nominaciones y marcaciones de separación. Sobre el desafío que esto implica como parte de los procesos de descolonización del pensamiento, Suely Rolnik remarca la necesidad de:

No ceder a la voluntad de conservación de las formas de existencia y a la presión que esta ejerce contra la voluntad de potencia de la vida en su impulso de producción de diferencia. Al contrario, buscar sostenerse en el hilo tenue de este estado inestable hasta que la imaginación creadora construya un modo de cuerpo-y-habla que, al ser portador de la pulsión de lo extraño-familiar, sea capaz de actualizar el mundo vital que esta experiencia anuncia, permitiendo así que las formas antagónicas terminen de morirse (Rolnik; 2019, 175).

Insistir en estas grietas, por tanto, implica apostar a la construcción de posiciones $-\mathrm{o}$ a la disolución de todas ellas-, explorando la multiplicidad y simultaneidad de modos para habitar lo diferente o incierto, enfatizando en el dinamismo y movilidad que todas las relaciones que se instalan en el orden de lo viviente requieren. También supone un desafío por tramar a partir de lo común compartido formas más honestas y respetuosas de encuentro y diálogo. 


\section{Bibliografía:}

- Agamben, G; Profanaciones. Ed. Adriana Hidalgo, Bs. As. 2005

- Alexanthropos Alexgaias: El manifies to Antiadultista

- Arendt, H: La condición Humana. El poder y el espacio de la aparición. Ed. Paidós, Buenos Aires, 2003.

- Artaud, A; El Ombligo de los Limbos y El pesa-nervios. 1925, sin mas datos.

- Athanasiou A. y Butler J.: Desposesión: lo performativo en lo político. Ed. Eterna Cadencia, Ciudad Autónoma de Buenos Aires, 2017.

- Barbero, JM; De los medios a las mediaciones. Ed. Gustavo Gili, Barcelona, 1987.

- Barbero JM; Jovenes, comunicación e identidad, 2002, sin más datos.

- Baratta, A.; Infancia y Democracia, 2009. Sin más datos

- Barna, A.; "Convención Intemacional de los Derechos del Niño. Hacia un abordaje desacralizador" en Kairos, Revista de temas sociales. Publicación de la Universidad Nacional de San Luís Año 16. № 29, 2012

- Bauman Z: «Between Us, the Generations». J. LARROSA (editor): On Generations. On coexistence between generations. Barcelona: Fundació Viure i Conviure, 2007

- Benjamin, W; "Infancia en Berlín hacia el 1900". Noticia de un fallecimiento. Ed. Alfaguara, Madrid, 1982.

- Benjamin, W; El narrador. Ed. Taurus, Madrid, 1991.

- Benjamin, W; El libro de los pasajes. Ed. Akal, Madrid, 2005

- Benjamin, W; Discursos Interrumpidos I. Madrid: Taurus, 1982

- Butler, J.: Cuerpos que importan: sobre los límites materiales y discursivos del "sexo". Introducción. Ed. Paidós, Bs. As., 2015

- Butler J; Vida precaria. El poder del duelo y la violencia. Ed. Paidós, BS. As., 2006

- Cháves, M. y Segura R.; Hacerse un lugar: circuitos y trayectorias juveniles en ámbitos urbanos, Ed. Biblos, La Plata, 2014

- Cháves, M.; Experiencias Juveniles de la Desigualdad. Grupo Editor Universitario, La Plata, 2016.

- Colangelo, A; La crianza en disputa: medicalización del cuidado infantil en la Argentina, entre 1890 y 1930. Tesis Doctoral, UNLP, La Plata, 2012.

- Cussianovich, A: "Paradigmas de las culturas de infancia como formas de poder". En ensayos sobre Infancia II. Universidad Mayor de San Marcos, Lima, 2012.

- Declaración de Moscú de los Derechos del Niño (1918)

- Delfino S.; Programa del seminario: DEBATES EPISTEMOLÓGICOS. LA PERSPECTIVA COMUNICACIONAL DE ABORDAJE. Facultad de Periodismo y Comunicación Social -UNLP-, La Plata, 2016.

- De Sousa Santos, B; Epistemologías del Sur. Revista Intemacional de Filosofía Iberoamericana y Teoría Social, Año 16. $\mathrm{N}^{\circ}$ 54, Universidad del Zulia. Maracaibo-Venezuela, 2011.

- Deleuze, G. y Guattari, F.; Mil Mesetas, Ed. Pretextos, 1980

- Delugny, F; Semilla de Crápula: Consejos para educadores que quieran cultivarla. Ed- Cactus-Tinta Limón. CABA, 2017;

- Deligny, F; Lo arácnido y otros textos. Ed. Cactus. CABA, 2015

- Deligny, F; Cartas a un Trabajador Social. Ed. Cactus. CABA, 2021

- Duarte Quapper, C; El adultocentrismo como paradigma y sistema de dominio. Tesis Doctoral. Universidad Autónoma de Barcelona. Barcelona, 2012

- Duarte Quapper, C; Tesis doctoral: El adultocentrismo como paradigma y sistema de dominio. Universidad Autónoma de Barcelona. Es paña, 2014

- García Dauder, Silvia; Fertilizaciones cruzadas entre la psicología social de la ciencia y los estudios feministas de la ciencia. Athenea Digital 4. 2003. En: Cruz, M.A., Reyes, M.J. y Comejo, M.; Conocimiento situado y el problema de la subjetividad del investigador/a. Cinta moebio 45, Santiago de Chile, 2012

- Fernández E.J.: Disputas y tensiones en el abordaje de problemáticas relativas a las infancias y adolescencias es colarizadas. En: Grinberg J. e Isacovich P (Coomp.): "Infancias y juventudes a 30 años de la Convención sobre los Derechos del Niño: políticas, normativas y prácticas en tensión”. José C. Paz: Edunpaz, 2020.

- Fernández, E. J.; No es puro cuento: vínculos entre docentes, niñas y niños en el acceso a la lectura literaria. (Tesis de Maestría). Maestría en Trabajo Social, Facultad de Trabajo Social. Universidad Nacional de La Plata, 2015.

- Fernández EJ; Inscripción del Trabajo Social en espacios escolares Relaciones entre agentes de Trabajo Social y niñas, niños y adolescentes (2009-2016). Tes is Doctoral. FTS-UNLP, La Plata, 2018. 
- Feixas, C y Leccardi C; El concepto de generación en las Teorías sobre la juventud. Revista Ultima Década N³4, CIDPA, Valparaíso, 2011.

- Graham, M.; Reflexiones sobre el Sistema de Protección de Derechos de niños, niñas y adolescentes. Viejos y nuevos desafíos. En Revista del Ministerio Público de la Defensa de la Nación. Noviembre 2018.

- Gaitán, L. y Liebel, M: El poder de los niños y niñas. Notas sobre el protagonismo de movimientos infantiles en la actualidad. Revista Sociedad e Infancias. ISSN: 2531-0720.

- Haraway, D. J.: "Ciencia, cyborgs y mujeres. La invención de la naturaleza". Capitulo 7: Conocimientos situados: la cuestión científica en el feminismo y el privilegio de la perspectiva parcial. Madrid, 1995.

- Herrera Flores, Joaquín (s/f). La Reinvención de los Derechos Humanos. Atrapasueños. Andalucía. España. Disponible en http://www.derechoshumanos.unlp.edu.ar/assets/files/documentos/lareinvencionde-los-derechos-humanos pdf

- Huergo, J. : Métodos de investigación cualitativa en comunicación. Mimeo. La Plata, 2001.

- Kaufman A; La Pregunta por lo acontecido. Ensayos de anamnesis en el presente argentino. Ed. La Cebra, Buenos Aires, 2012.

- Korczak, J.: Si yo volviera a ser niño. Editorial Rayuela, Buenos Aires, 2014.

- Korczak, J: Cómo amar a un niño. Varsovia, 1918 Sin mas datos.

- Korczak, J: Diario del Gueto. Ed. Seix Barral. Buenos Aires, 2018.

- Lanfranconi, Ana; Walter Benjamin: Infancia y Politización. Universidad de Barcelona. Barcelona, 2017

- Llobet, V.: ¿Fábricas de niños?. Las instituciones en la era de los derechos de la infancia. Noveduc, Buenos Aires, $201^{\circ}$.

- Liebel, M: Janusz Korczak, los derechos y el protagonismo de la infancia. Revista Educación Social $\mathrm{N}^{\circ} 28$, Junio 2019.

- Mannheim, K.; «El problema de las generaciones». Revista Española de Investigaciones Sociológicas, Barcelona, 1928.

- Magistris, Gy Morales S; Niñez en Movimiento, del adultocentrismo a la emancipación. Cap. I Hacia un Paradigma otro: niñxs como sujetos políticxs protagonistas de la transformación social. Buenos Aires: Chimbote Editorial. 2018.

- Markowska-Manista, M y Zakrzewska-Oledzka, D: La pedagogía de Janusz Korczak y los métodos de trabajo participativo con los niños por sus derechos humanos. Revista Sociedad e Infancias, Madrid, 2019. ISSN: 2531-0720.

- Pavez Soto, I.; Sociología de la Infancia: las niñas y los niños como actores sociales. Revista de Sociología, 27, 81-102, 2012.

- Platero Mendez, L.: Metáforas y articulaciones para una pedagogía crítica sobre la interseccionalidad. Barcelona, 2014.

- Qvortrup, J: Visibilidades das crianças e da infancia. Revista Linhas Críticas, vol. 20, núm. 41, Universidade de Brasília. Brasilia, 2014.

- Solnit, R; "Una Guía sobre el arte de perderse". El azul de la distancia. Ed. Fiordo, Buenos Aires, 2020

- Uranga, W.: Cuaderno de Cátedra $\mathrm{N}^{\circ}$ 2. Taller de Planificación de Procesos Comunicacionales. Facultad de Periodismo y Comunicación Social -UNLP-. La Plata, 2012.

- Villalta, C. y Llobet, V.; Resignificando la protección. Nuevas normativas y circuitos en el campo de las políticas y los dispositivos jurídico-burocráticos destinados a la infancia en Argentina. Revista Latinoamericana de Ciencias Sociales, Niñez y Juventud, 13(1), 167-180, 2015.

- Weber, M: Economía y Sociedad. Ed. Fondo de Cultura Económica, Mexico DF, 1987.

- Willis, Paul: Notas sobre el método. En Hall, Stuart et al. (eds) “Gulture, Media, Language”, Hutchinson, Londres, 1980. 